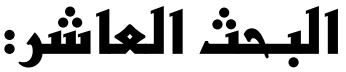

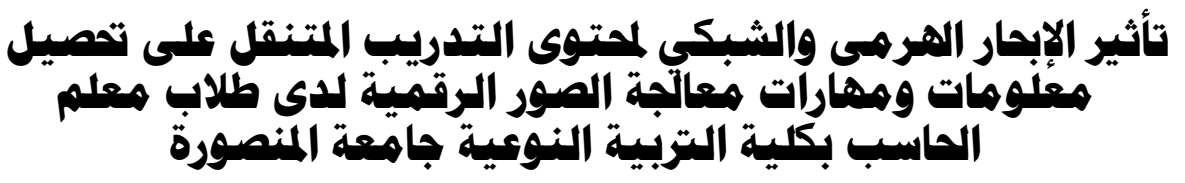

: إعتاد

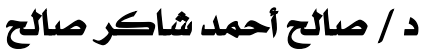 \\ أستاذ مساعد تكولوجيا التعليم التمايح \\ كليت التربيت النوعيت جامعت المنصورة
}





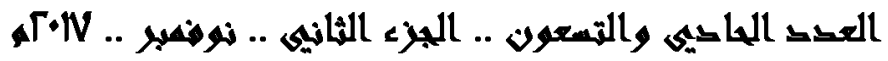

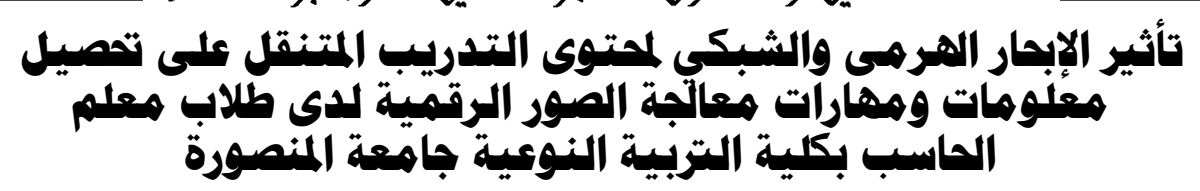

\author{
د / صالح أحمد ثاكر ماكر صالح \\ أستاذ مساعد تكولوجيا احمليا التعليم

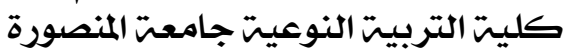

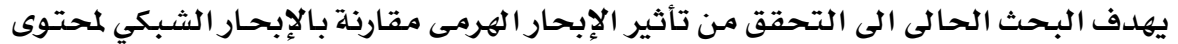

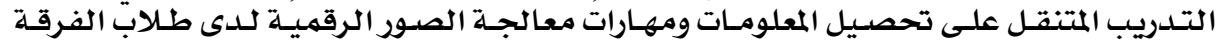

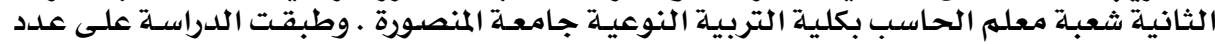

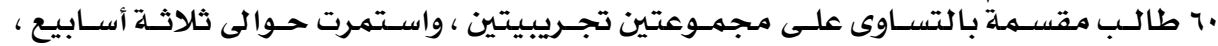

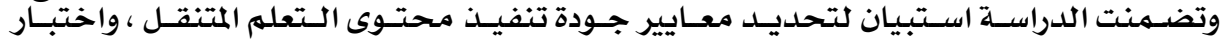

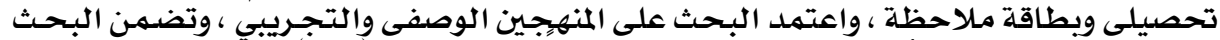

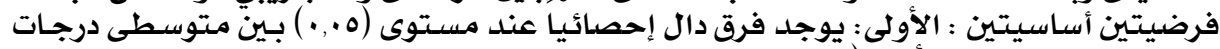

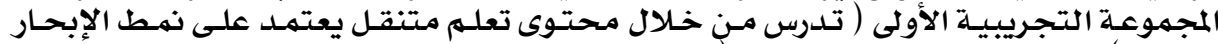

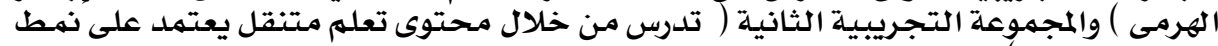

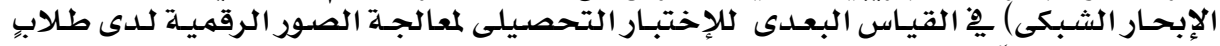

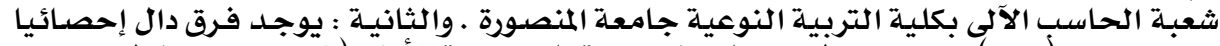

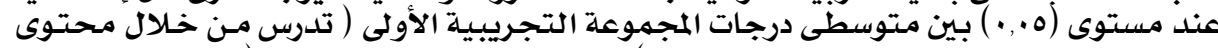

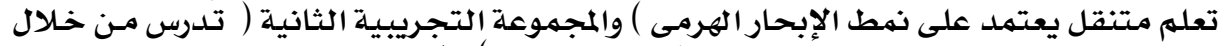

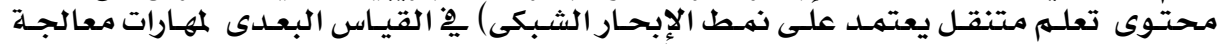

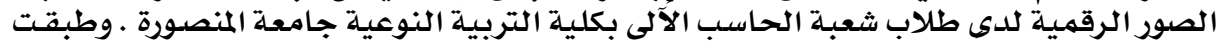

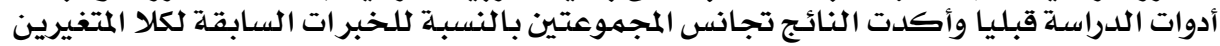

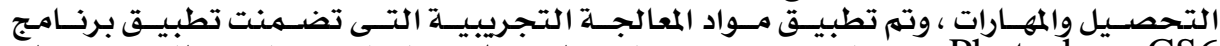

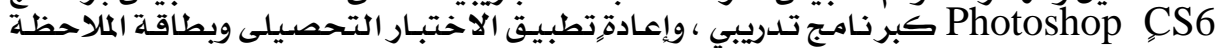

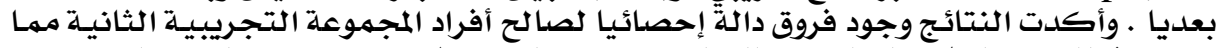

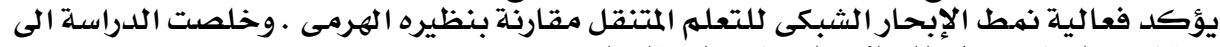

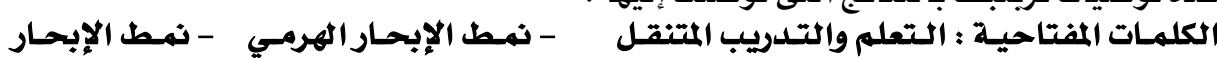

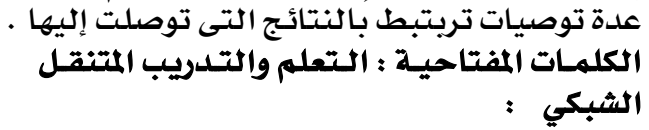

The Effect of Hierarchical Navigation compared to the Networking navigation Mobile Training Content on Information Achievement and Digital Image Processing Skills Among Second Year Students in Computer

Section at the Faculty of Specific Education, Mansoura University Dr. Saleh Ahmed Shaker Saleh

\title{
Abestract :
}

The current research aims to investigate the effect of hierarchical navigation compared to the networking navigation of mobile training content on information achievement and digital image processing skills among second year students enrolled in Computer section at the Faculty of specific Education, Mansoura University. The study was applied to the number of 60 students divided equally into two experimental groups, and lasted about three weeks. The study included a questionnaire to determine the quality standards for the implementation of mobile learning content, achievement test and 


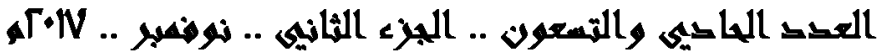

observation checklist. The study used both descriptive and experimental methods. The study included two basic hypotheses: The first stated that there is a statistically significant difference at the level (0. 05) between the mean scores of the first experimental group (taught through mobile learning content based on hierarchical navigation pattern) and the second experimental group (taught through mobile learning content based on networking navigation pattern) in the post administration of the achievement test for the processing of digital images among second year the students enrolled in Computer section at the Faculty of specific Education, Mansoura University. The second hypothesis stated that there is a statistically significant difference at the level (0. 05) between the mean scores of the first experimental group (taught through mobile learning content based on hierarchical navigation pattern) and the second experimental group (taught through mobile learning content based networking navigation pattern) in the post administration of the digital image processing skills among second year the students enrolled in Computer section at the Faculty of specific Education, Mansoura University. The study instruments were applied before the treatment and the results confirmed the equivalence between both groups in the previous experiences of both variables: achievement and skills. The experimental treatment was applied that included the application of Photoshop CS6 as training, the achievement test and the observation checklist were post administered. The results confirmed that there was a statistically significant difference in favor of second experimental group. This confirmed the effectiveness networking navigation pattern in mobile learning compared to hierarchical navigation. The study concluded several recommendations related to the findings of the study.

Keywords: Mobile Learning and Training - Hierarchical Navigation Networking Navigation.

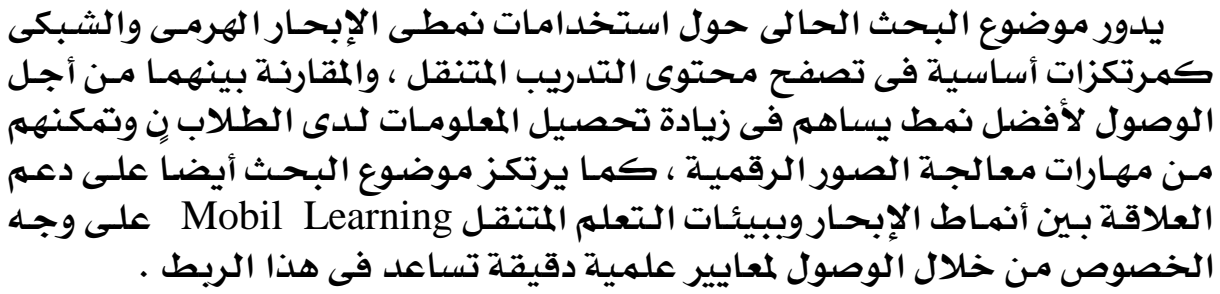




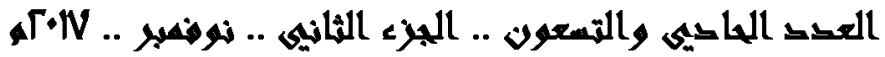

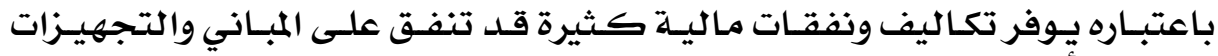

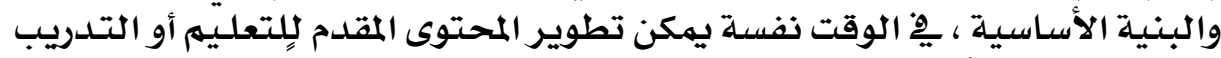

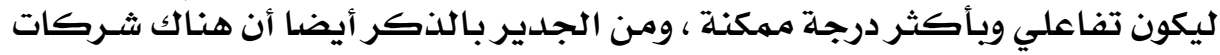

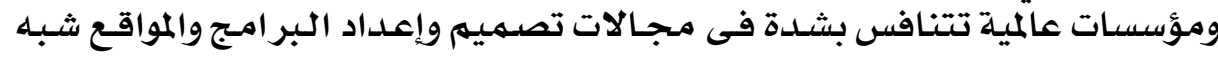

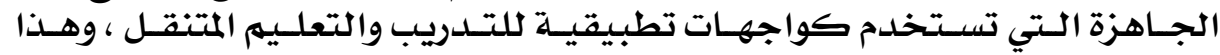

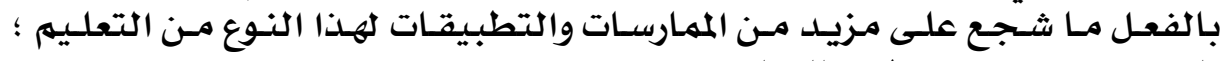

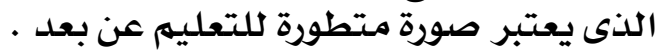

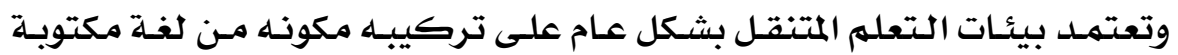

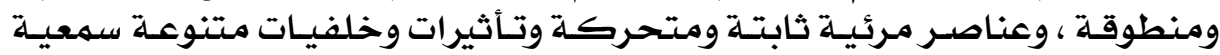

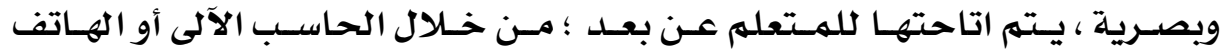

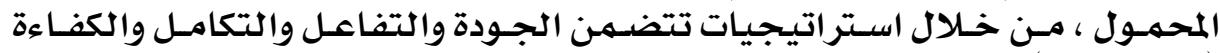

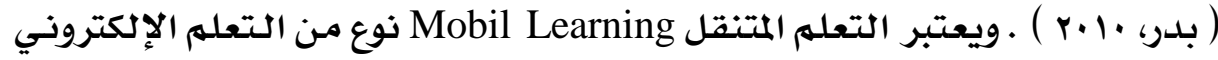

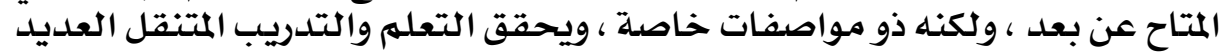

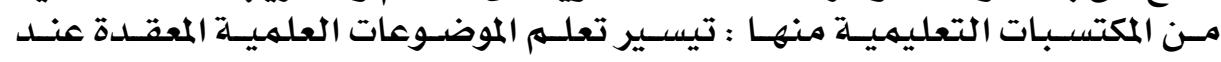

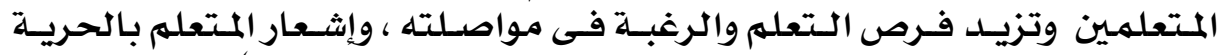

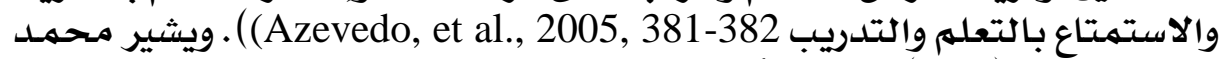

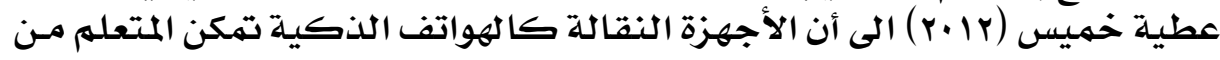

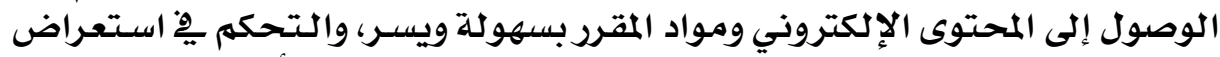

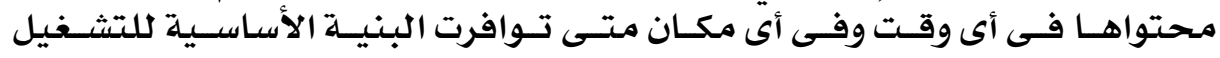

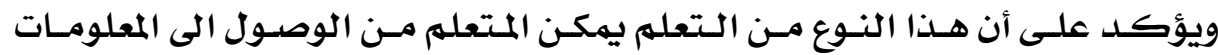

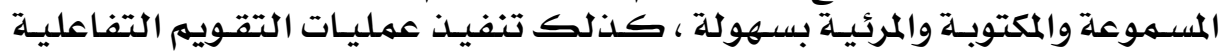

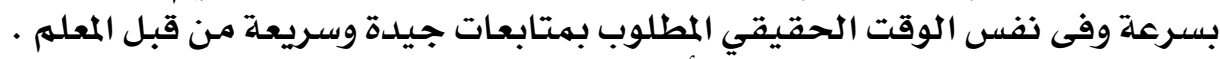

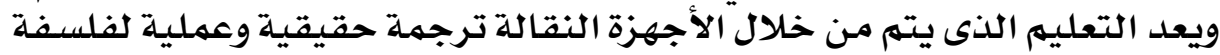

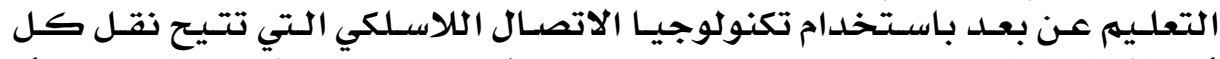

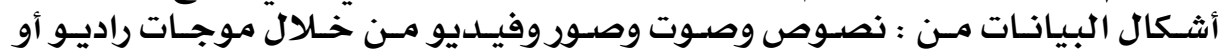

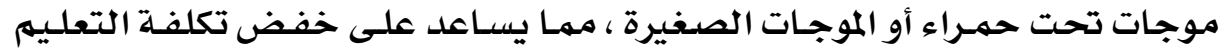

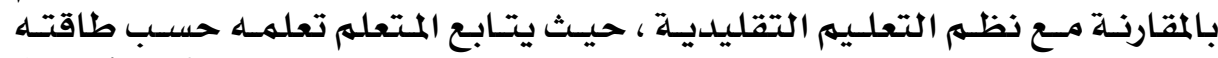

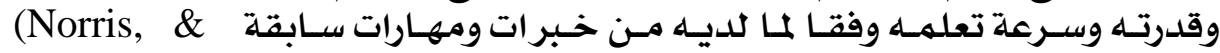

Soloway, 2011)

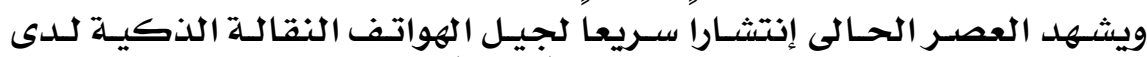

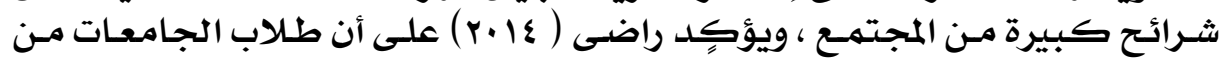

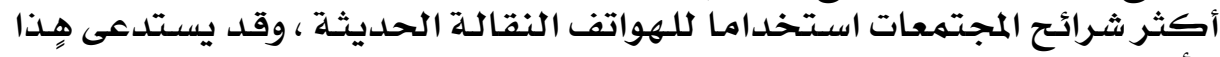

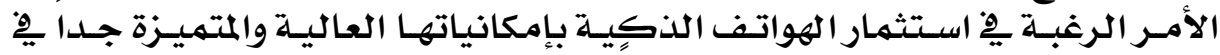

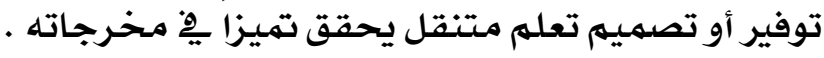

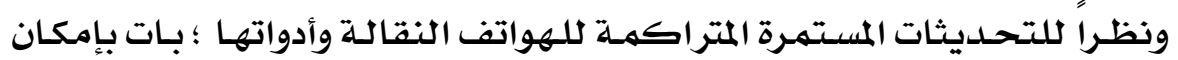

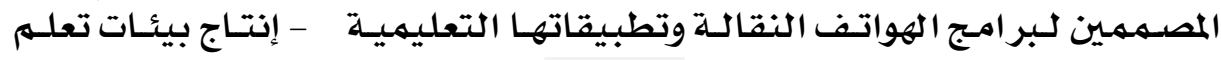




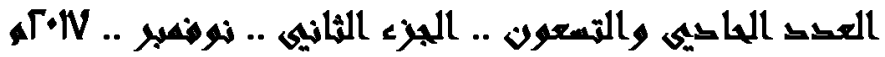

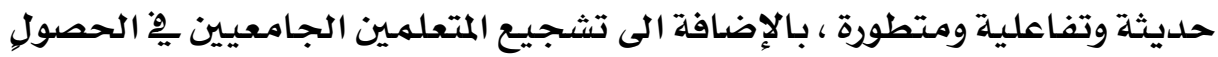

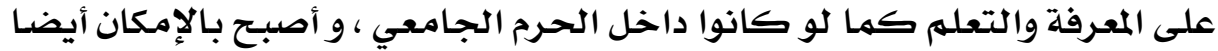

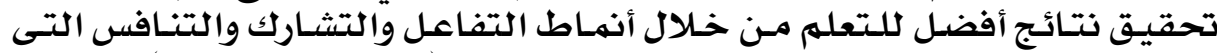

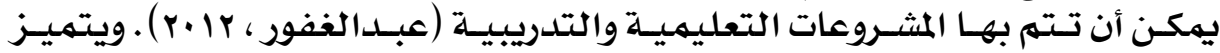

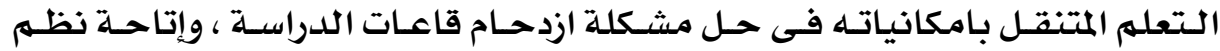

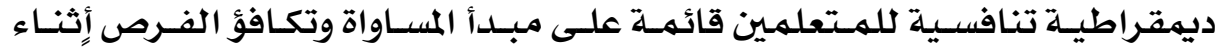

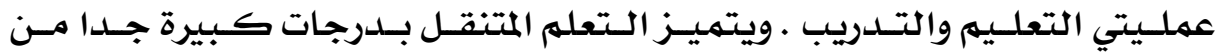

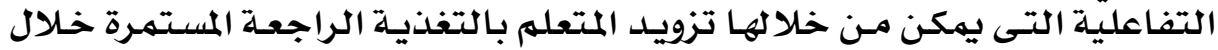

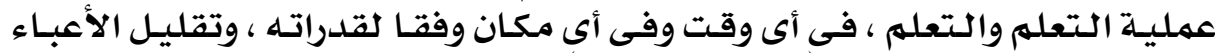

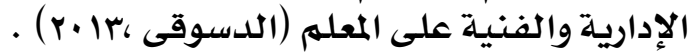

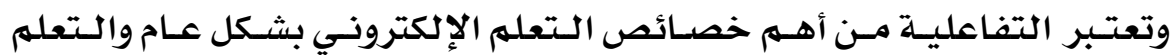

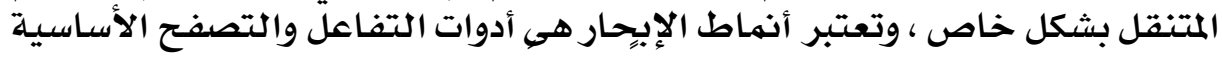

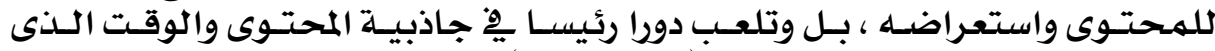

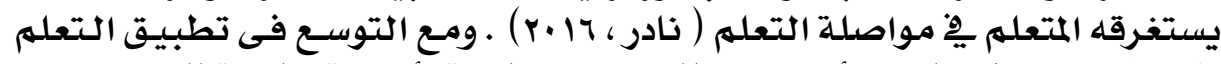

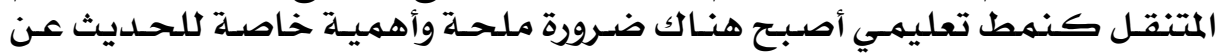

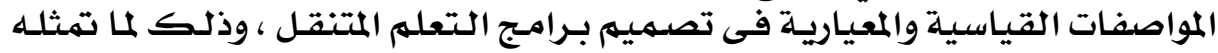

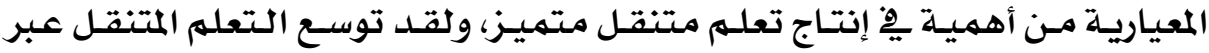

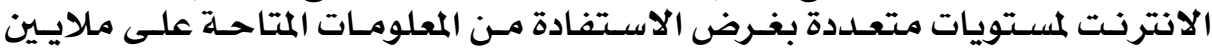

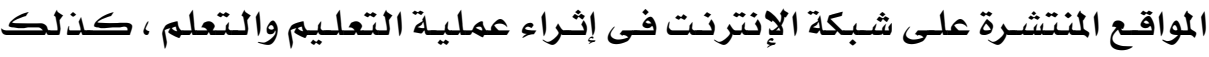

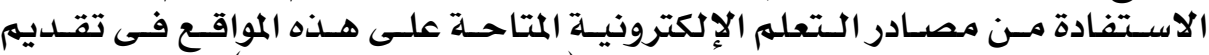

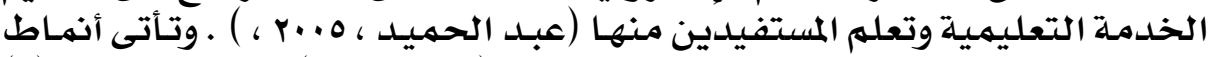

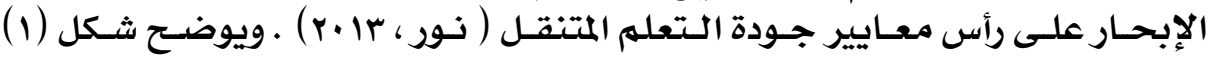

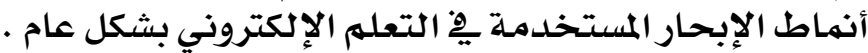

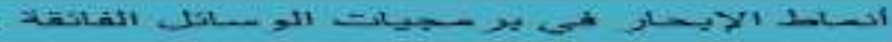

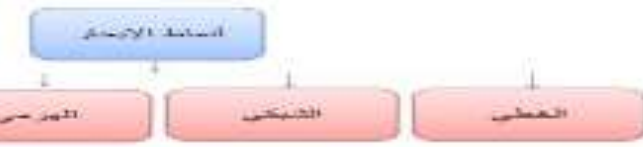

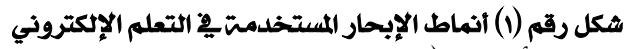

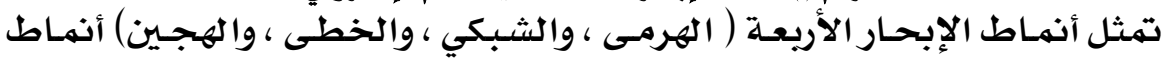

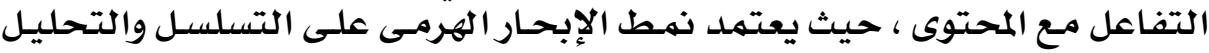

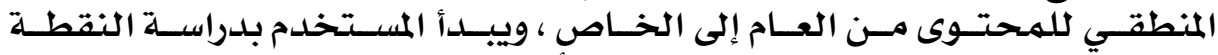

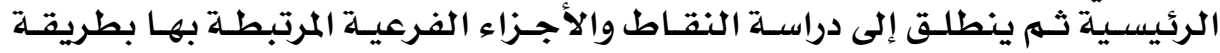

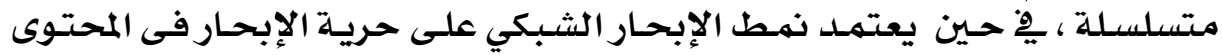

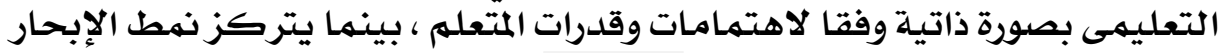




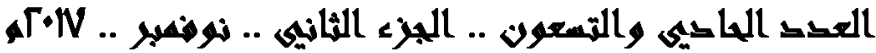

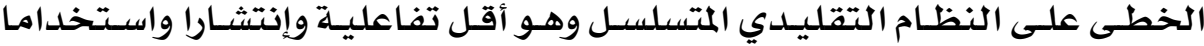

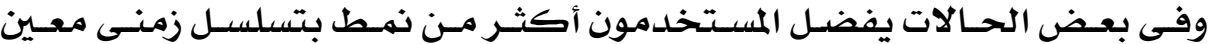

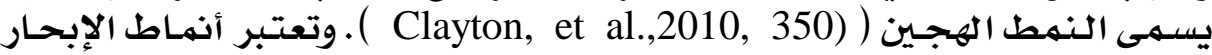

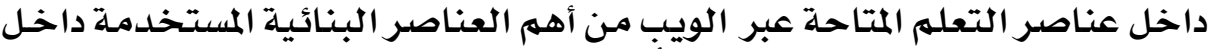

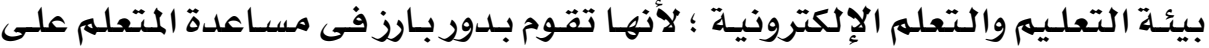

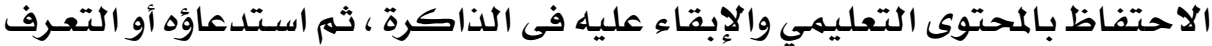

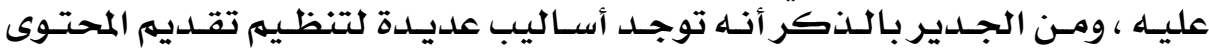

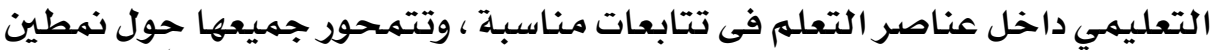

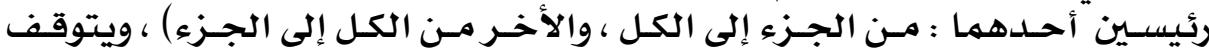

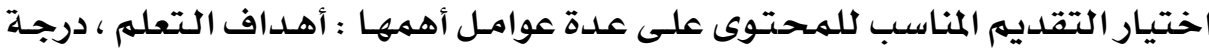

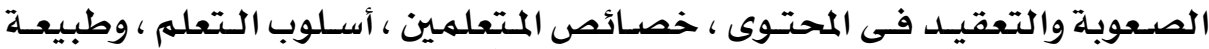

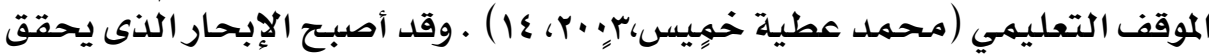

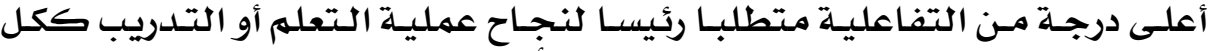

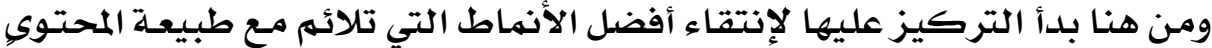

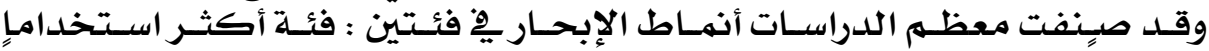

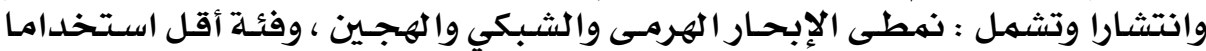

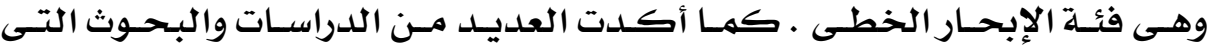

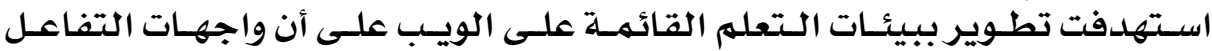

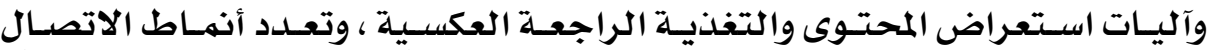

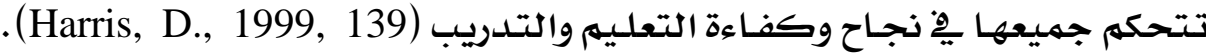

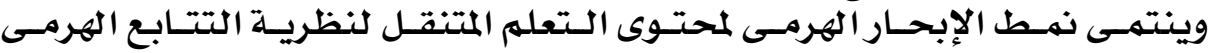

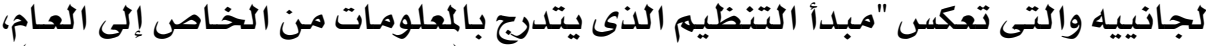

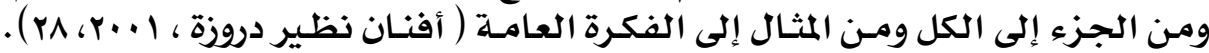

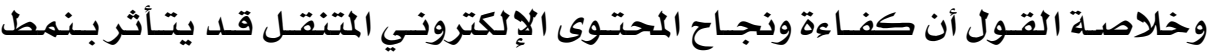

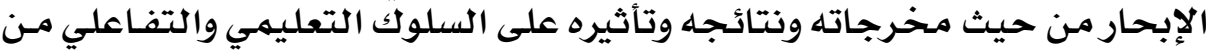

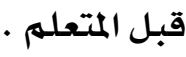

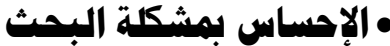

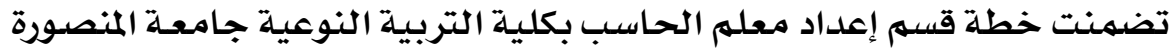

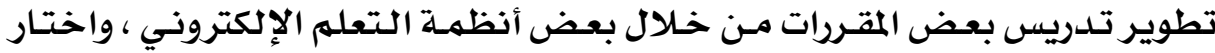

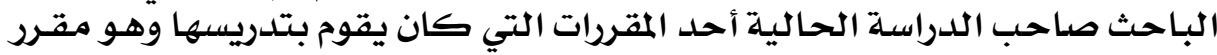

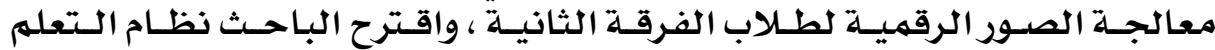

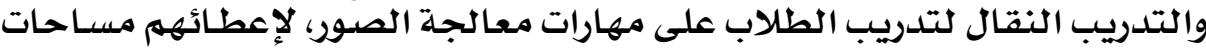

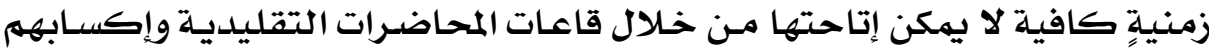

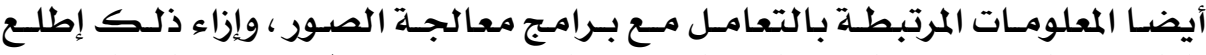

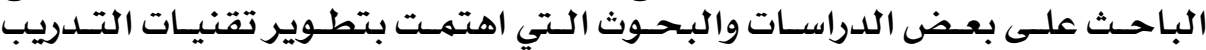

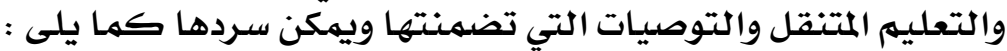




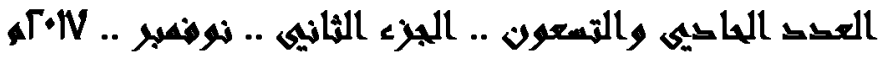

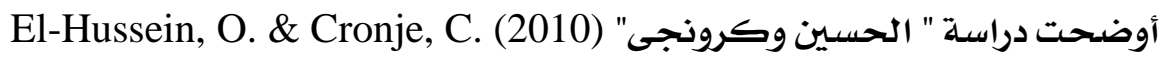

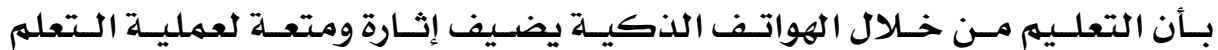

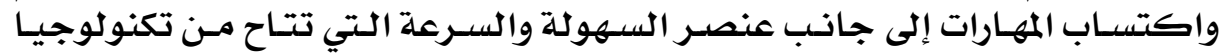

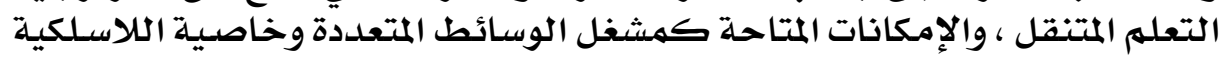

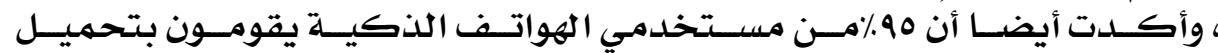

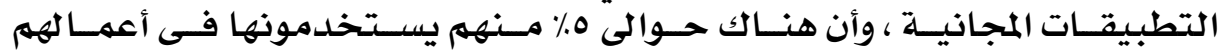

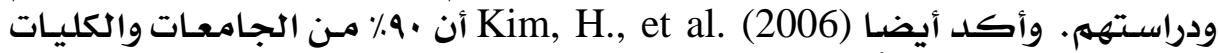

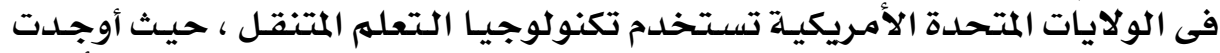

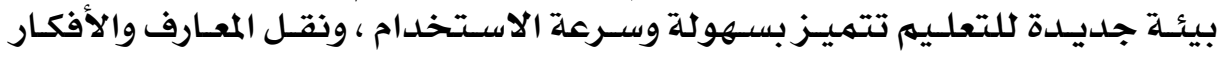

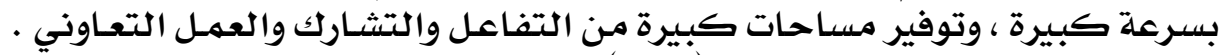

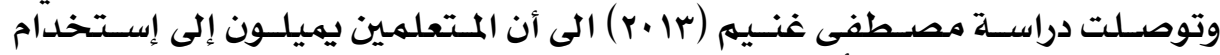

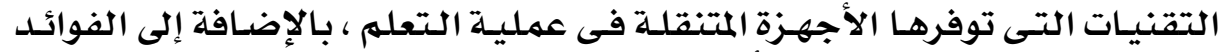

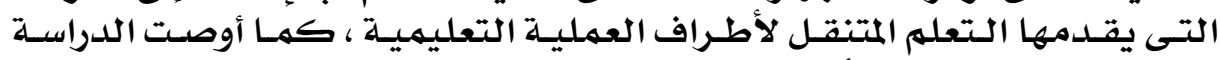

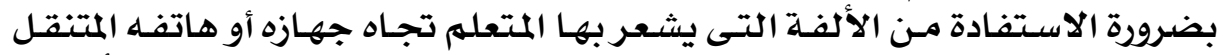

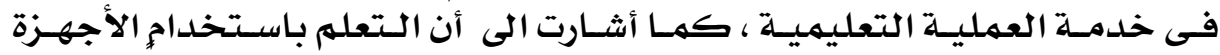

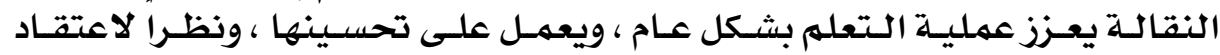

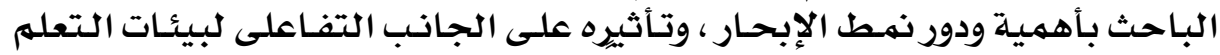

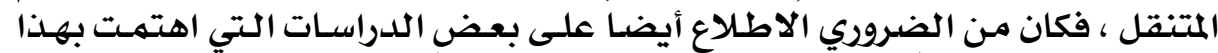

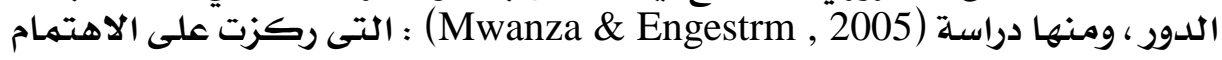

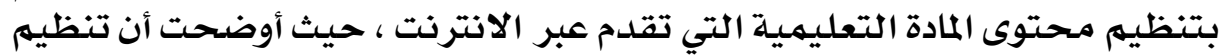

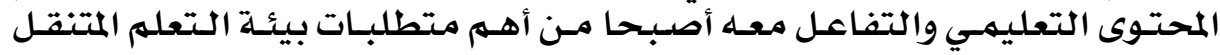

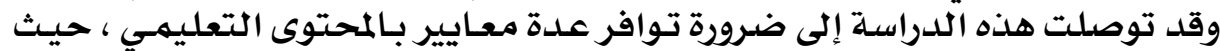

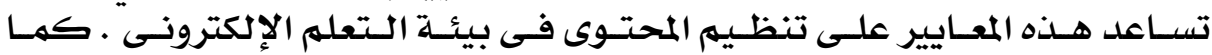

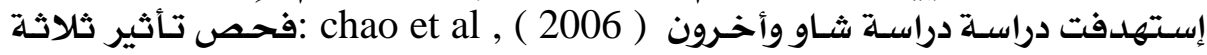

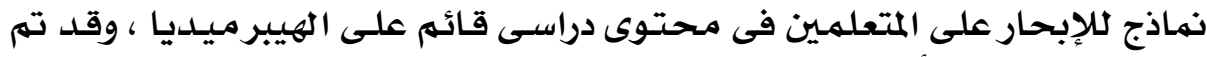

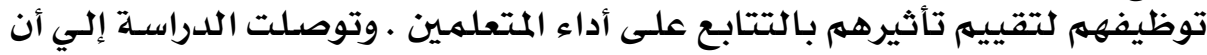

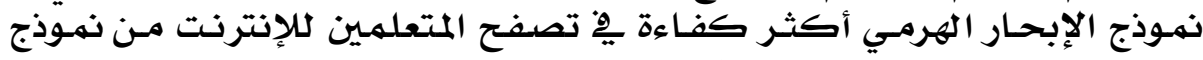

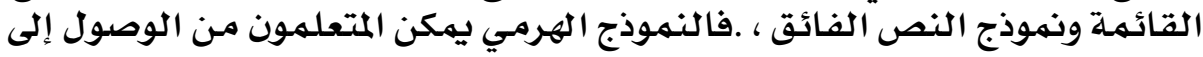

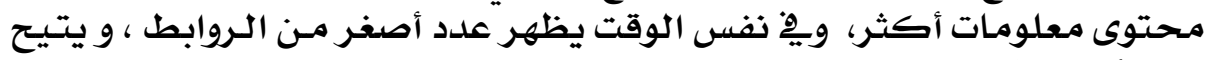

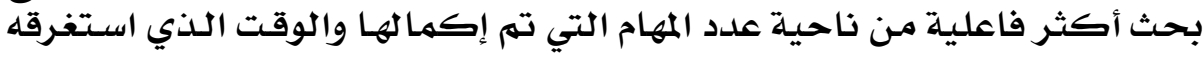

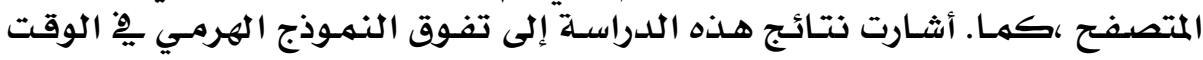

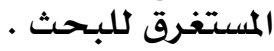

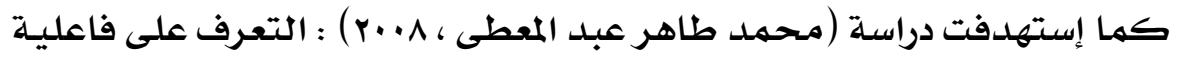

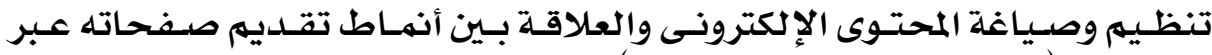

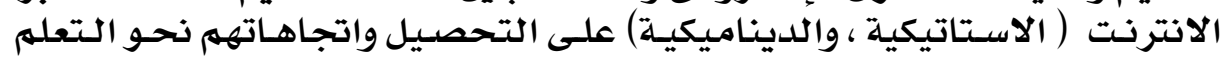

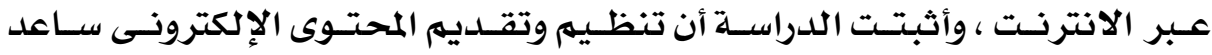




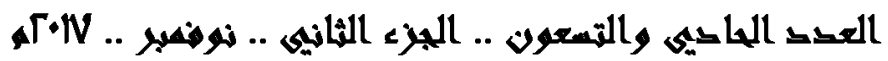

الطـلاب علـى الإقبـال علـى المحتـوى والتفاعـل معسه واكتســاب المعلومـات وزيـادة

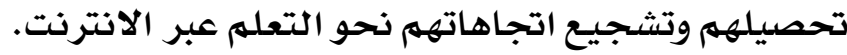

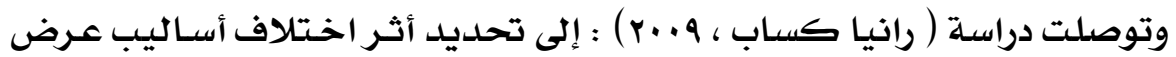

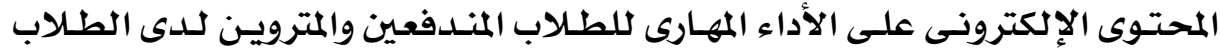

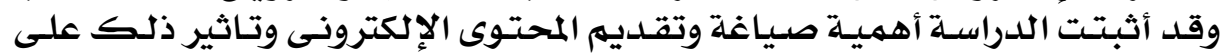

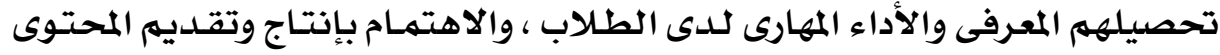

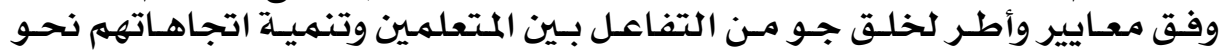

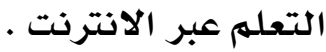

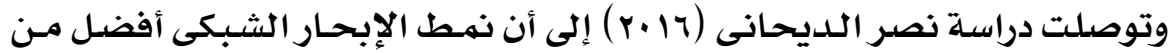

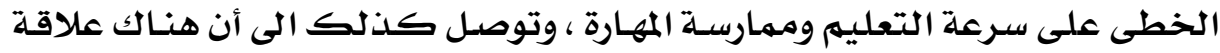

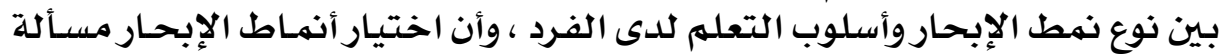

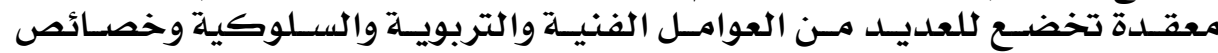

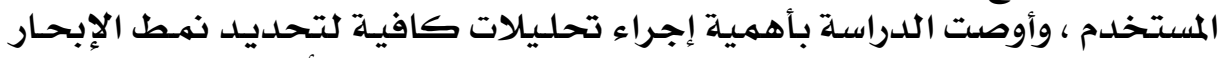

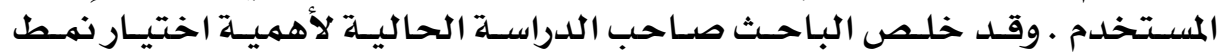

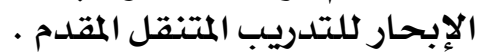

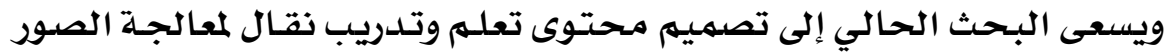

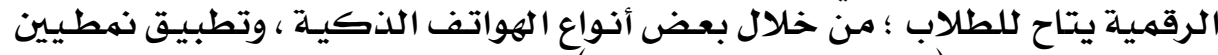

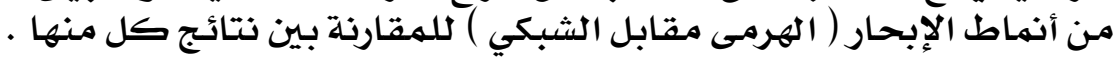

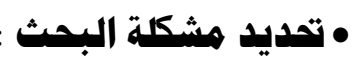

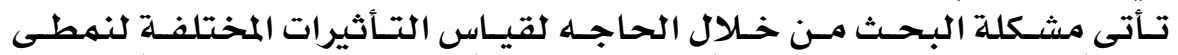

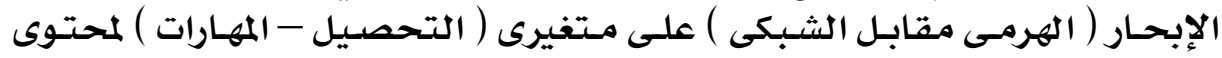

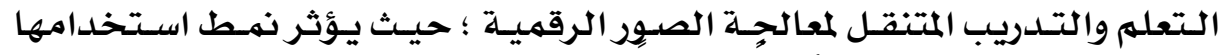

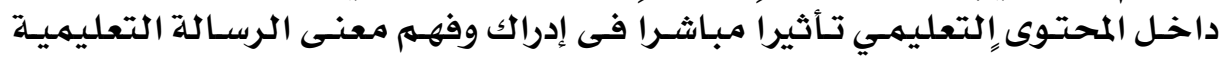

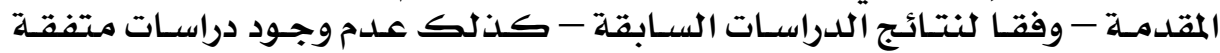

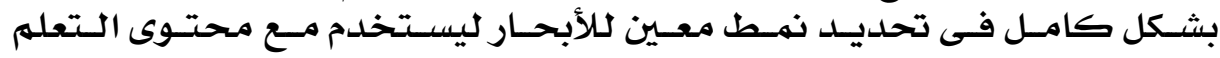

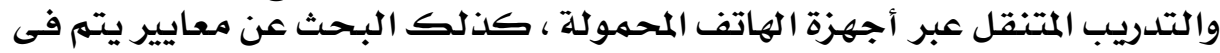

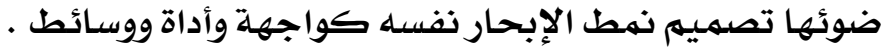

فى ضوء مـا تقدم يهكن تحلديد مشكلة البحث الحالي فى السؤال الرئيسي: ما معابير تصميم الإبحار الهرمى والإبحار الشبكي لمحتوى التدلدريب المتنقل ،

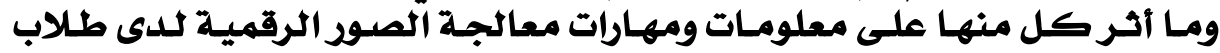

الفرقة الثانية ثعبة معلم الحماسب بكلية الثربية الثنوعية جامعة المنمورة

$$
\text { ويتفرع من السؤال الرئيسي الأسئلة الفرعيـة التالية : }
$$

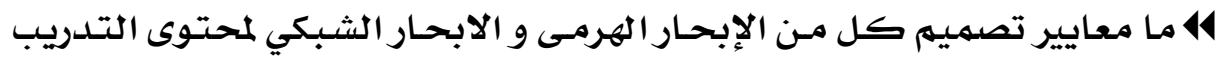

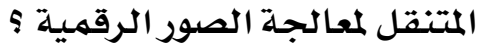




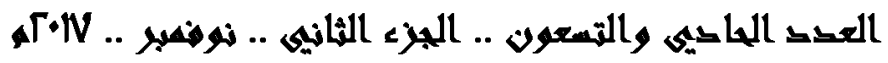

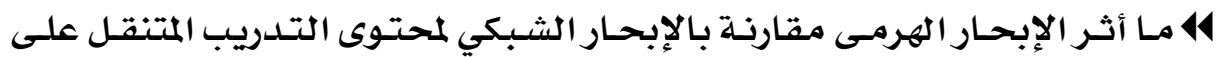

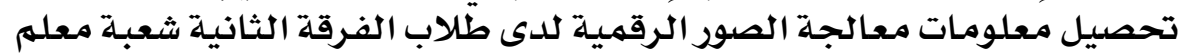

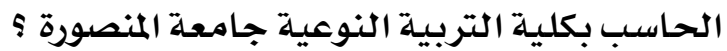

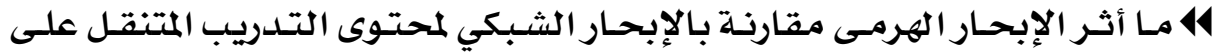

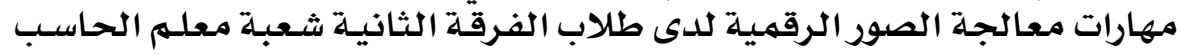
بكلية التربية النوعية جامعة المنصورة ؟ المعائ

$$
\text { • أهداف البحث : }
$$

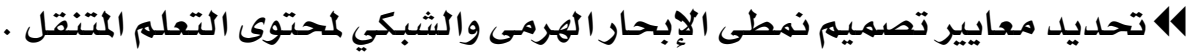

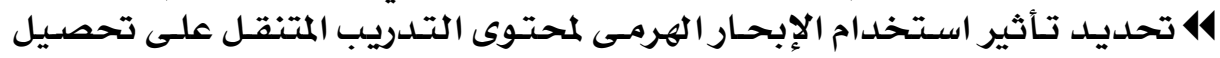

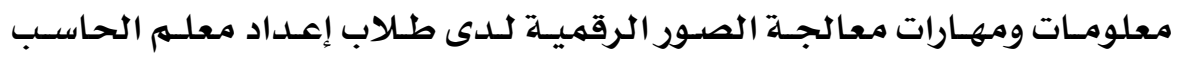

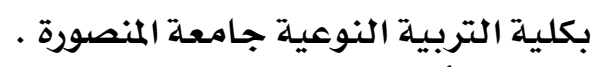

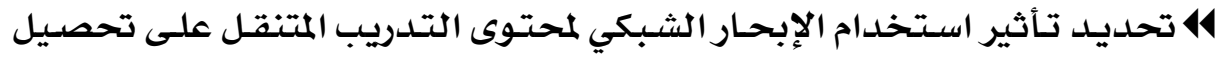

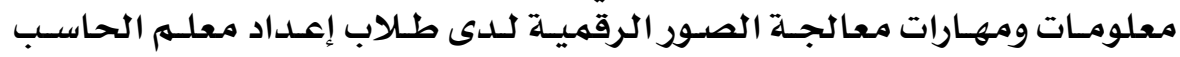

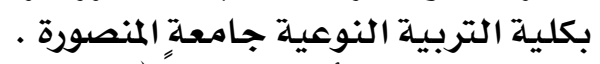

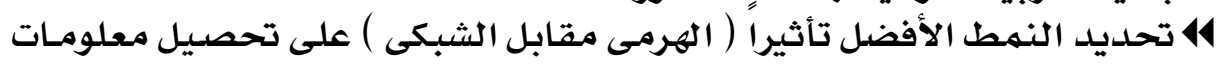

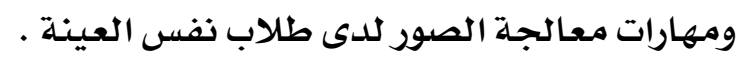

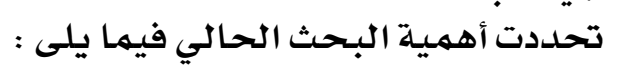

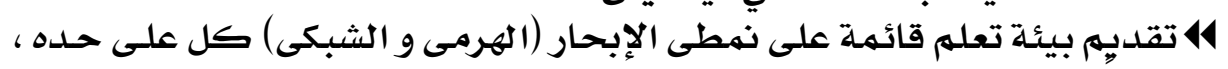

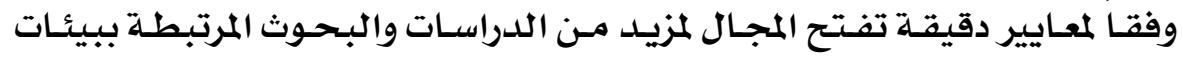

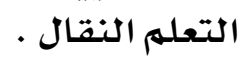

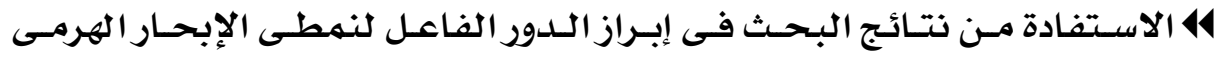

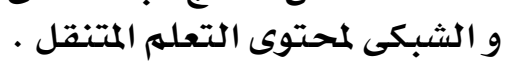

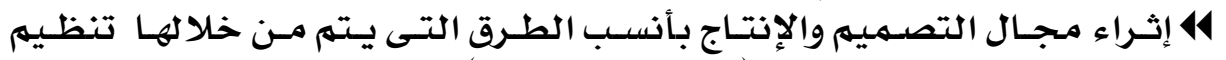

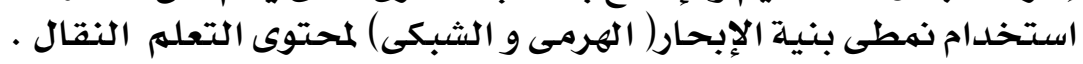

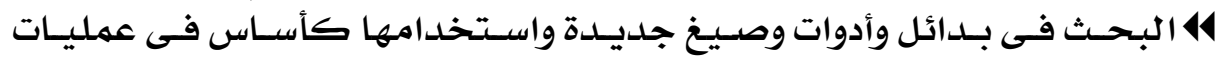

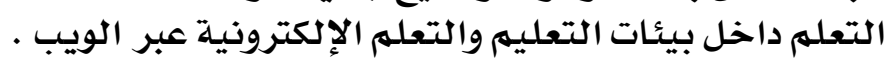

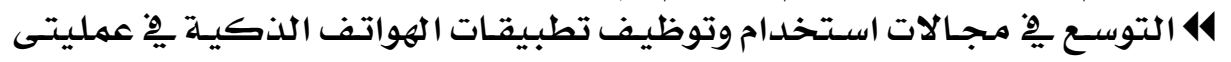

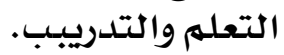

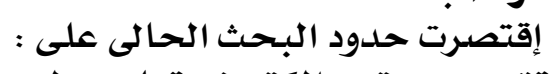

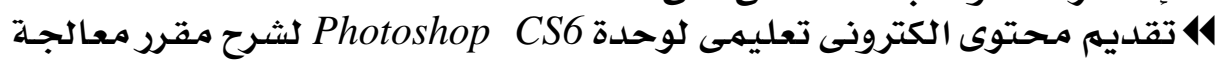

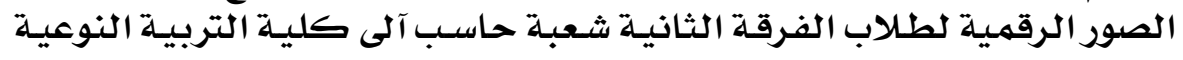




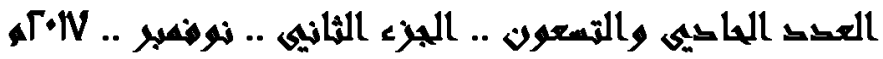

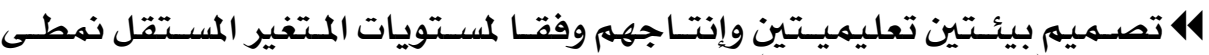

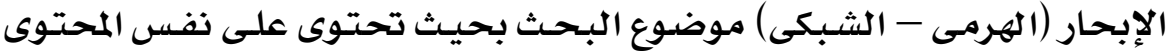

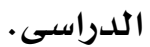

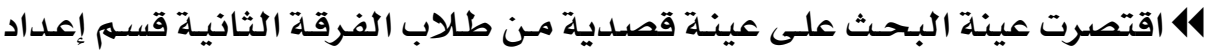

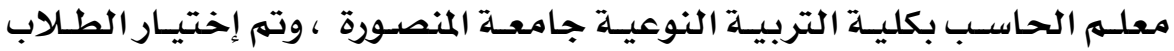

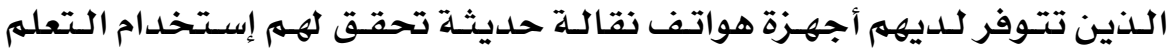

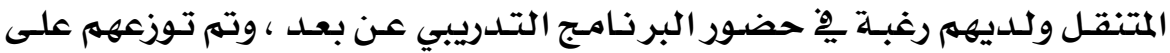

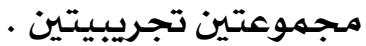

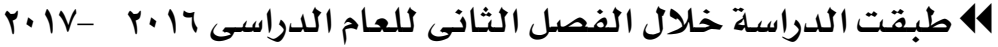

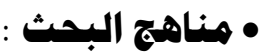

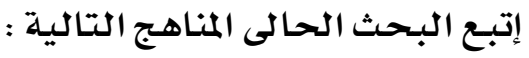

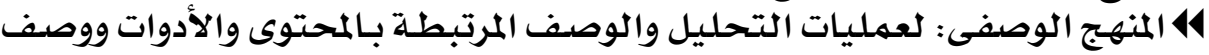

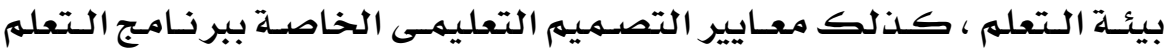

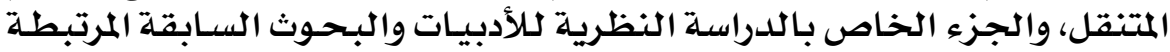

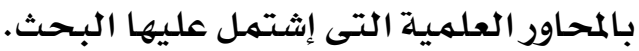

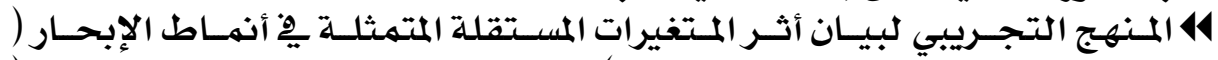

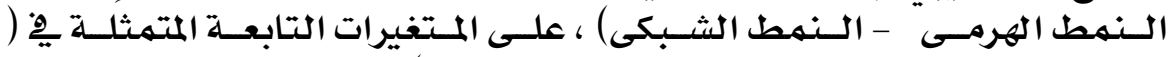

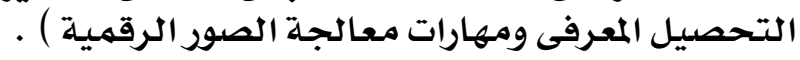

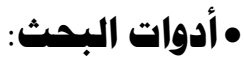
استخلدم البـحـث الحـالي الأدوات التاليـة مـن أجـل تحقيـق أهــاف البـحث المثـار

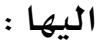
اليعان : استبيان للتحكيهم على معايير تصميم أنهاط الإبحسار الهرمى والشبكي لمحتوى

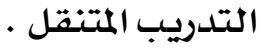

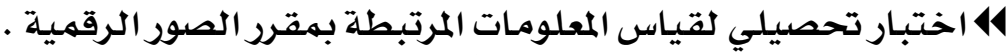

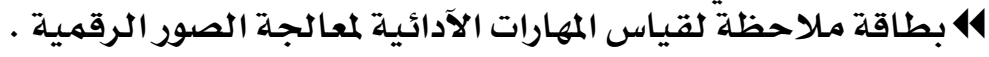

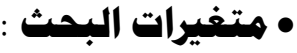

$$
\begin{aligned}
& \text { إثتمل البحثث على المتغيرات البت التالية: }
\end{aligned}
$$

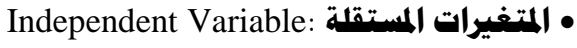

$$
\begin{aligned}
& \text { 14 نمط الإبحار الهرهى. }
\end{aligned}
$$

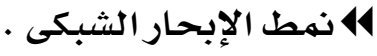

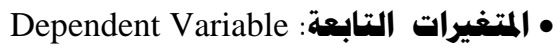

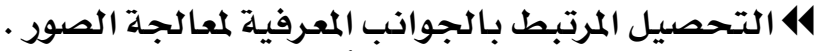

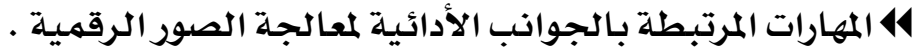

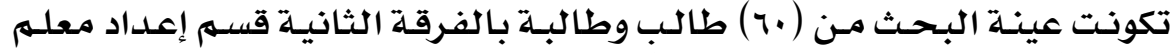

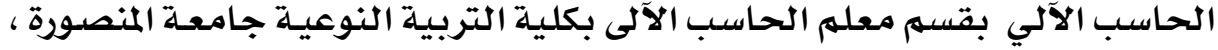

\section{$\varepsilon \forall q$}




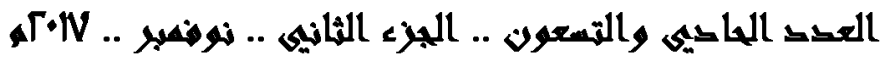

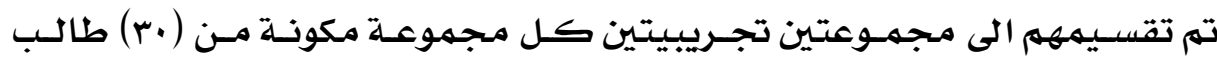

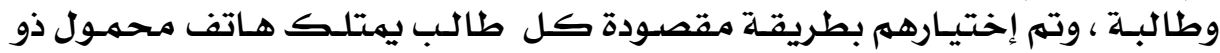

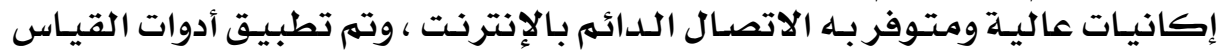

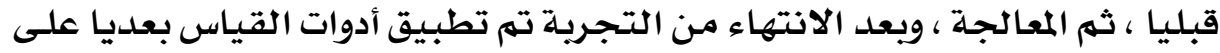

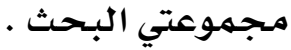

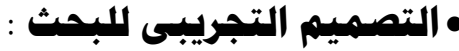

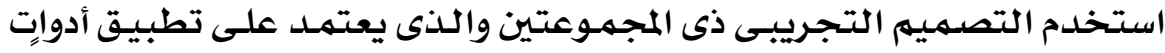

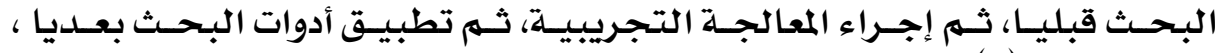
ويوضح شكل (r) التصميم التجريبى للبحثي.

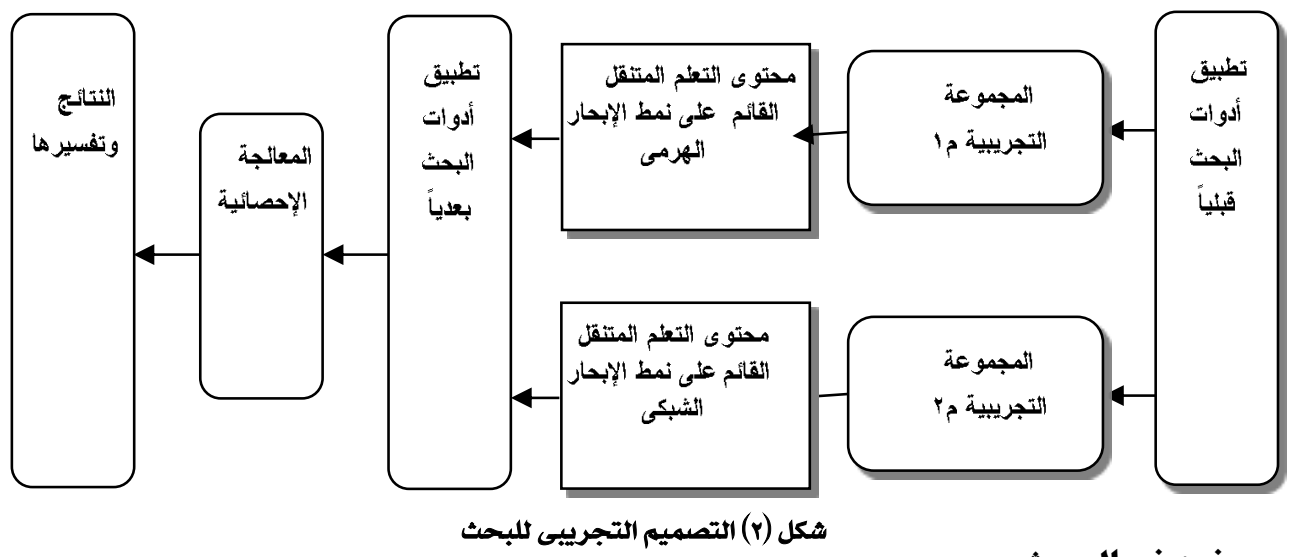

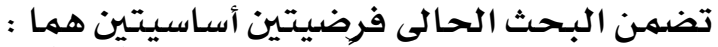

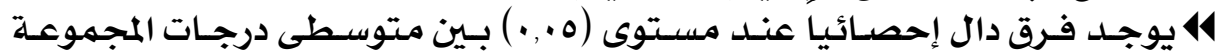

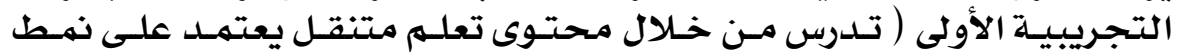

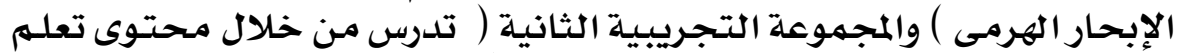

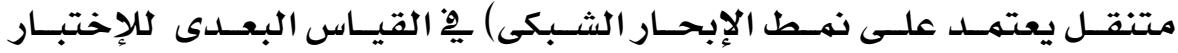

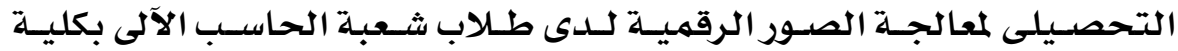

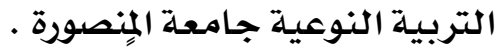

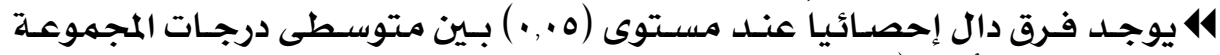

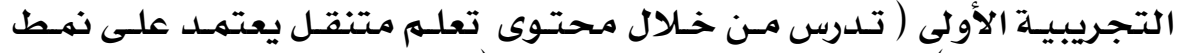

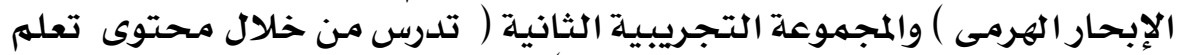

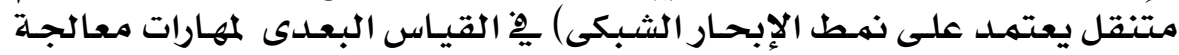

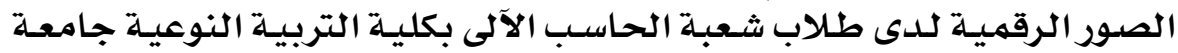

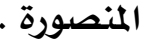

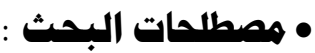
إثتمل البحث الحالى على المصطلحات التالية :

\section{$\varepsilon \varepsilon$.}




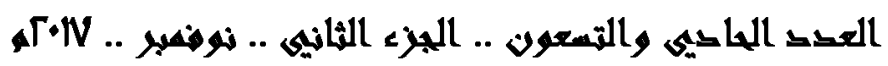

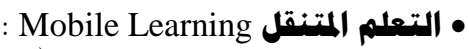

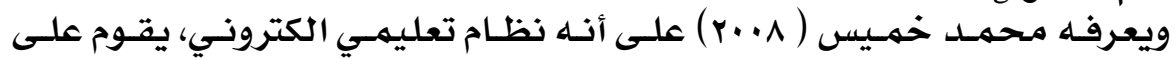

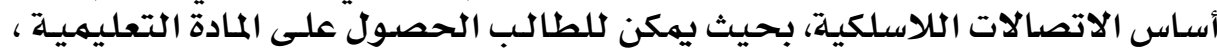

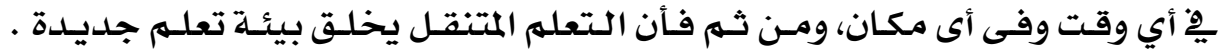

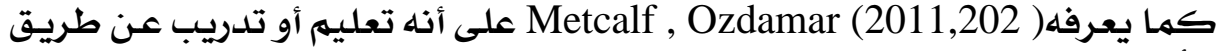

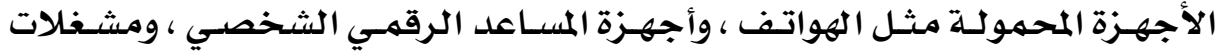

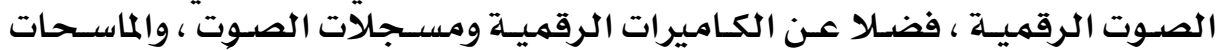

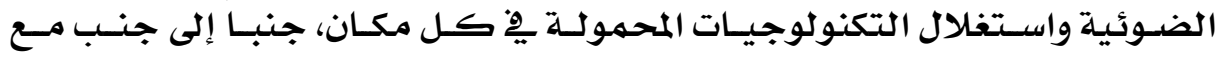

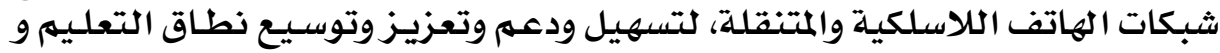

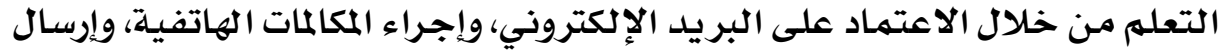

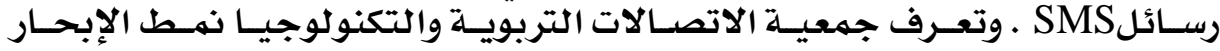

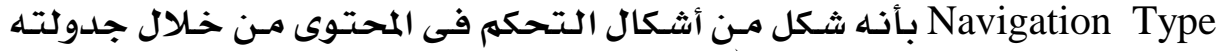

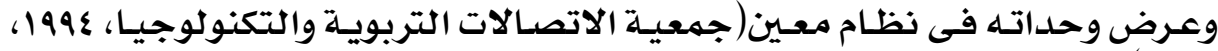

. $(1990$

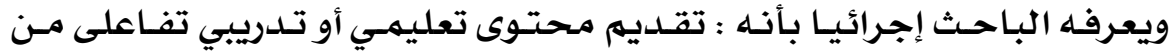

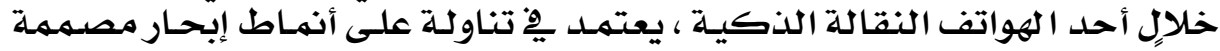

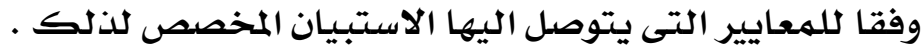

: Hierarchical type • •

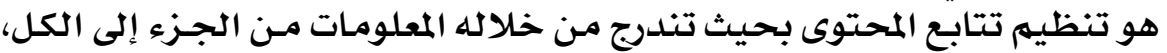

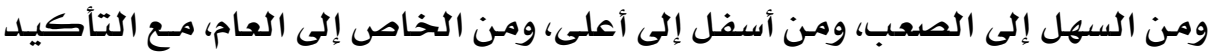

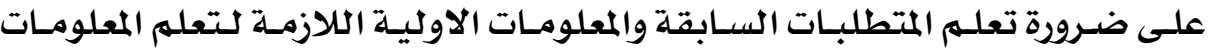

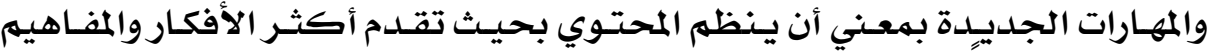

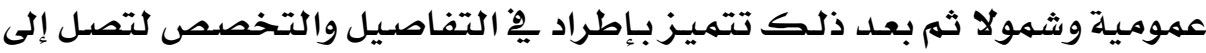

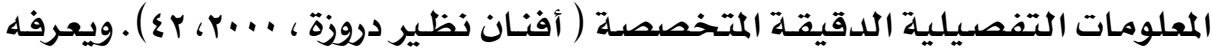

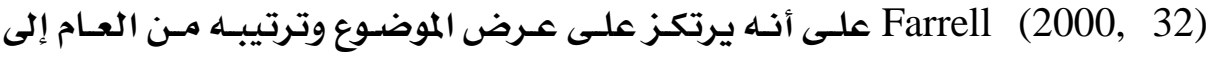

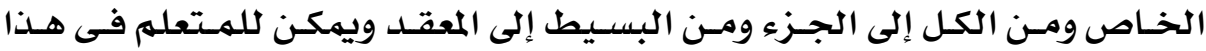

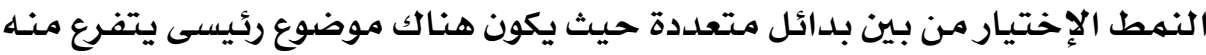

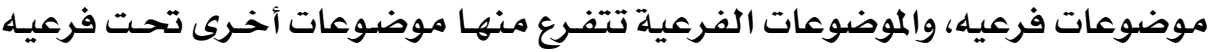

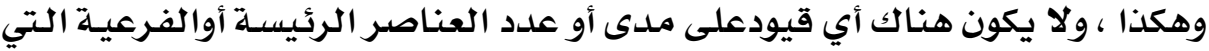

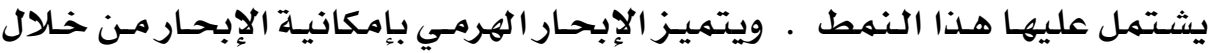

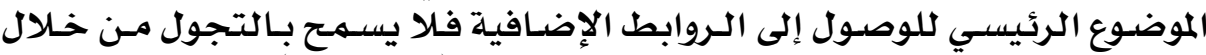

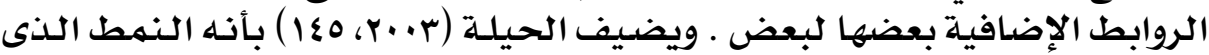

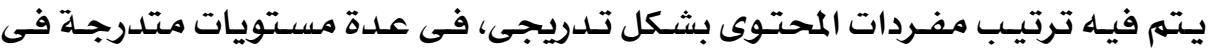

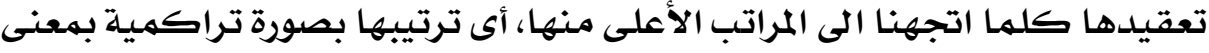

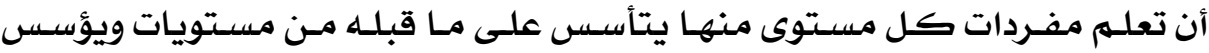

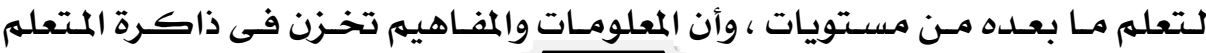




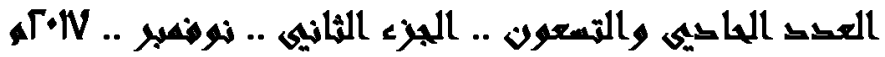

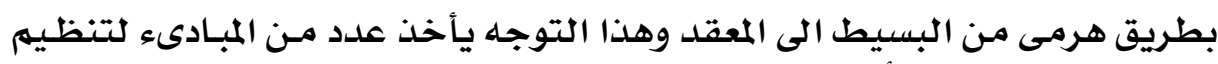

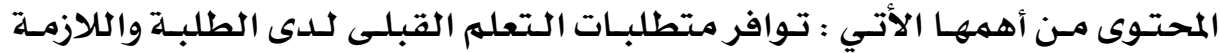

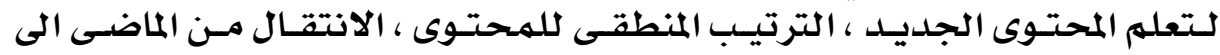

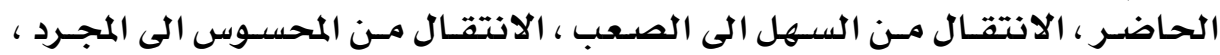

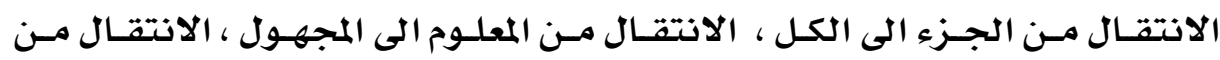

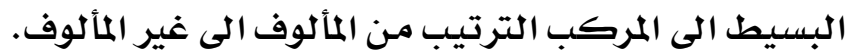

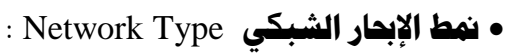

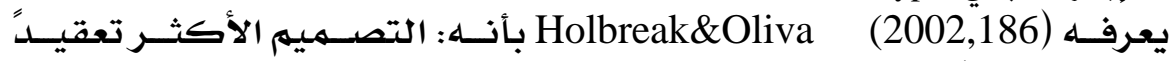

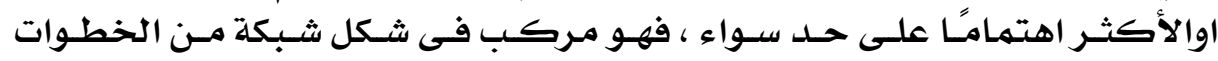

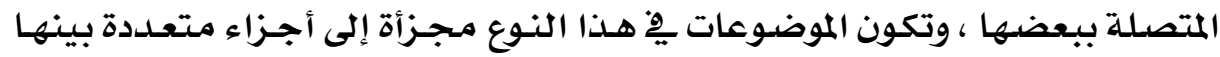

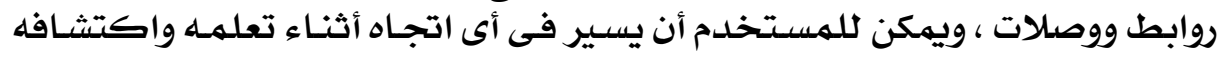

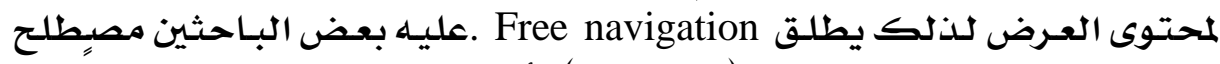

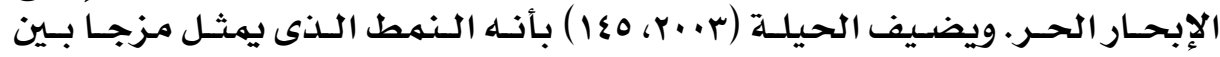

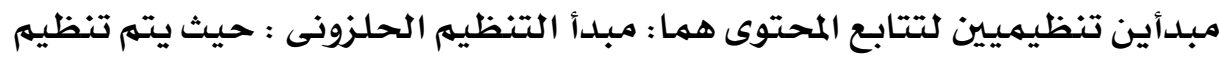

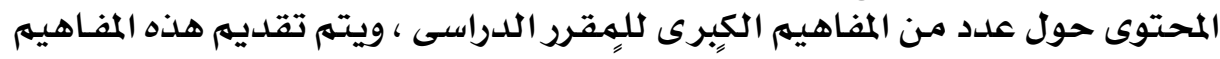

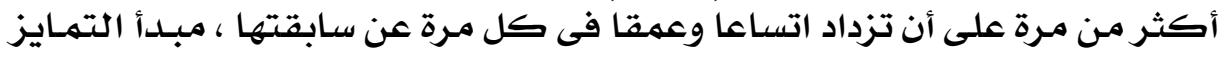

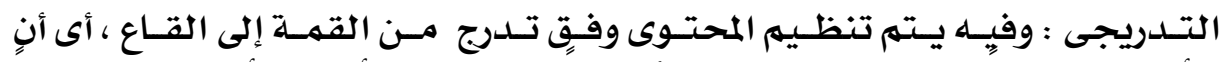

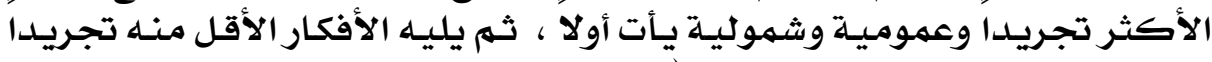

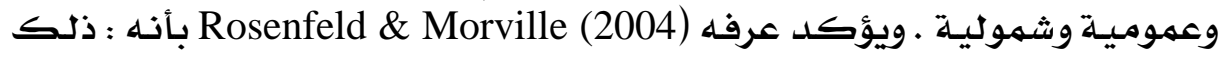

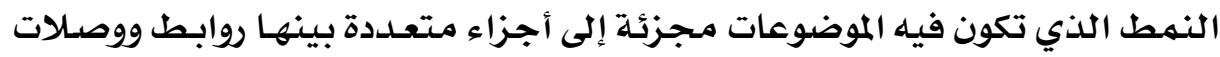

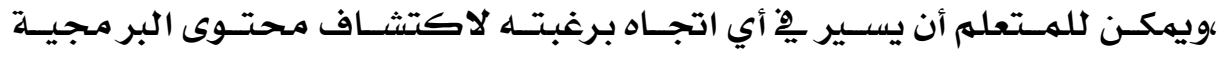

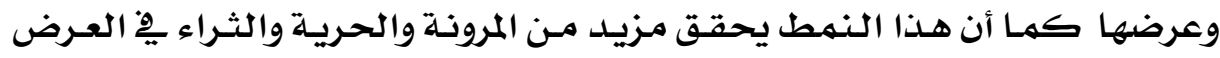

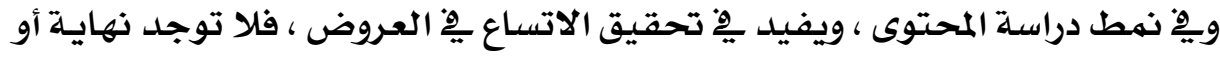

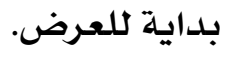

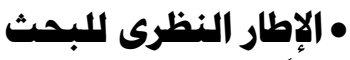

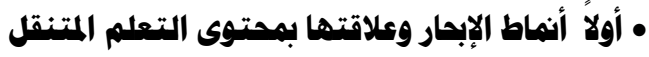

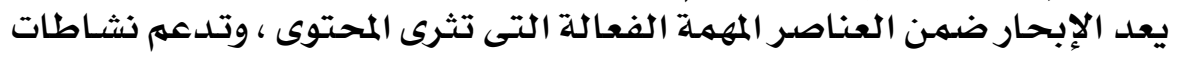

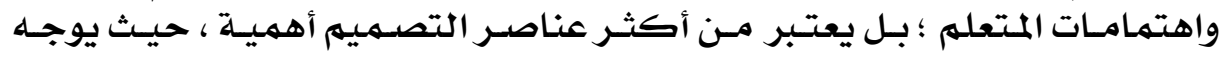

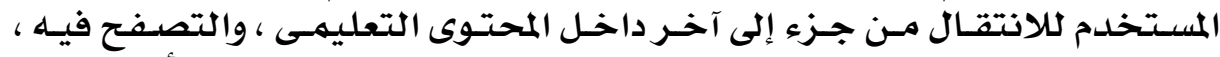

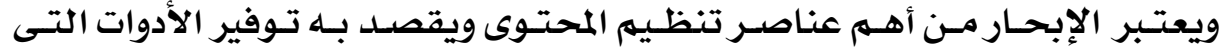

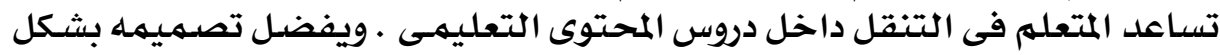

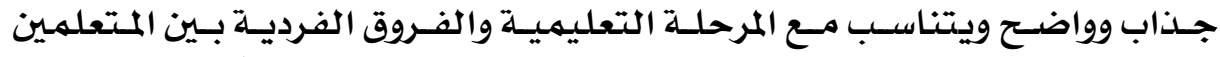

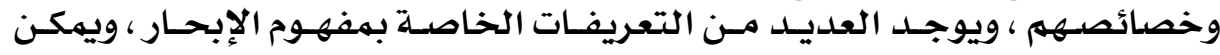

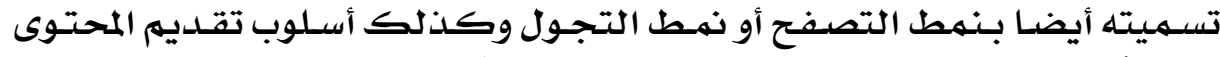

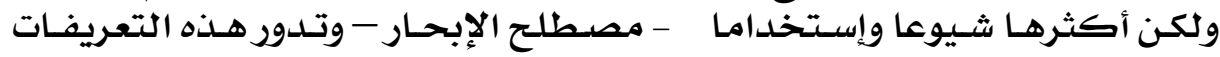

\section{$\varepsilon \varepsilon Y$}




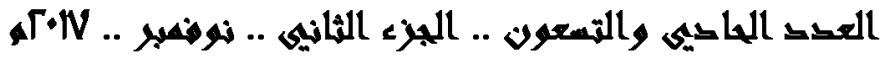

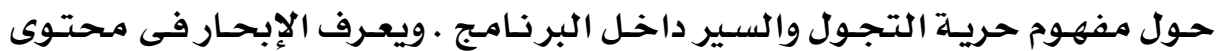

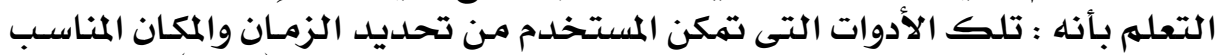

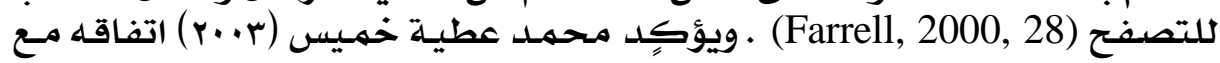

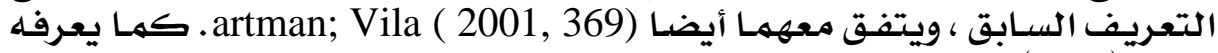

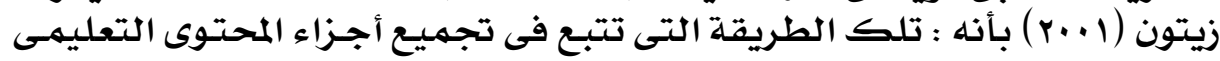

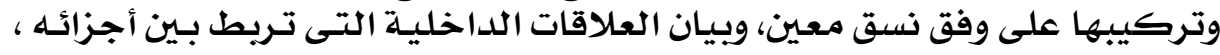

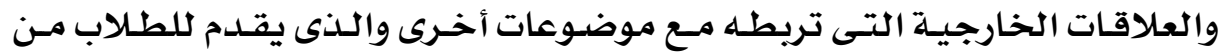

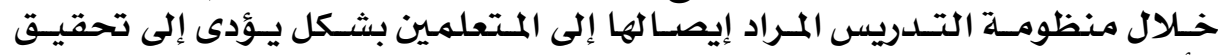

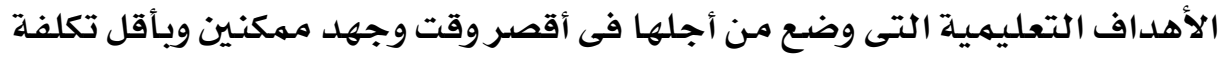

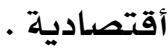

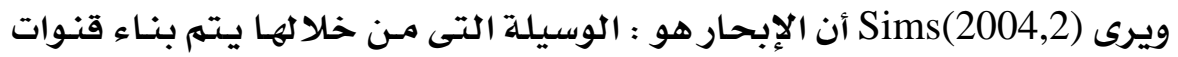

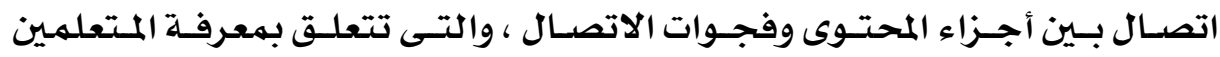

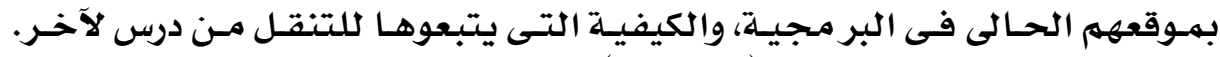

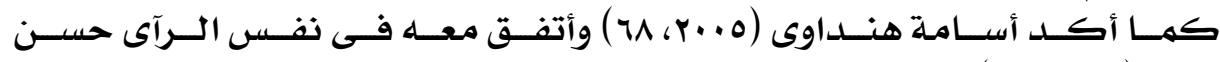

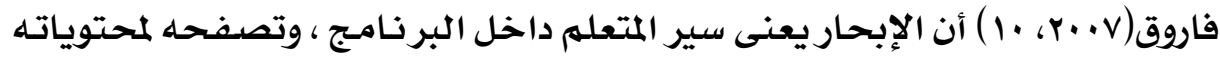

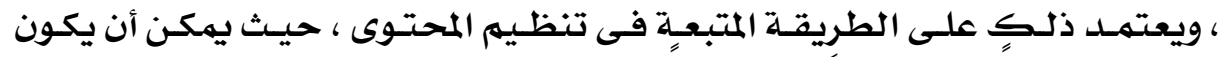

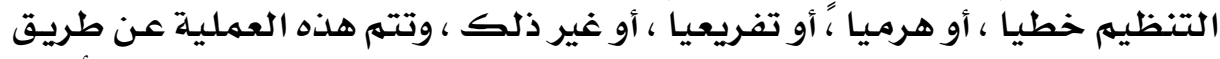

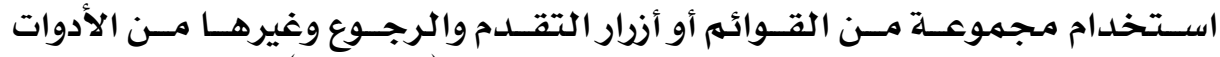

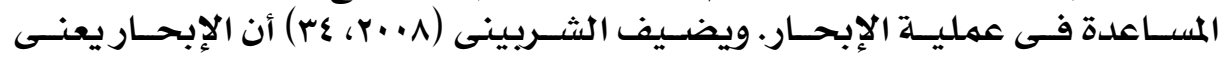

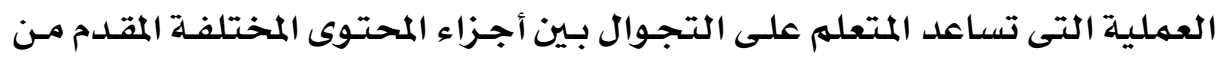

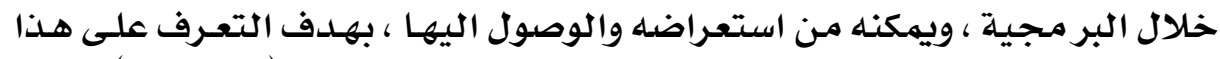

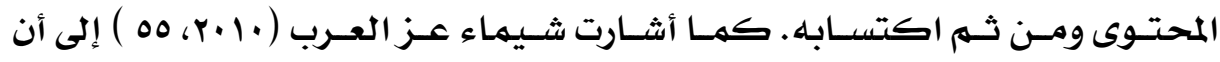

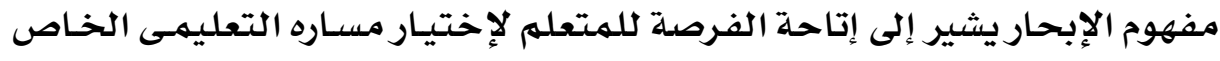

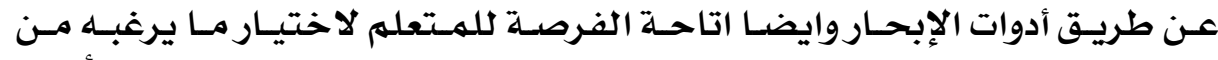

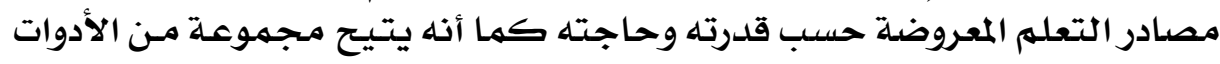

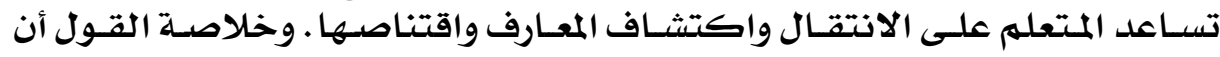

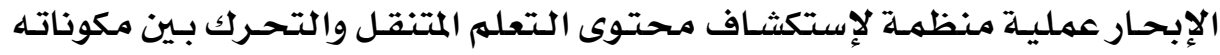

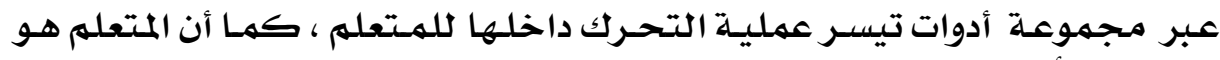

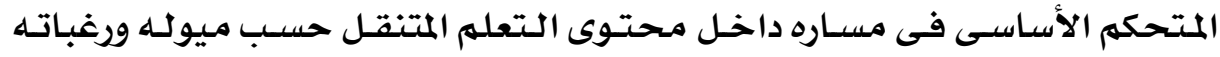

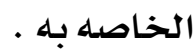

• Navigation Types أنماط الإبحار ل

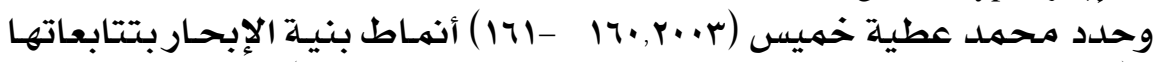

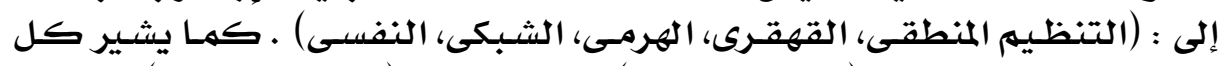

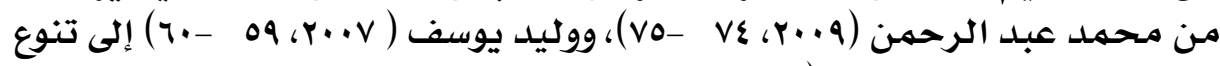

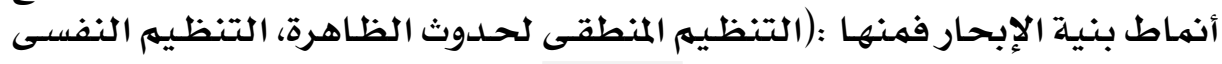

\section{$\varepsilon \varepsilon r$}




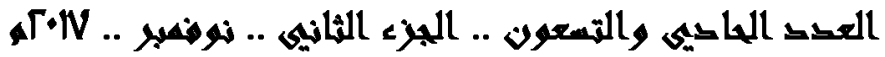

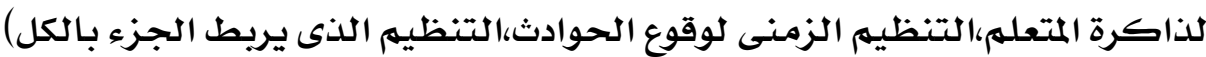

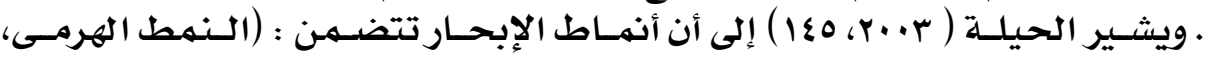

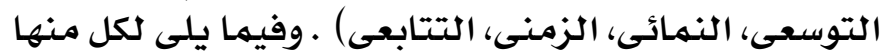

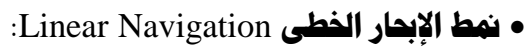

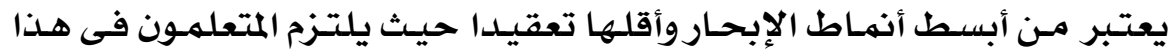

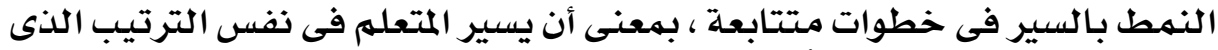

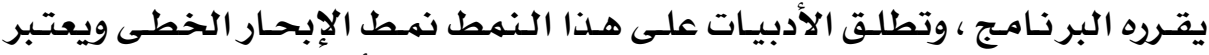

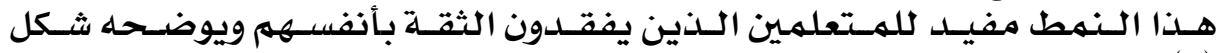

(Chuen et al, 2004).(r)

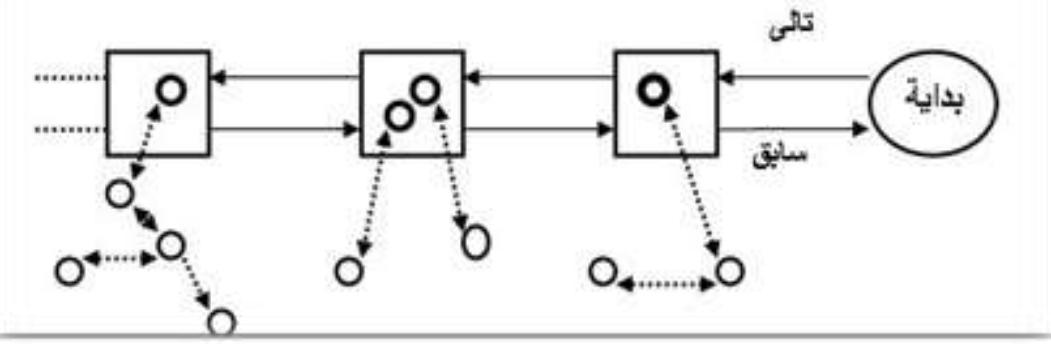

شكل (r) نمط الإبحار الخطى

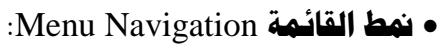

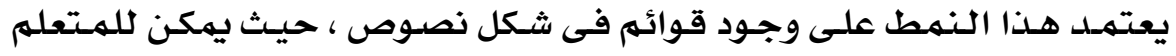

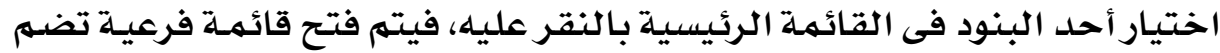

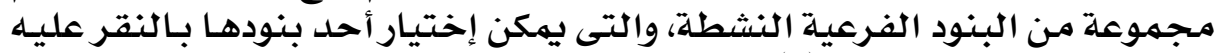
كتصفحه . ويوضه من البنود الفرعل (ع ) :

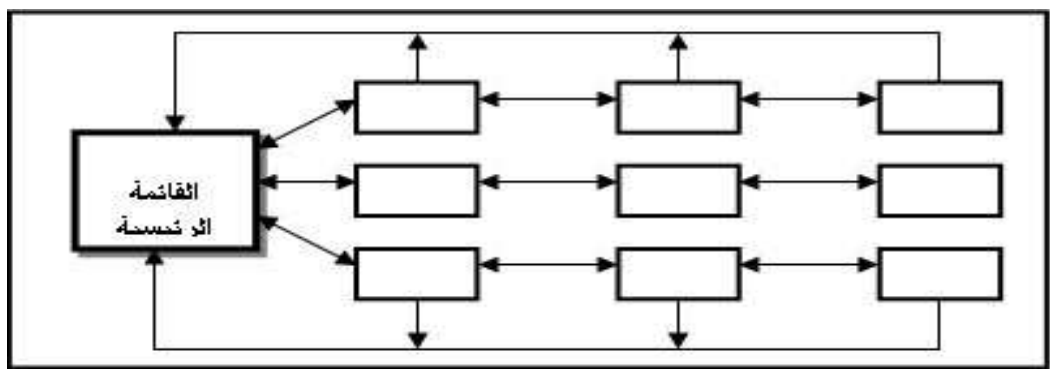

شكل (ع) نمط الإبحار القائمة

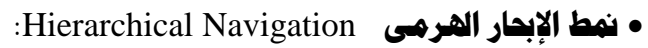

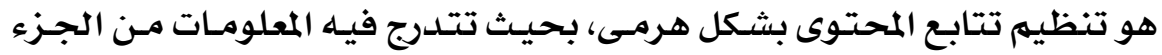

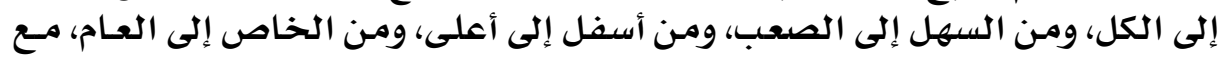




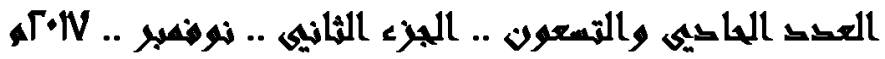

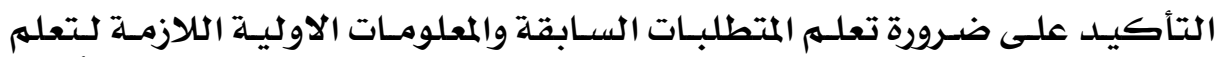

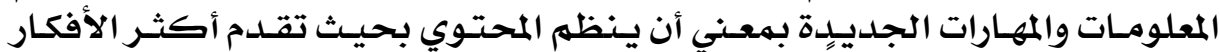

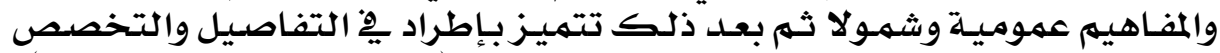

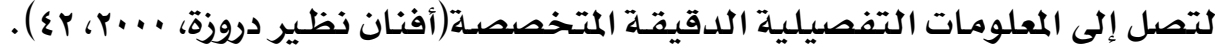

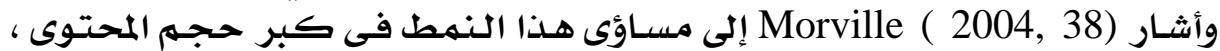

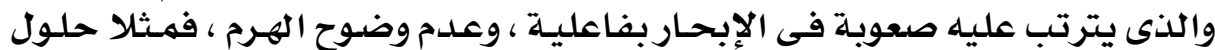

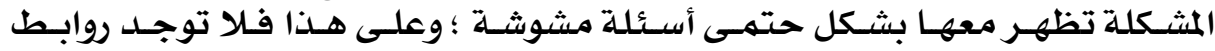

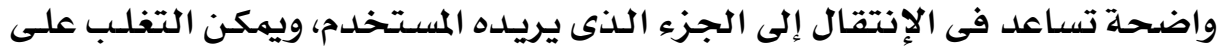

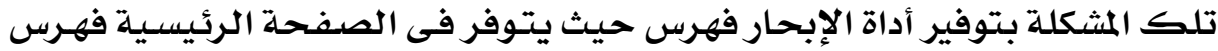

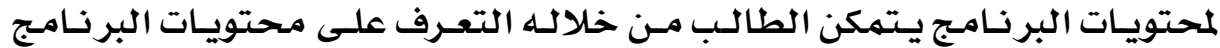

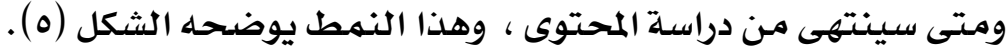

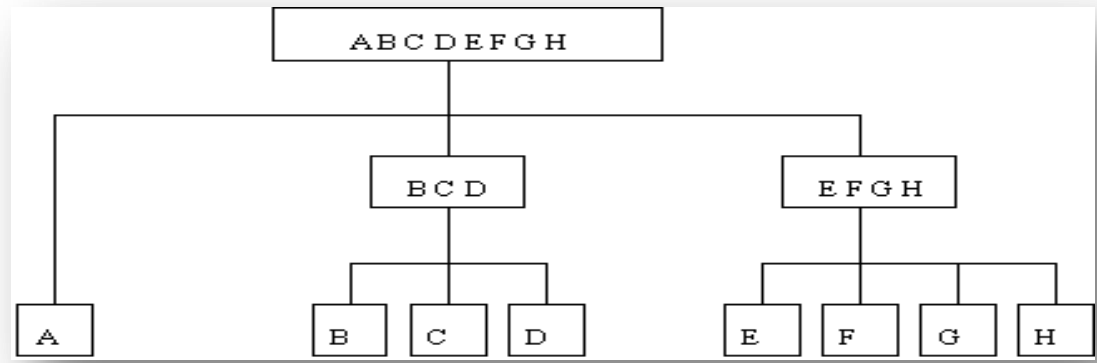

شكل (o) نمط الإبحار الهرمى (Chuen,2004)

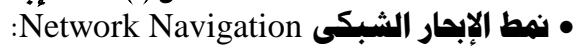

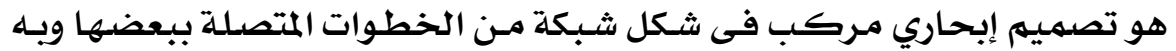

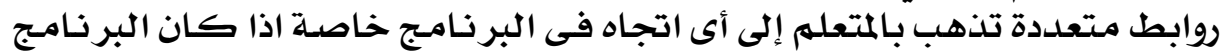

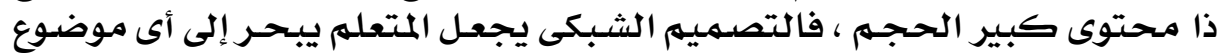

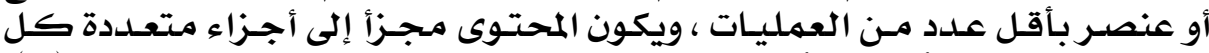

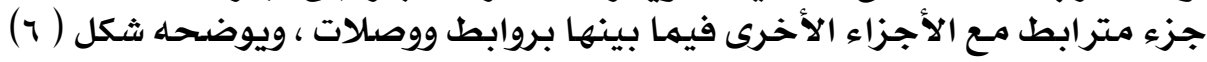

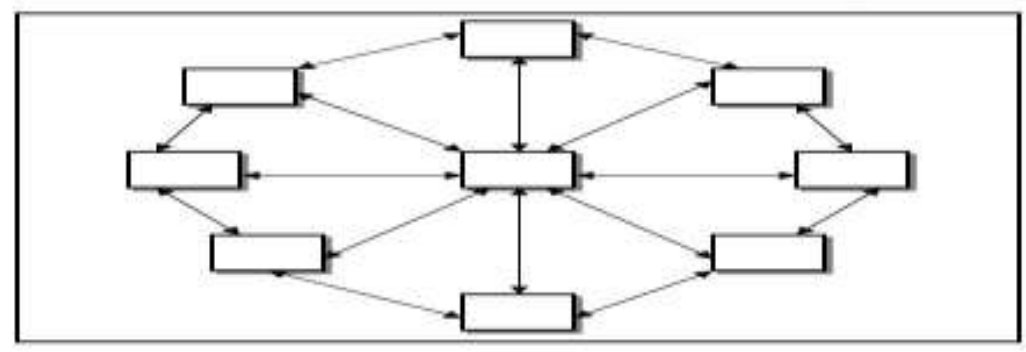

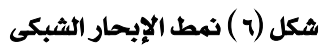




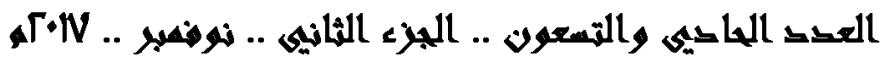

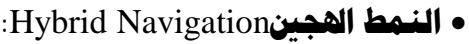

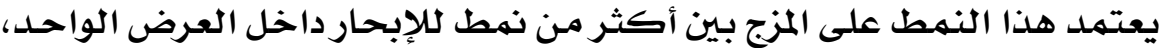

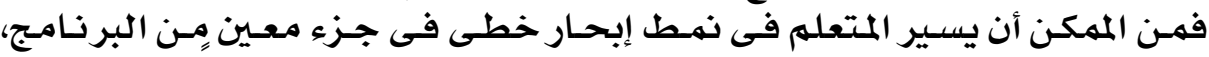

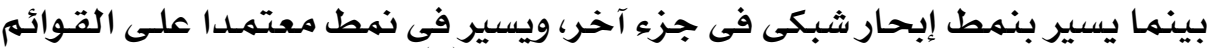

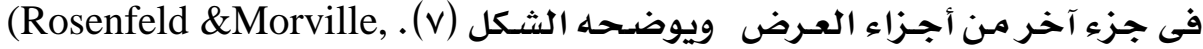
2004, 43)

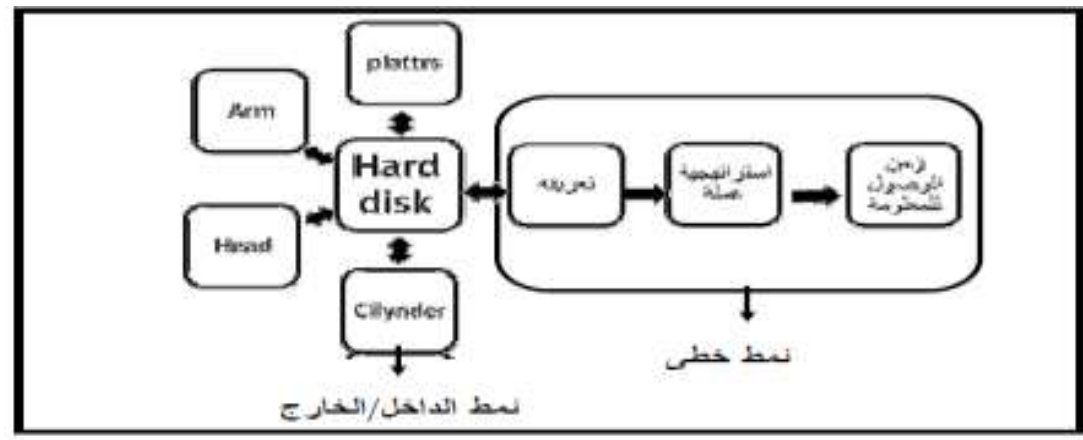

ثكل (v) نمط الإبحار الهجين

• ثانياً أدوات الإبمار لمتوى التعلم المتنقل Navigation Tools:

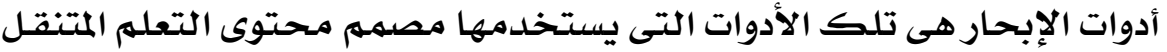

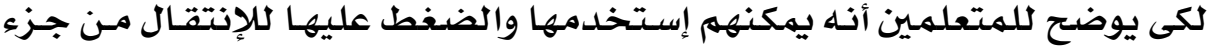

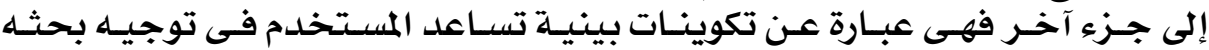

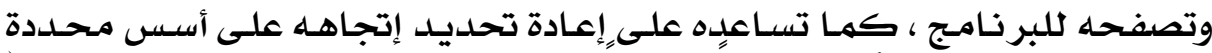

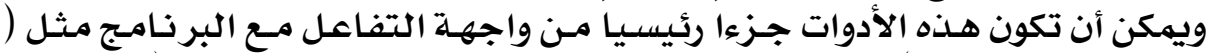

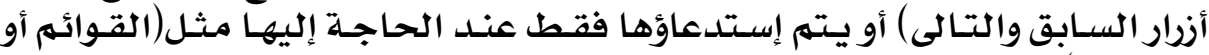

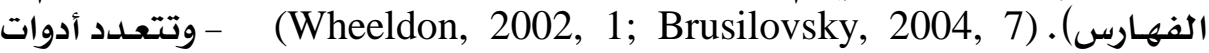
الإبحار التى يهكن الإعتمهاد عليها فى محتوى التعلم المتتقل منها : ه فهرس الكلهـات المفتاحيـة Keyword Index : وتعنى فهرس للههارات الرئيسيسة

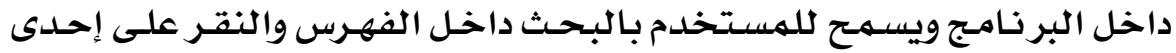

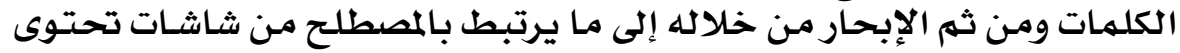

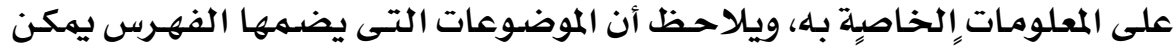

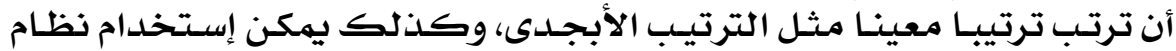

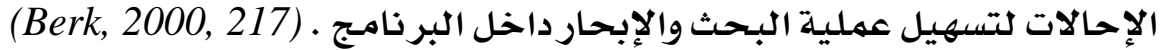
4أزرار التالى والسـابق Next / Previous Buttons : وتكون أزدار موجـودة داخـل

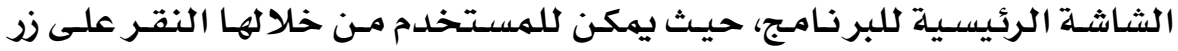

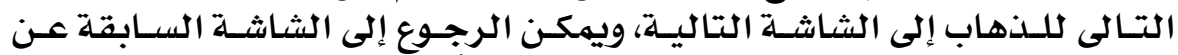

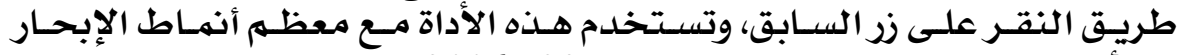

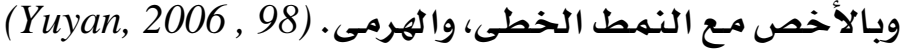




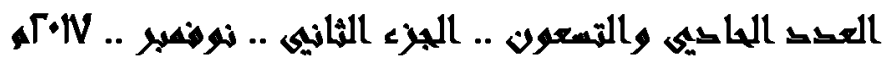

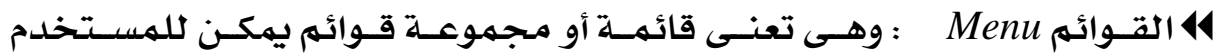

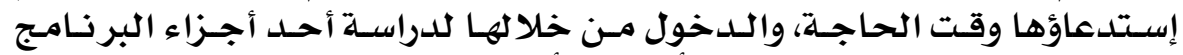

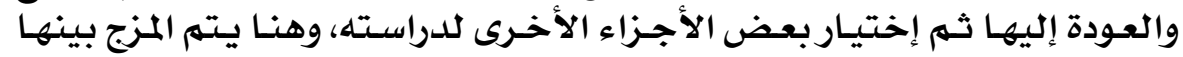

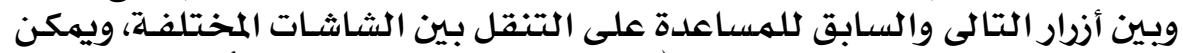

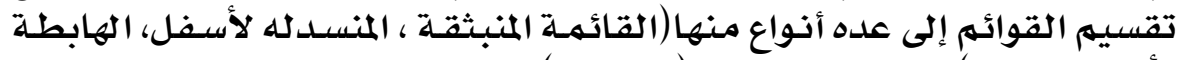

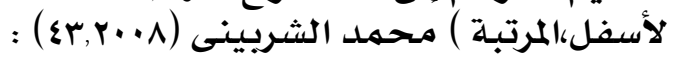

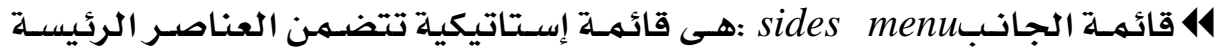

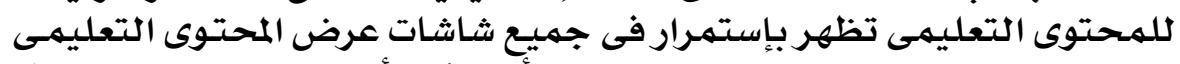

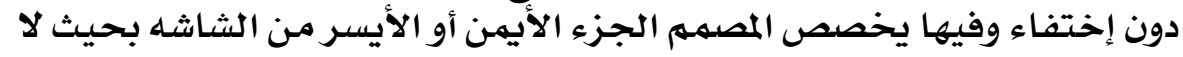

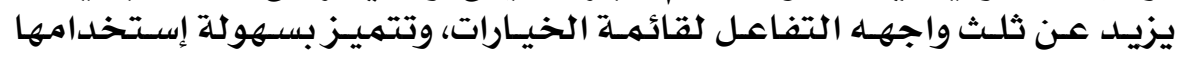

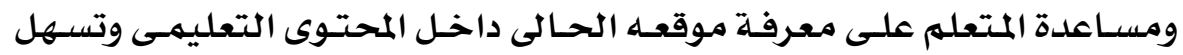

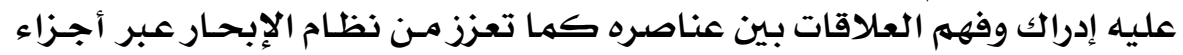

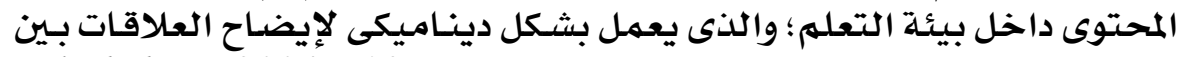

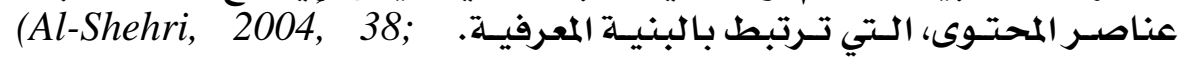
Buendía, 2006, 46̈7; Ean-Teng, 2010)

\ا القائمـة المخفيـhidden menu: هى قائمهة ديناميـة تظهر وتختفى، وهى أكثر

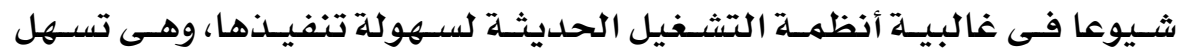

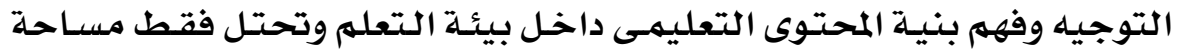

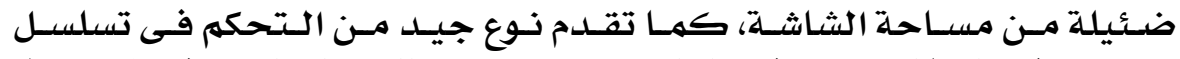

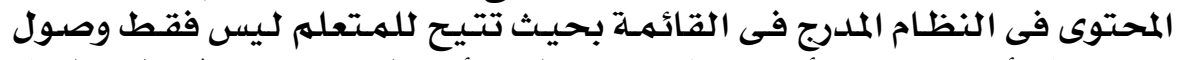

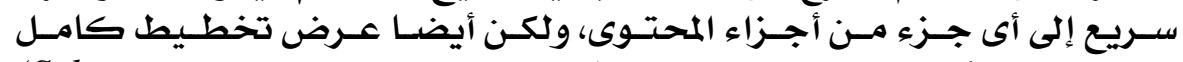

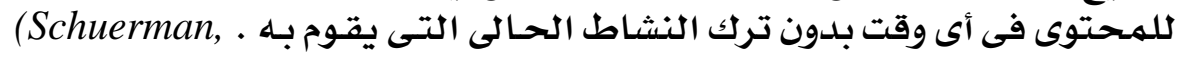
1991, 97; Alessi, 2008, 54; Bayram, 2005, 9)

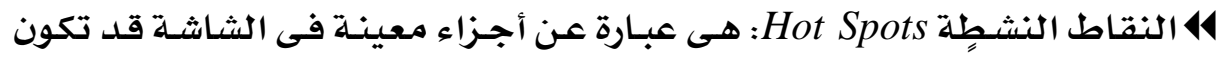

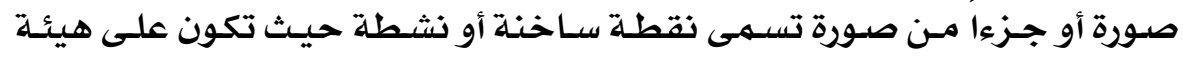

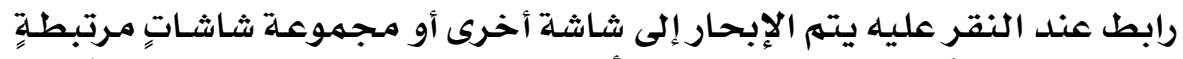

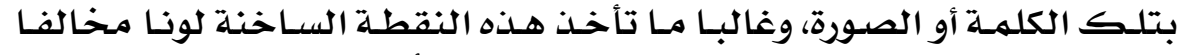

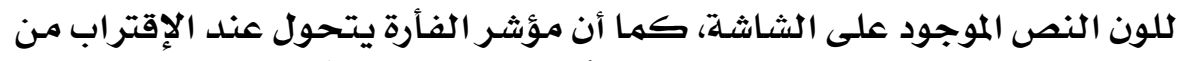

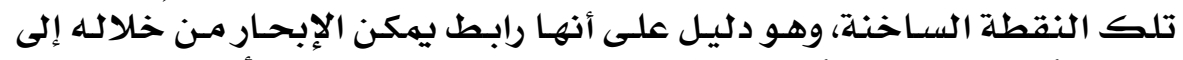

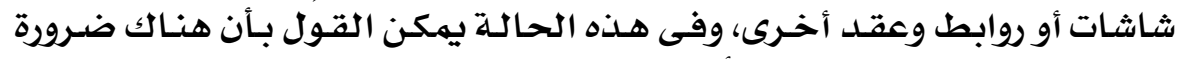

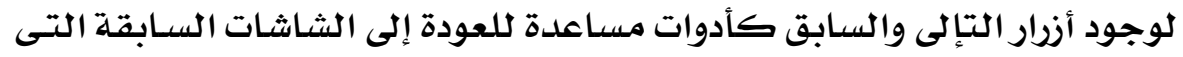

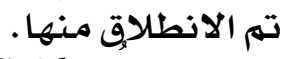

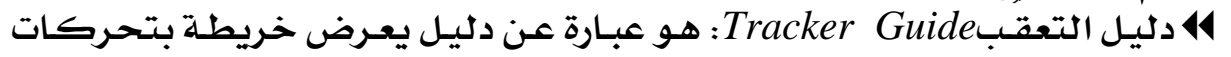

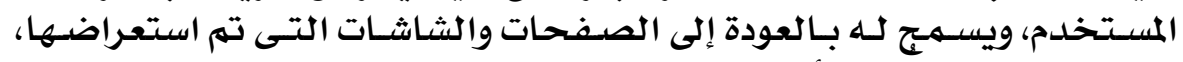

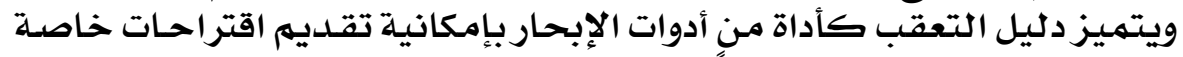

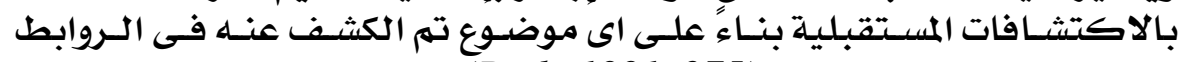
السابقة بواسطة المستخدم . (Berk, 1991, 275) 


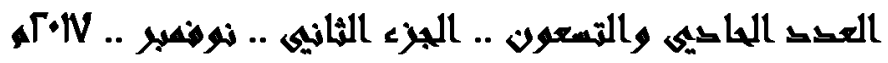

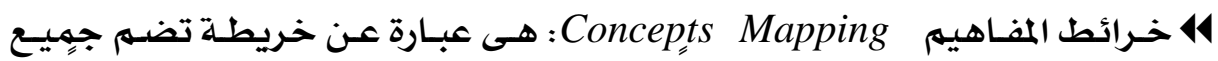

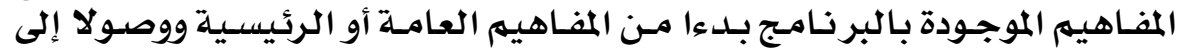

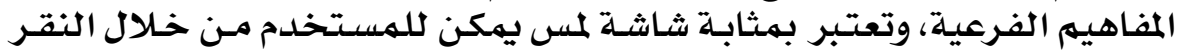

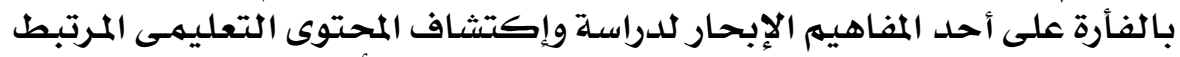

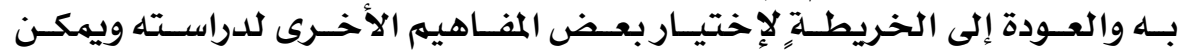

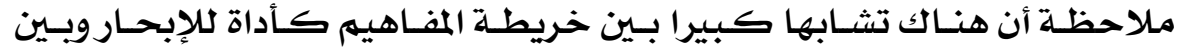

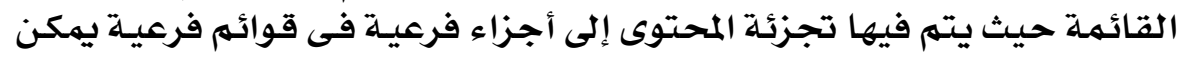

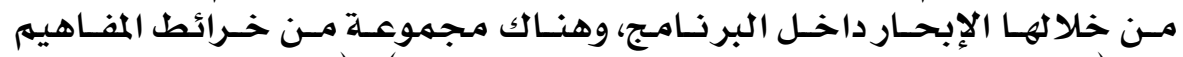

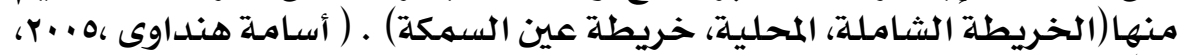

(o)

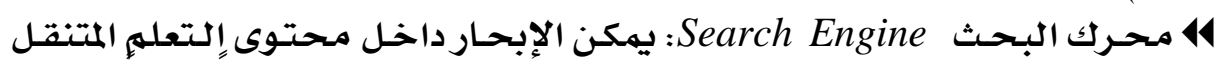

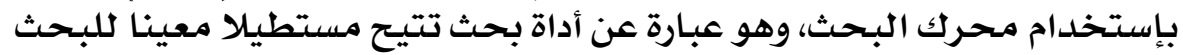

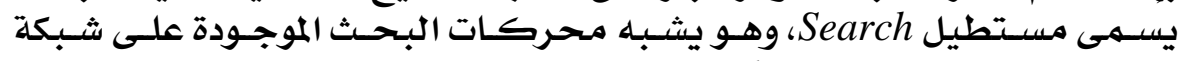

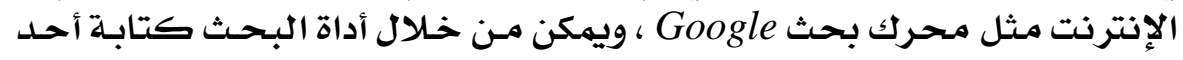

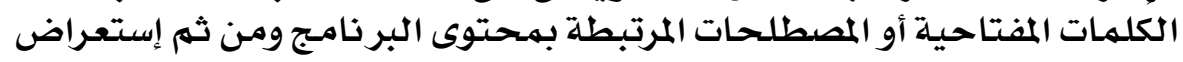

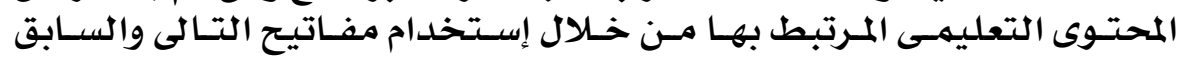
(Changef., 2003).

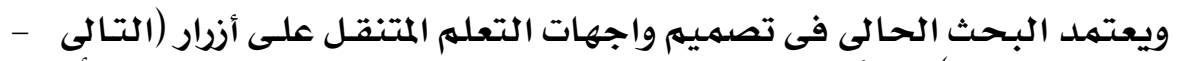

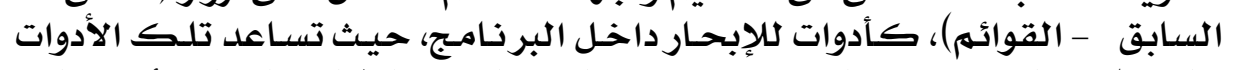

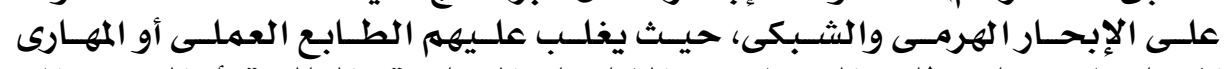

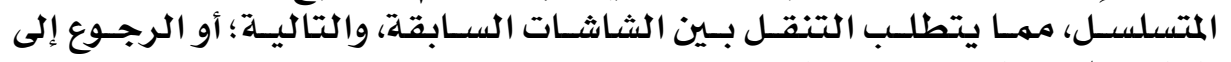
القائمة لإختيار جزء معين لمئل لدراسته.

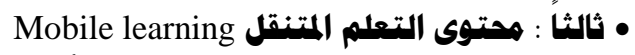

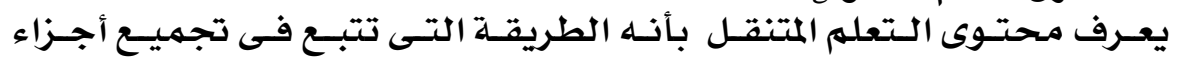

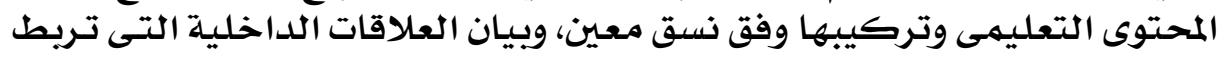

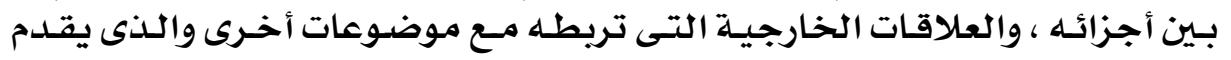

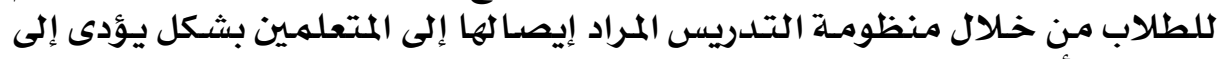

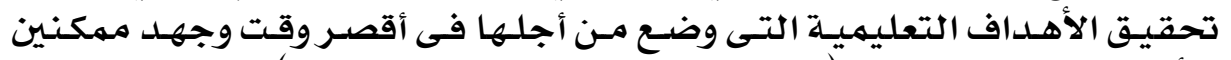

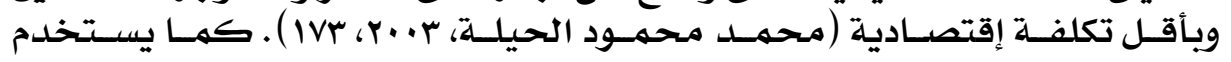

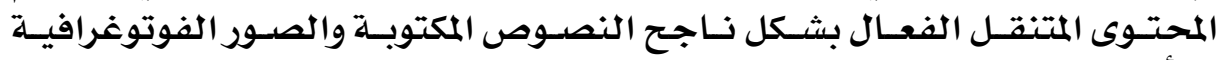

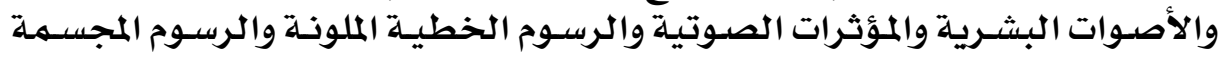

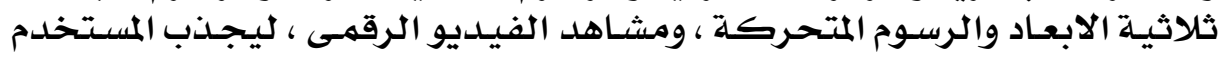

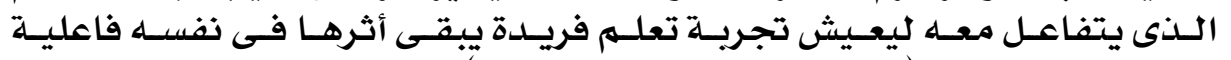

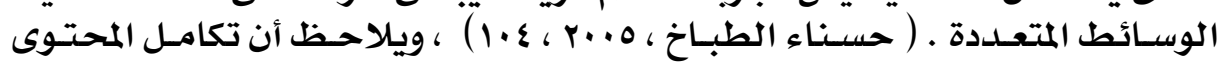

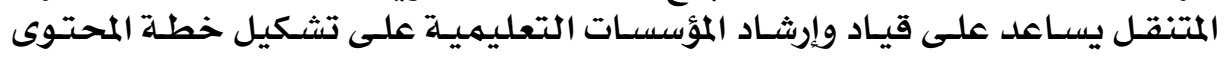

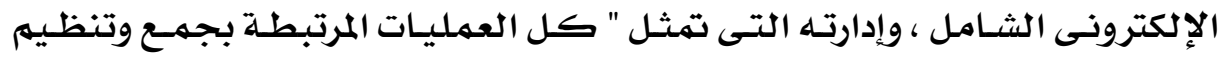




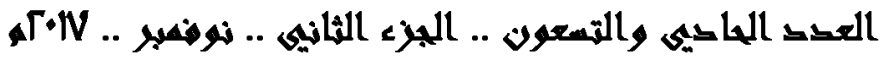

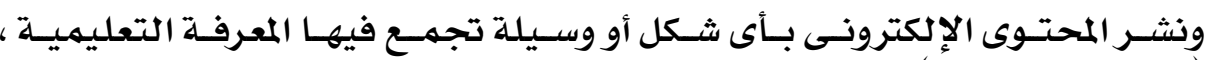

(Hubbard , 2006)

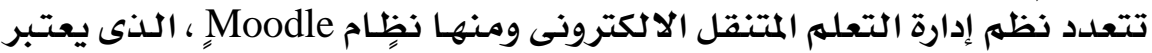

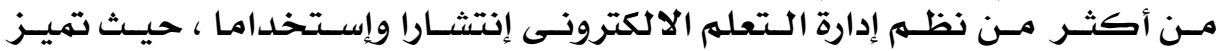

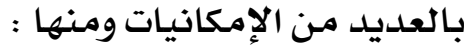

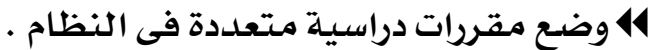

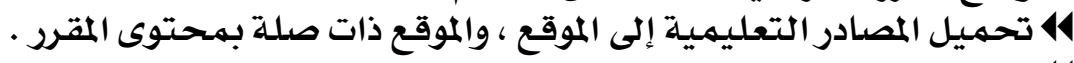

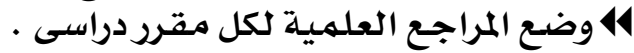

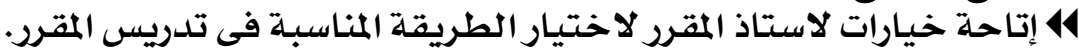
41414

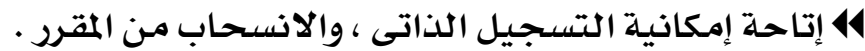

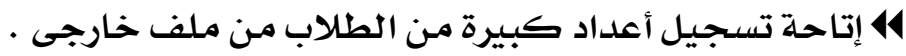

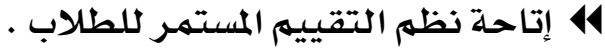

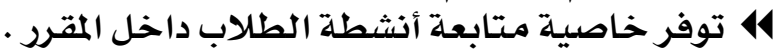

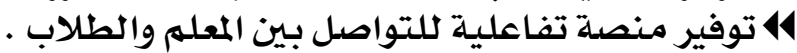

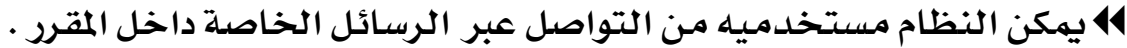
414

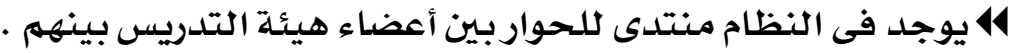

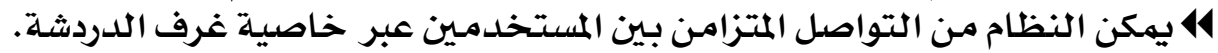
يوضح شكل (^ ) واجهة نظام (Moodle)

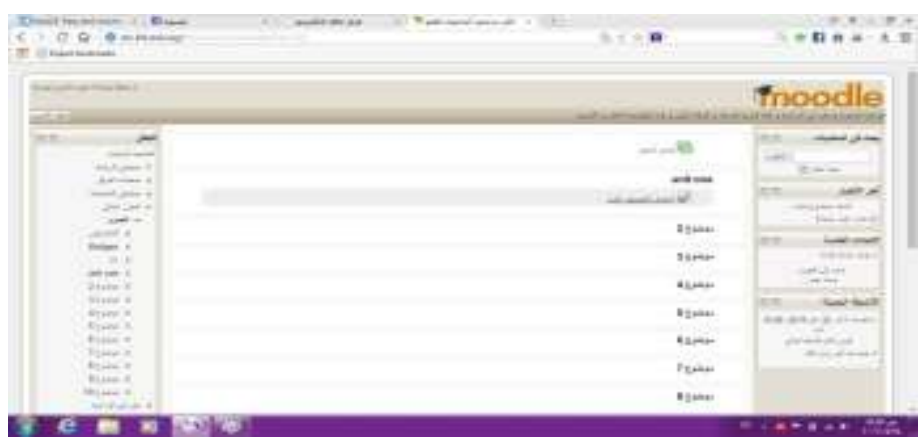

شكل (A) يوضح نظام إدارة محتوى التعلم المتنقل (Moodle)

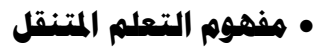

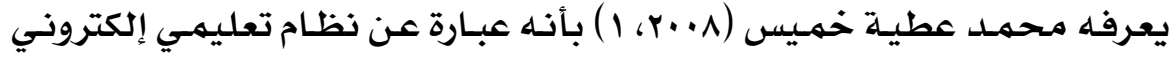

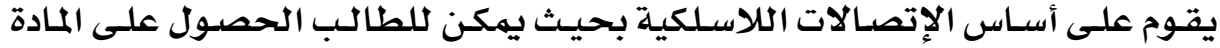

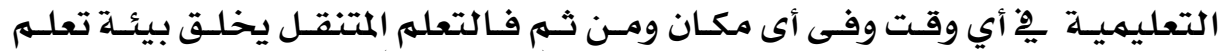

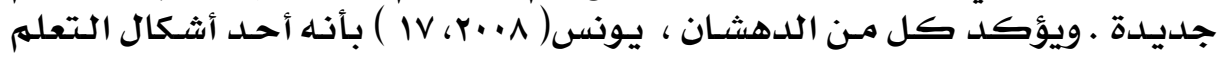

\section{$\varepsilon \varepsilon 9$}




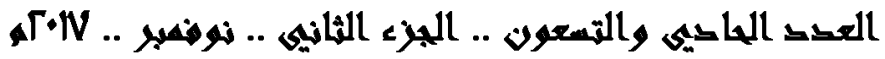

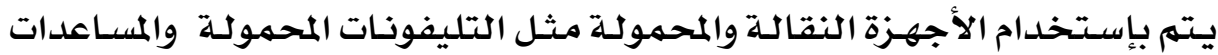

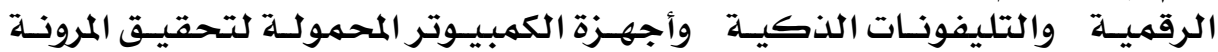

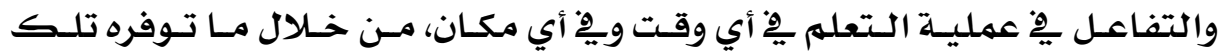

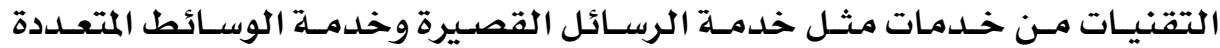

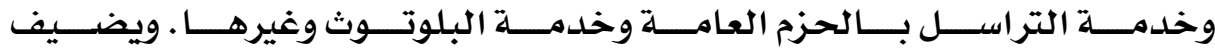

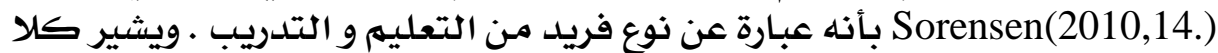

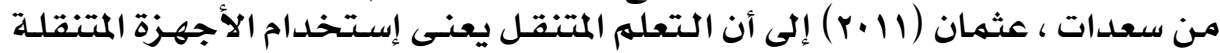

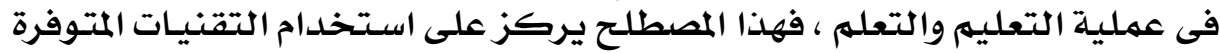

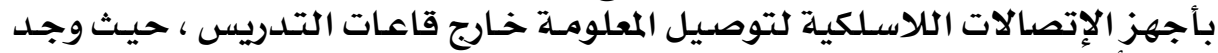
هذا الأسلوب ليالئم الظروف المتتفيرة الحادثة بعمليـة التعليهم والتعلم .

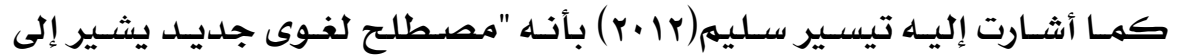

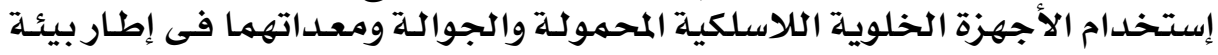

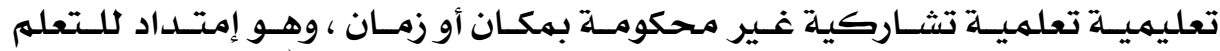

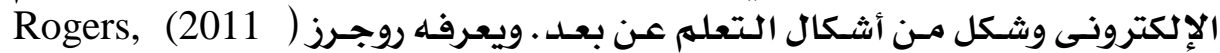

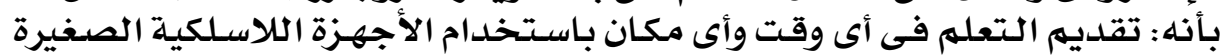

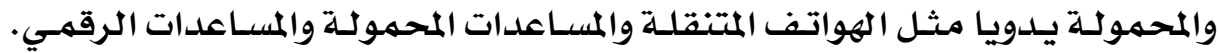
ويمكن استخلاص خصائص التعلم المتتقل فى ضوء ما ذكر في في النقاط التالية :

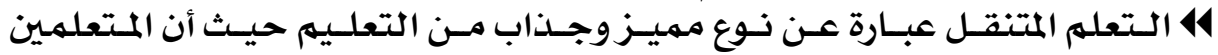

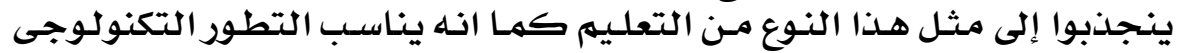

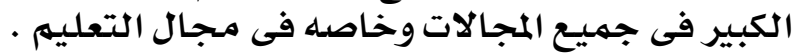

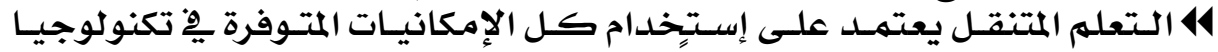

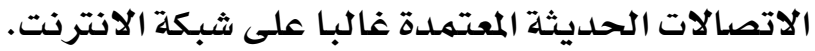

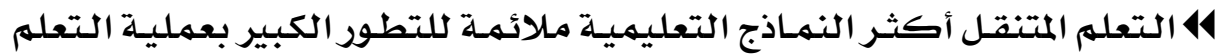

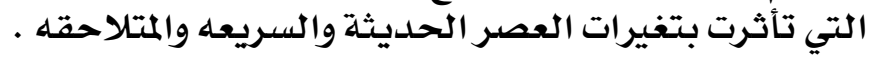

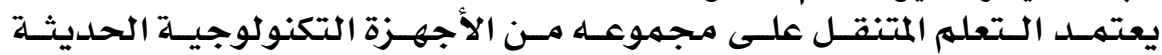

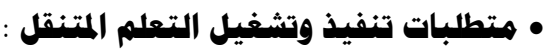
الموضسحه أدناه وهى :

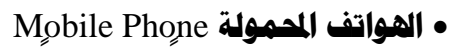

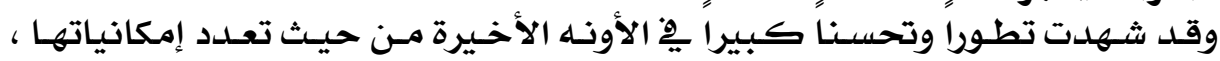

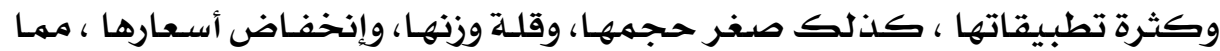

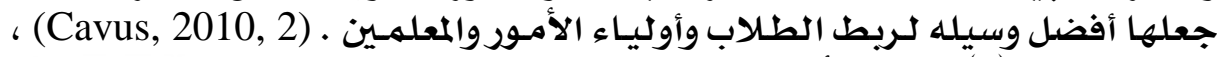

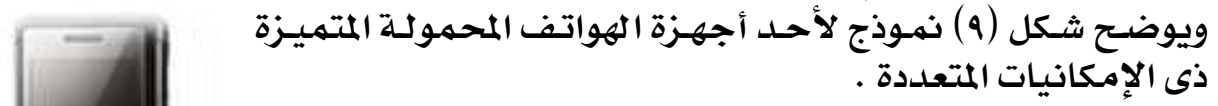




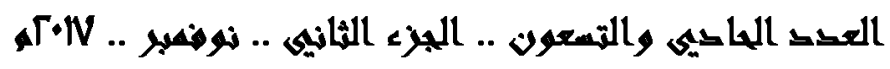

• أجهرة الكمبيوتر المهمولة laptop Computers:

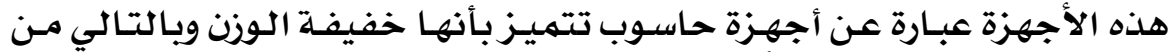

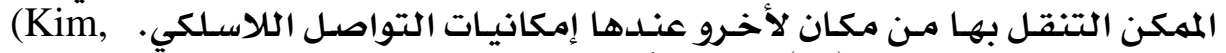

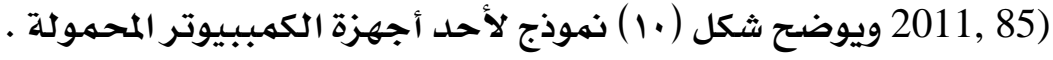

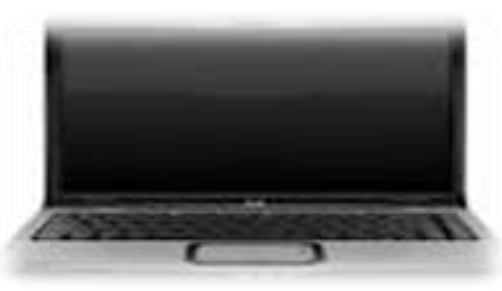

laptop Computer شكل (1) أحد أجهزة الكمبيوتر المحمولي

• التليفونات الذكية Smart Phones : -

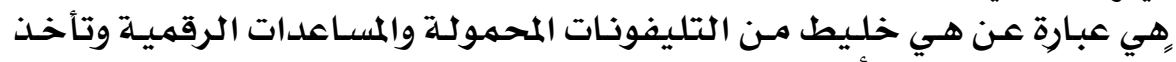

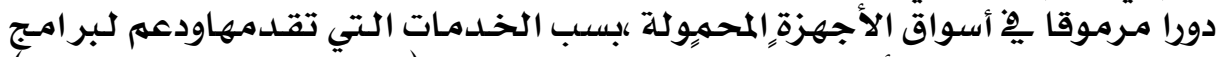

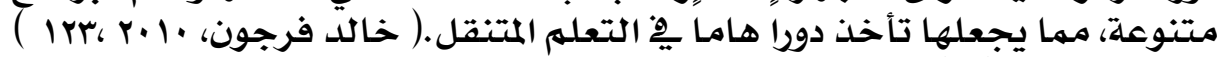
يوضحها شكل (11)
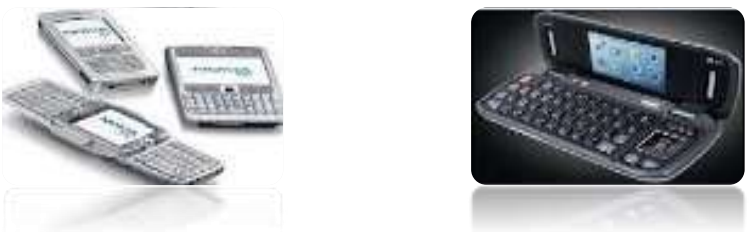

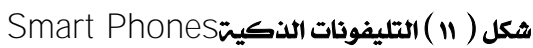

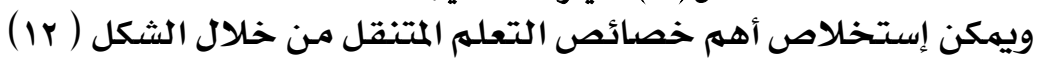

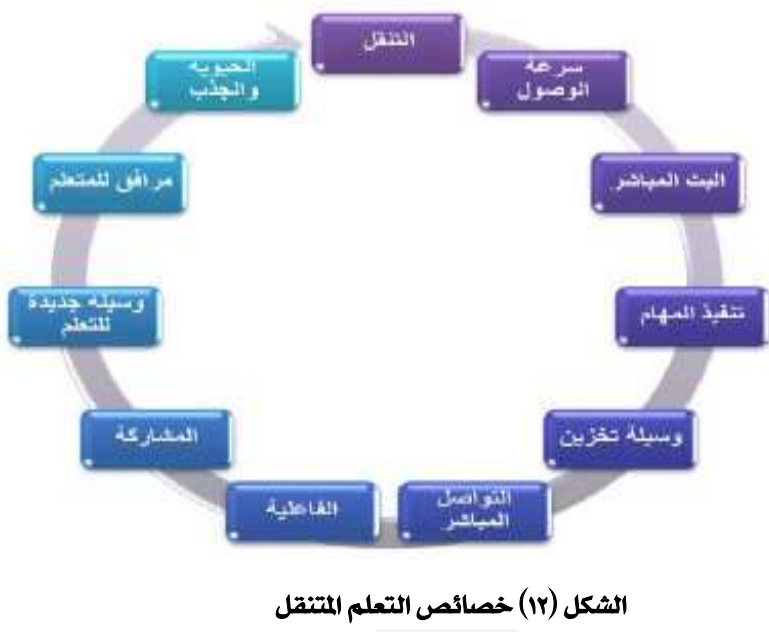

$\varepsilon \odot 1$

دراسات عربية في التزبية وعلم النفس (ASEP) 


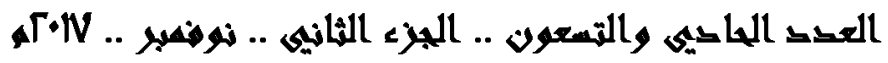

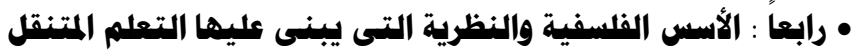

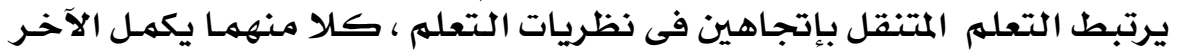

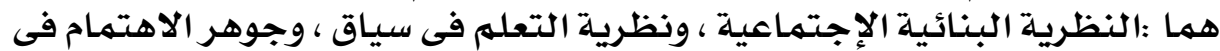

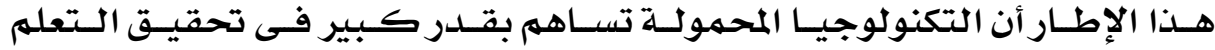

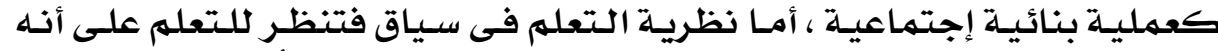

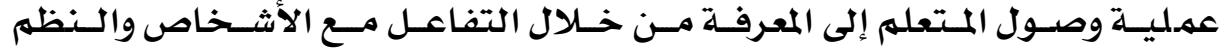

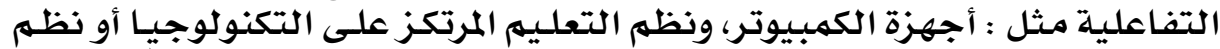

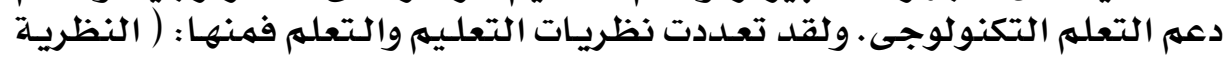

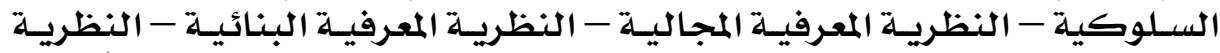

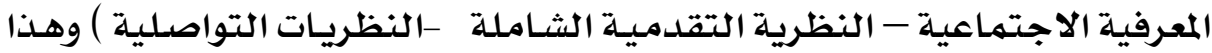

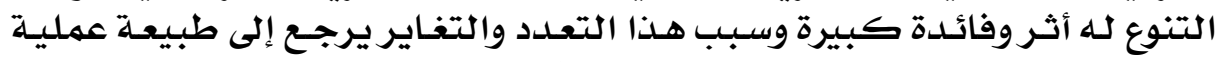

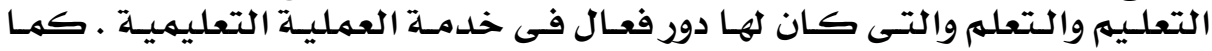

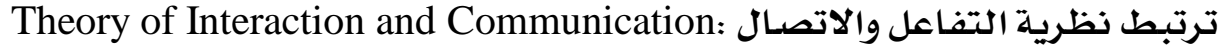

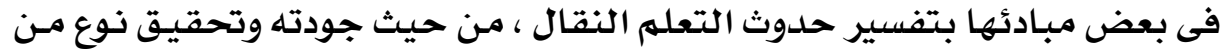

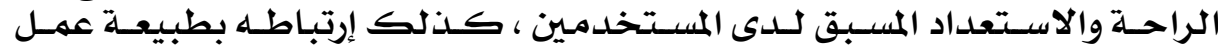

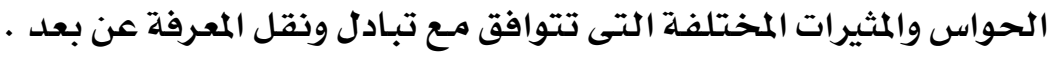

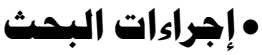

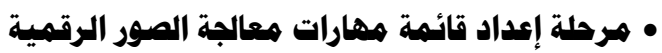

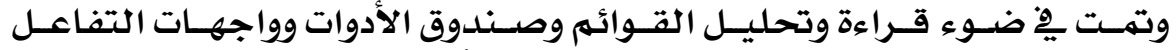

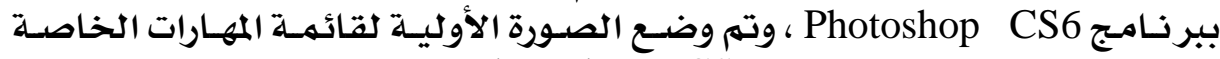

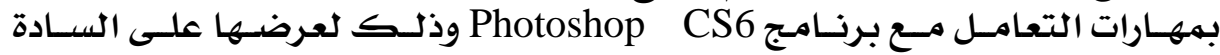

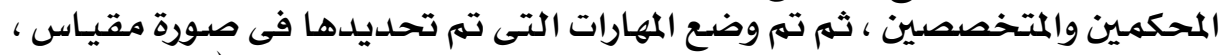

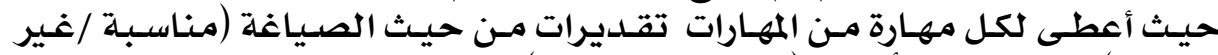

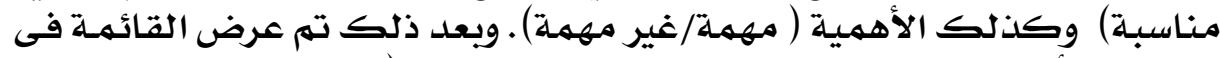

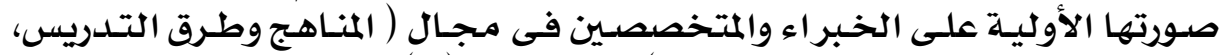

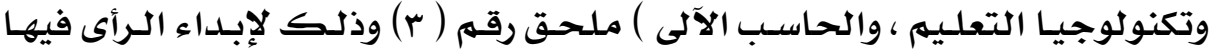

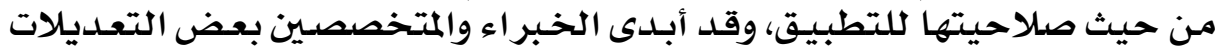

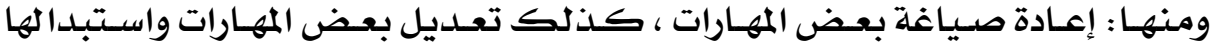

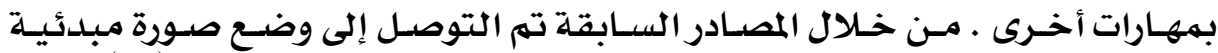

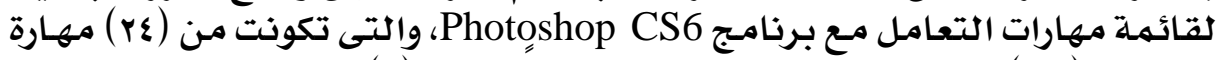

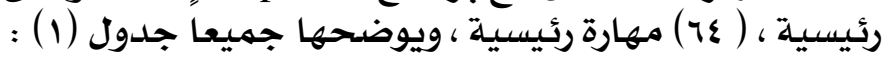

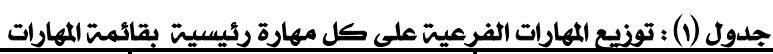

\begin{tabular}{|c|c|c|c|}
\hline المهارة الفرعيت & المهارة الرئيسيتة & الموضوعات & م \\
\hline ro & 1. & اللهارات الأساسيتي & 1 \\
\hline 10 & $\varepsilon$ & Photoshop C56 أهم أدوات & $r$ \\
\hline 1. & $\varepsilon$ & المرشحات والمؤثرات الخاصتة & $r$ \\
\hline 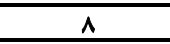 & 0 & التعامل مع الصور & $\varepsilon$ \\
\hline 7 & 1 & تطبيقات عمليتة & 0 \\
\hline $7 \varepsilon$ & $\overline{Y \varepsilon}$ & إجمالى & \\
\hline
\end{tabular}

\section{$\varepsilon \odot Y$}




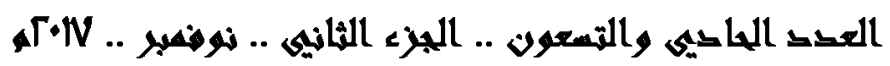

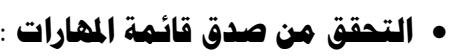

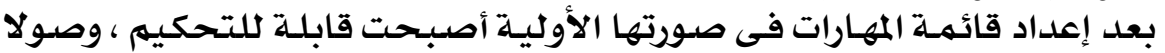

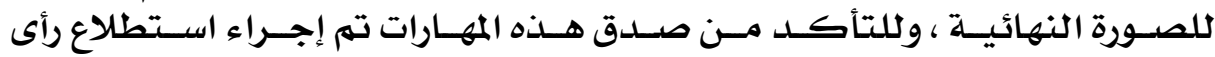

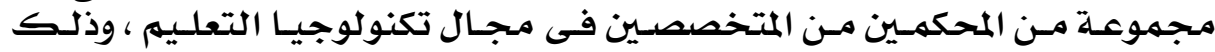

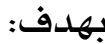

11 التأكد من صسحة الصياغة اللغويـة، والدقة العلمية لكل مهارة .

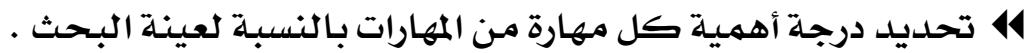

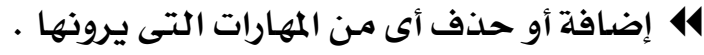

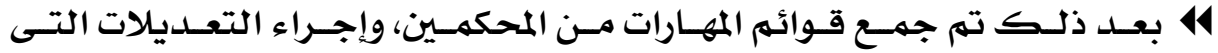

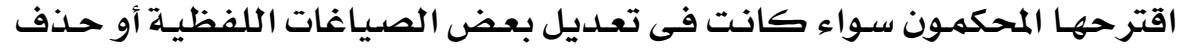

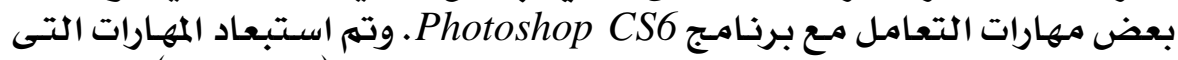

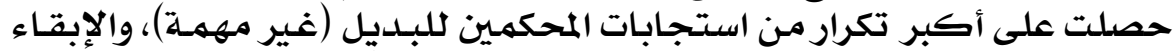

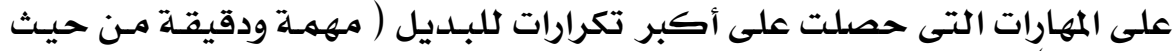

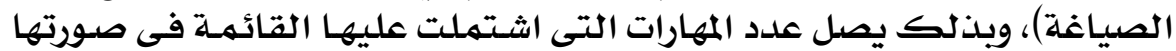

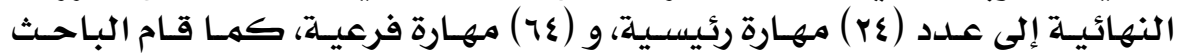

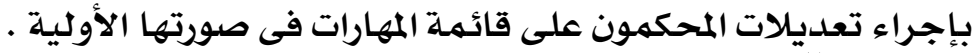

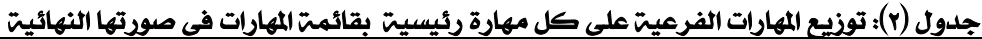

\begin{tabular}{|c|c|c|c|}
\hline المهارة الفرعيت & المهارة الرئيسيت & الموضوعات & م \\
\hline$r r$ & 1. & المهارات الأسعاسيتي & 1 \\
\hline ir & $\varepsilon$ & أهم أدوات Photoshop CS6 & $r$ \\
\hline 1. & $\varepsilon$ & المرثقحات والمؤثرات الخاصت & $r$ \\
\hline$\hat{\Lambda}$ & $\varepsilon$ & التعامل مع الصور & $\varepsilon$ \\
\hline$\varepsilon$ & 1 & تطبيقات عمليت & 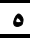 \\
\hline ov & $r r$ & إجمالى & \\
\hline
\end{tabular}

ويوضتح ملحق (1) القائمـة النهائية لمهارات معالجهة الصور الرقهية

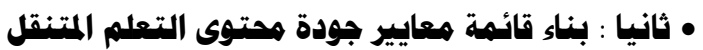

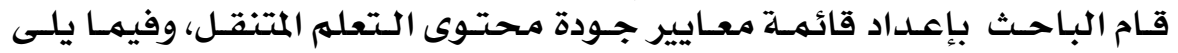

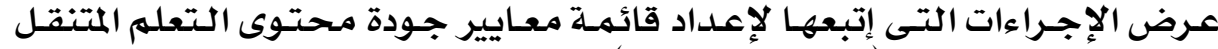

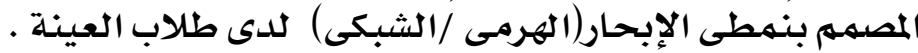

• تهديد الهدف العام :

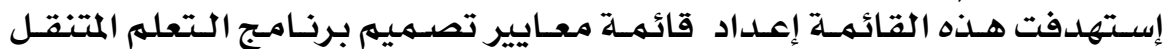

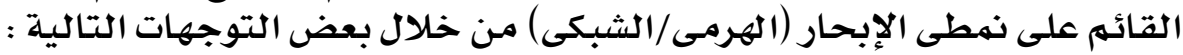

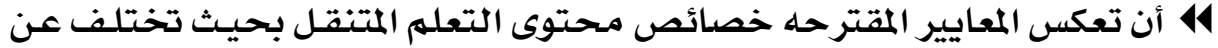

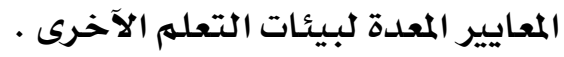

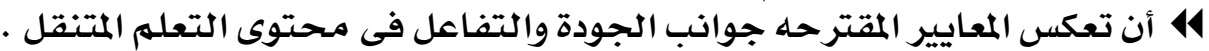

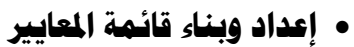

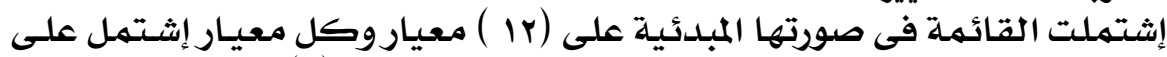

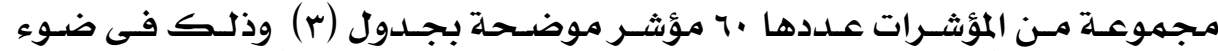

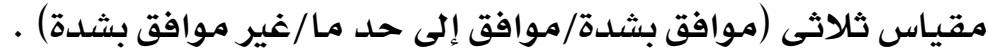

\section{$\varepsilon \odot \mu$}




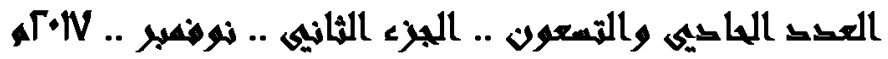
جدول (r): توزيع المؤثرات على كل معيار بقائمت المعايير المبدئيت

\begin{tabular}{|c|c|}
\hline عدد المؤثرات & ل المعيار \\
\hline 0 & المعيار الأول \\
\hline 0 & المعيار الثانى \\
\hline 0 & المعيار الثالث \\
\hline 0 & المعيار الرابع \\
\hline 0 & المعيار الخامس \\
\hline 0 & المعيار السادس \\
\hline 0 & المعيار السابع \\
\hline 0 & المعيار الثامن \\
\hline 0 & المعيار التاسع \\
\hline 0 & المعيار العاثر \\
\hline 0 & المعيار الحادى عشر \\
\hline 0 & المعيار الثانى عشر \\
\hline 7. & إجمالى \\
\hline
\end{tabular}

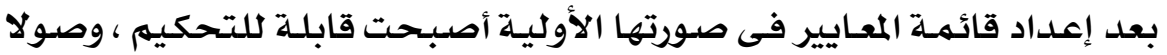

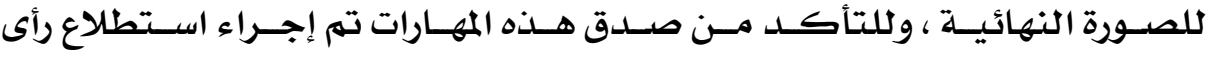

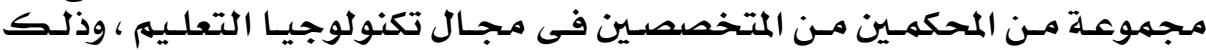

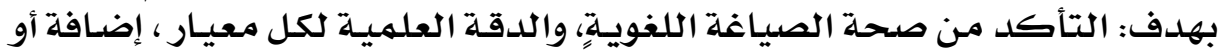

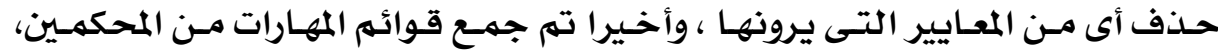

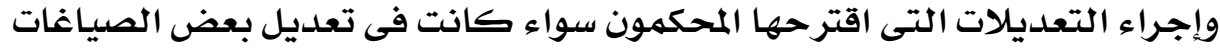

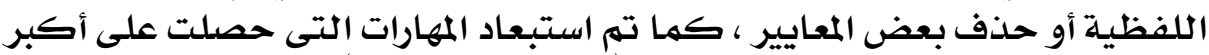

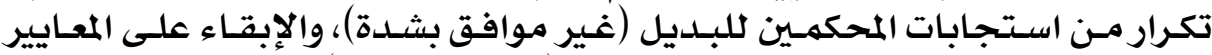

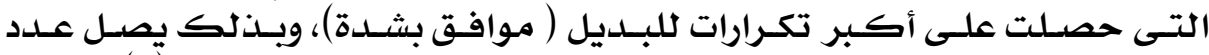

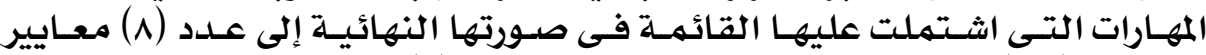

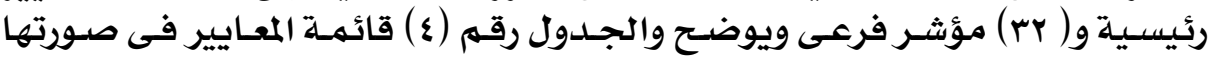
النهائية .

جدول (ع): توزيع المؤثرات على كل معيار بقائمت المعايير النهائيت

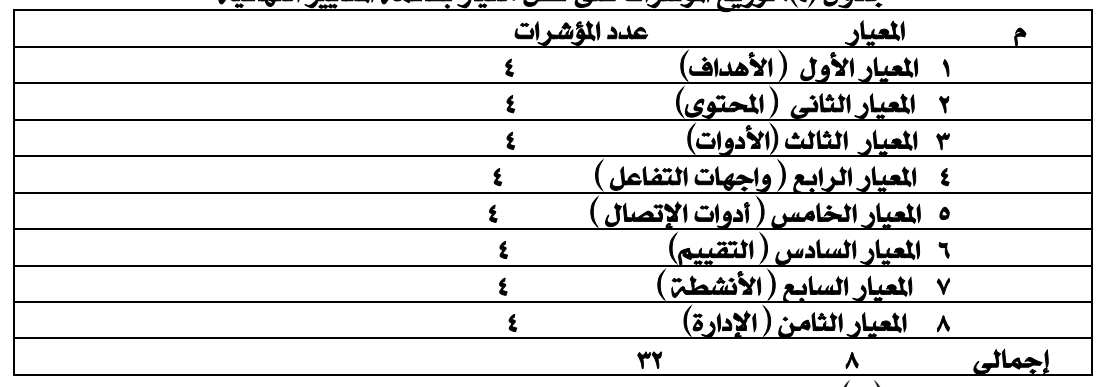

ويوضح ملحقى (Y) معايير جودة التعلهم المتنقل

\section{$\varepsilon \otimes \varepsilon$}




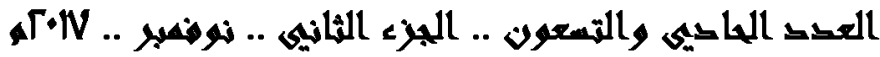

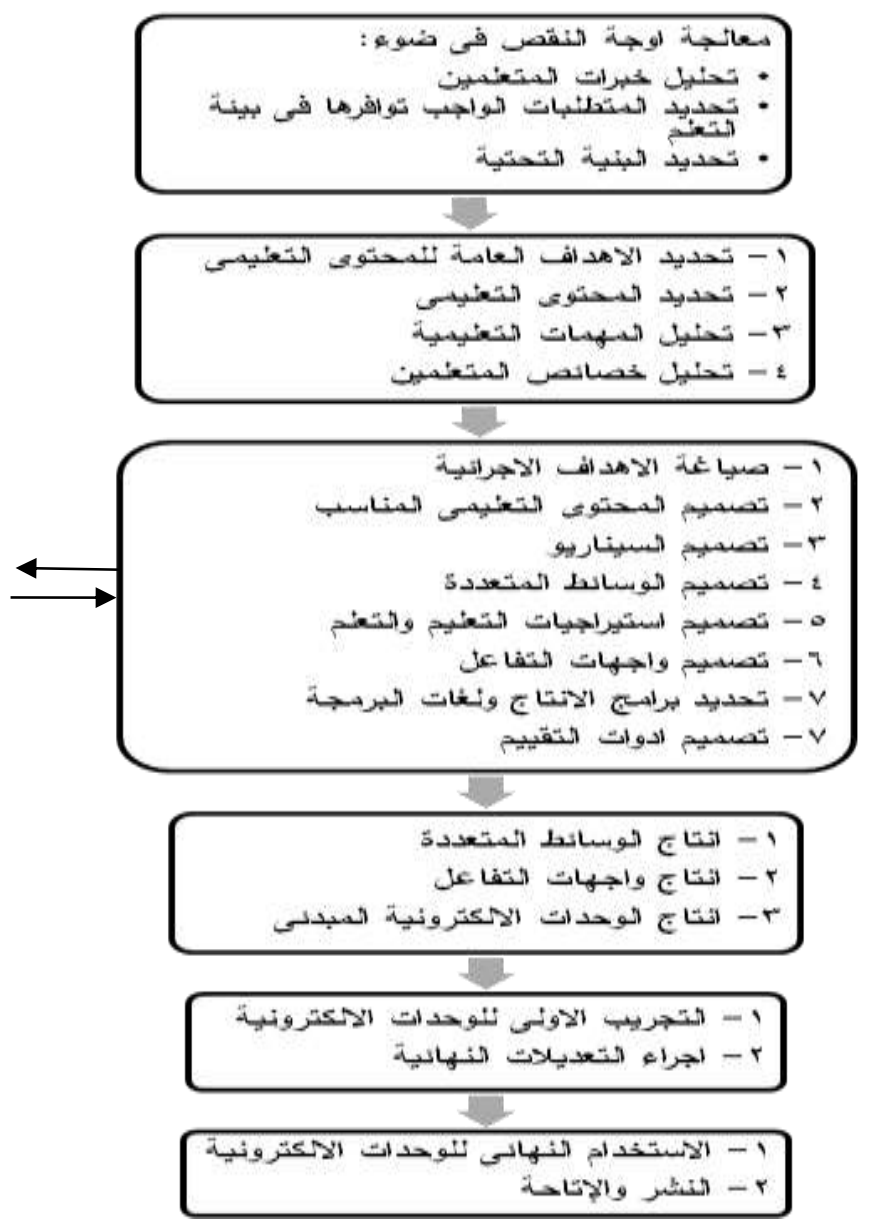

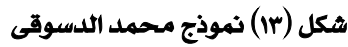

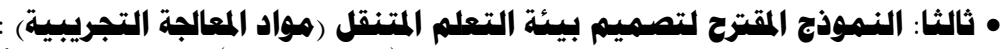

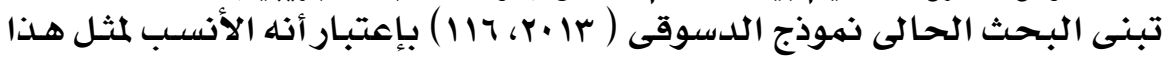

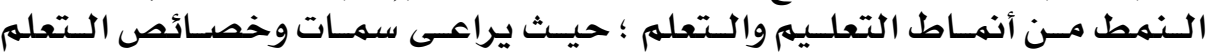

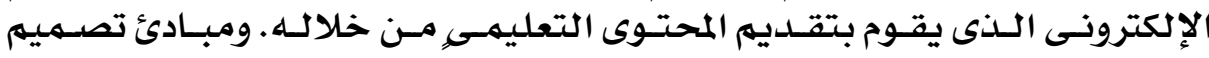

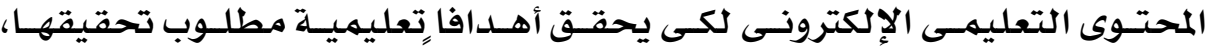

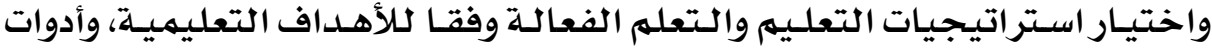

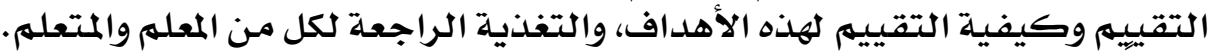

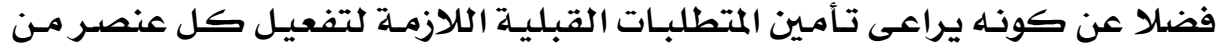

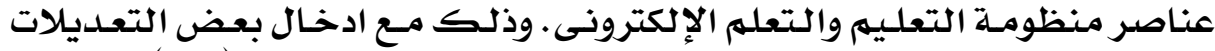

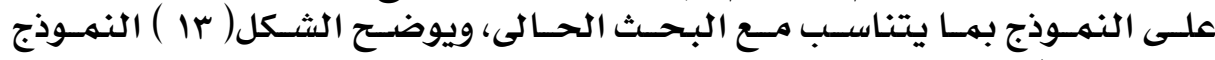

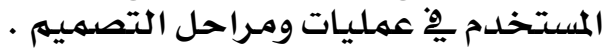

\section{$\varepsilon \theta \theta$}




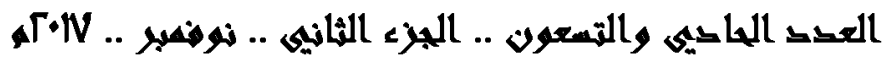

$$
\text { ويتضمن النموذج المشار اليه المراحل التالية : }
$$

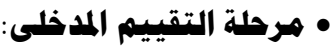

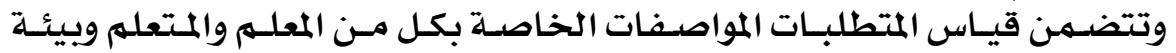

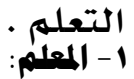

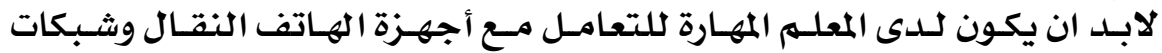

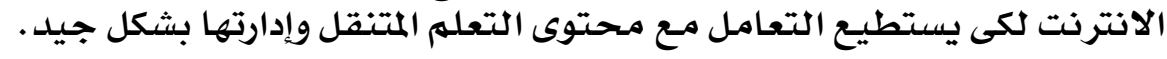

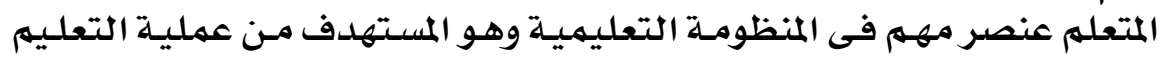

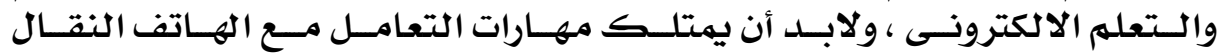

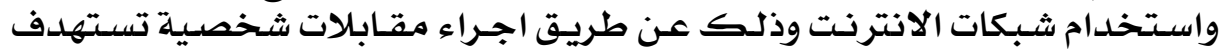

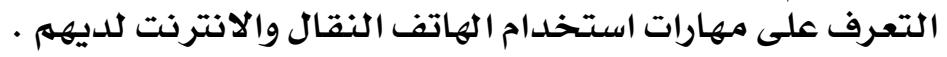

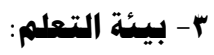

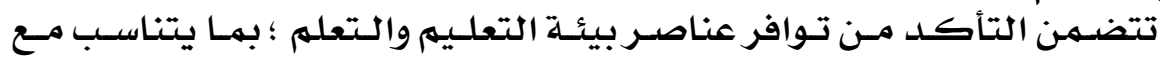

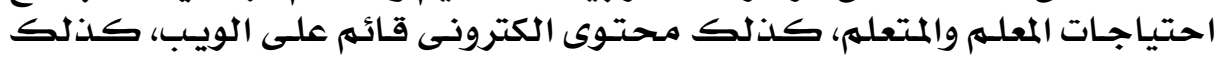

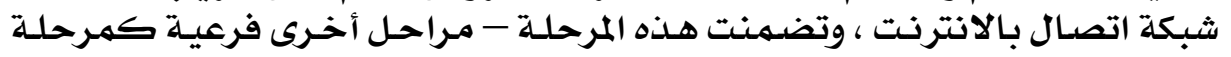

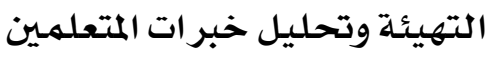
• ت تطليل خبرات المتعلمين بأجهزة التعلم المتنقل :

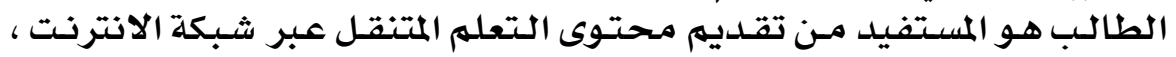

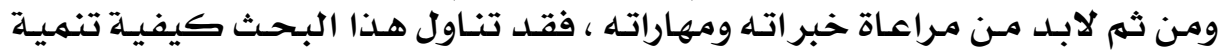

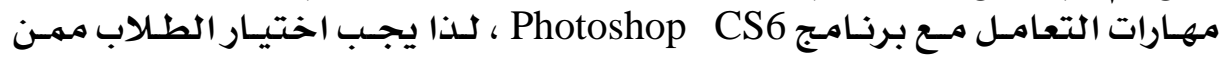

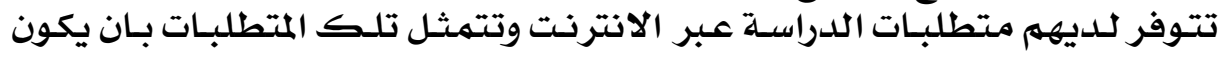

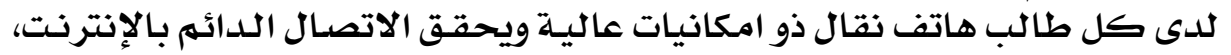

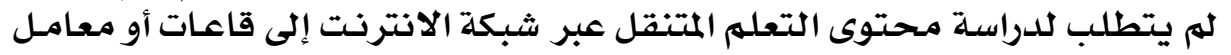

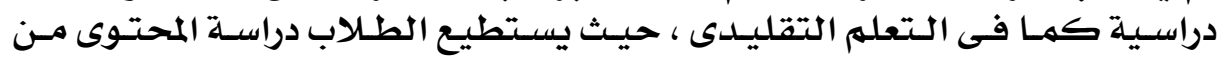

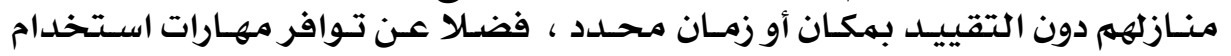

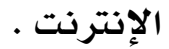

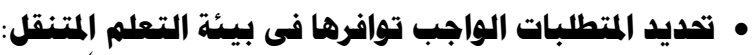

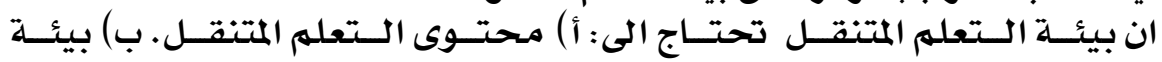

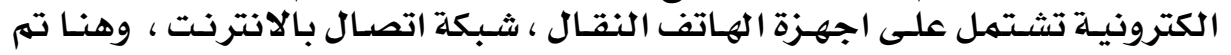

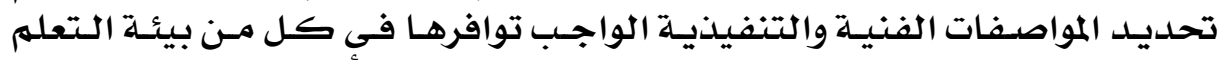

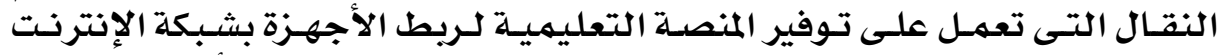

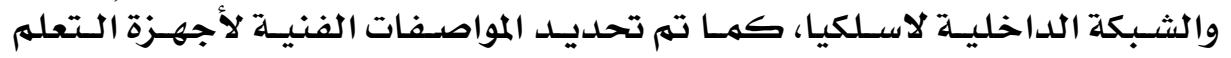

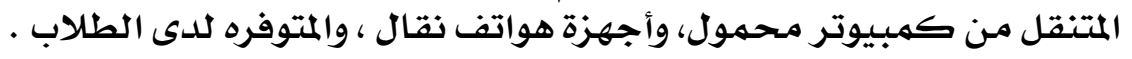

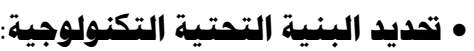

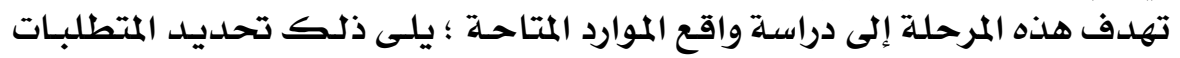

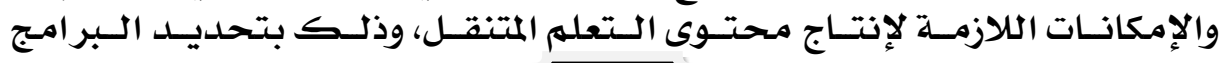




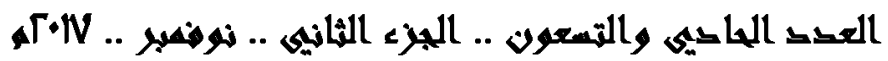

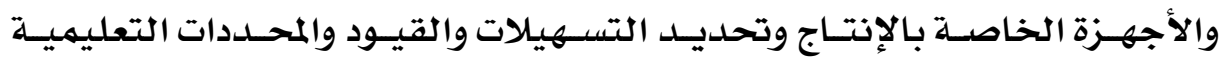

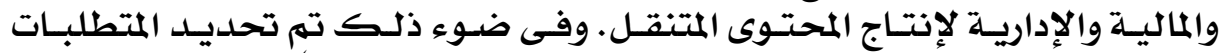

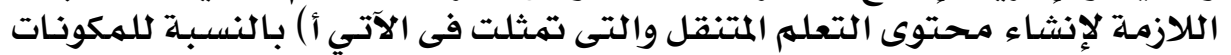

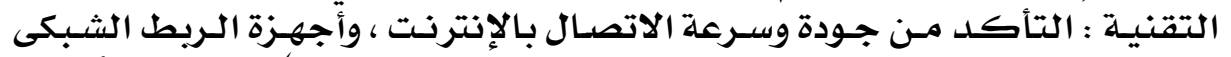

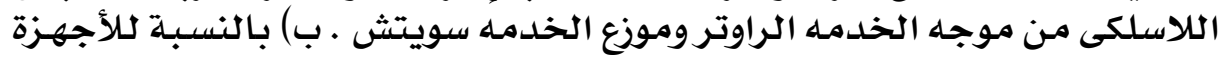

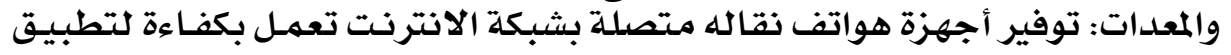

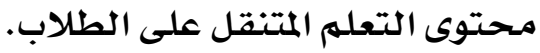

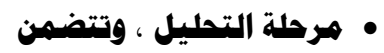

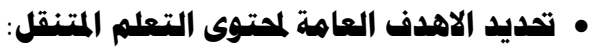

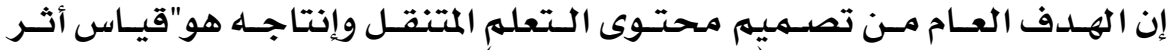

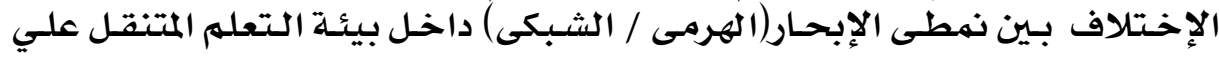

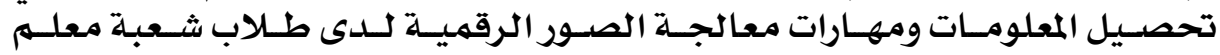

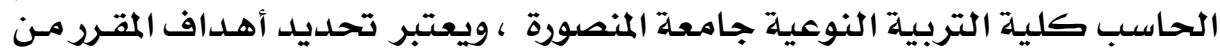

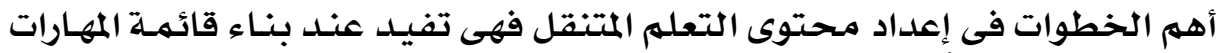

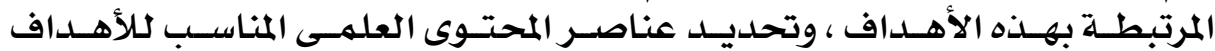

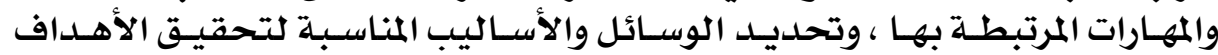

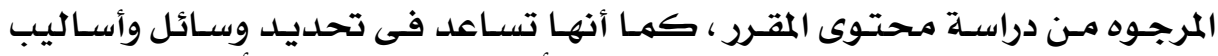

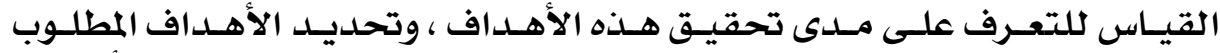

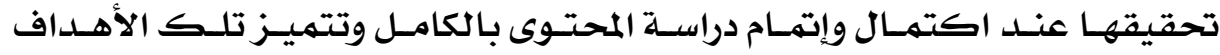

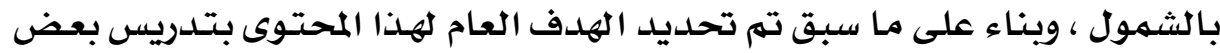

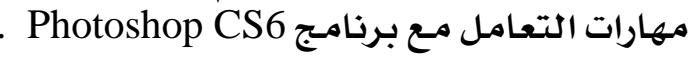

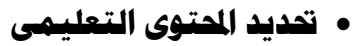

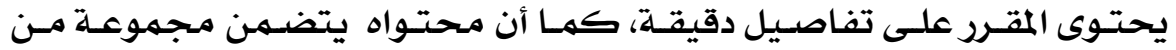

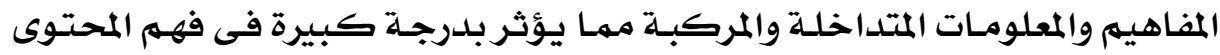

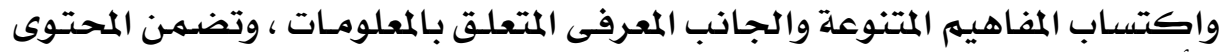

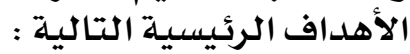

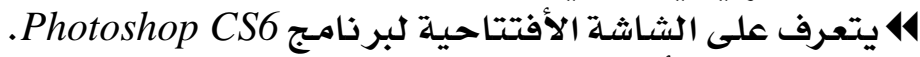

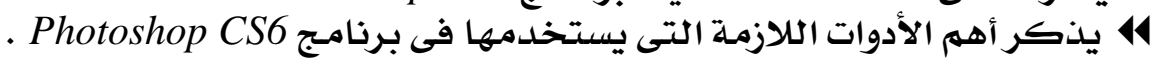

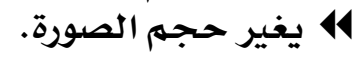

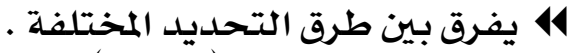

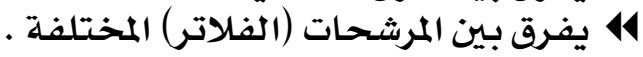
\$1 14

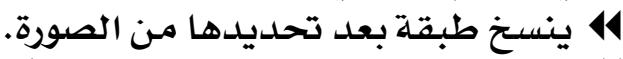

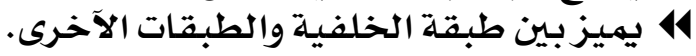

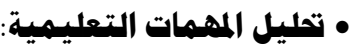

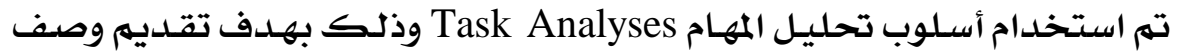

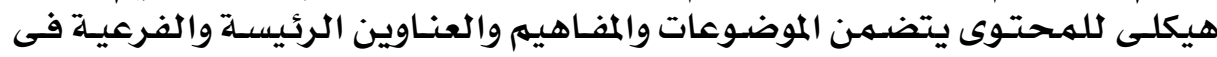

\section{$\varepsilon \odot V$}




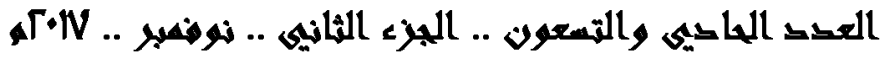

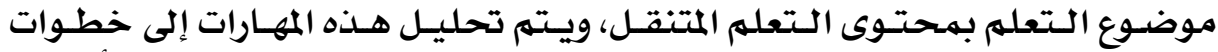

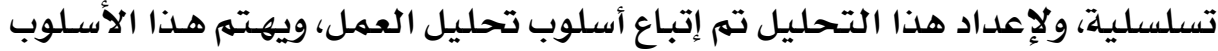

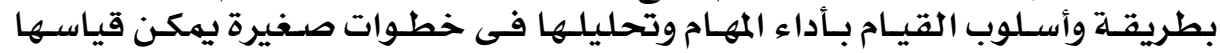

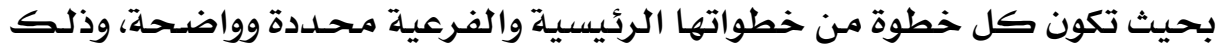

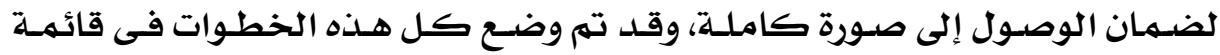

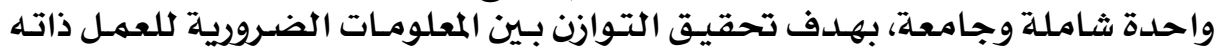

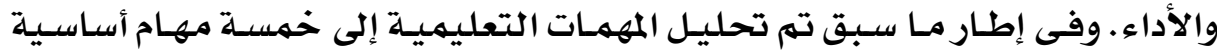

هى:

41 أولا : مفاهيه (مهارات) أساسية.

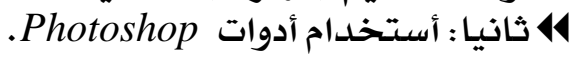

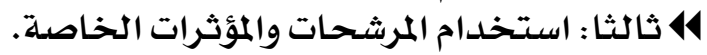

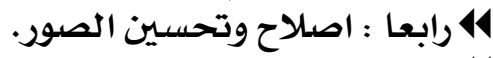

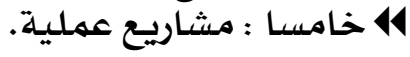

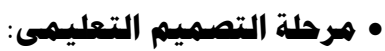

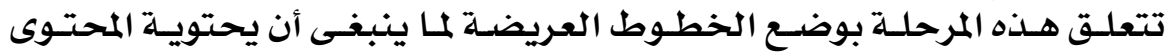

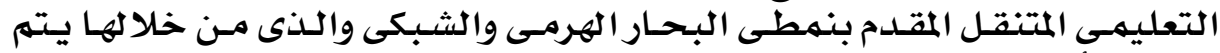

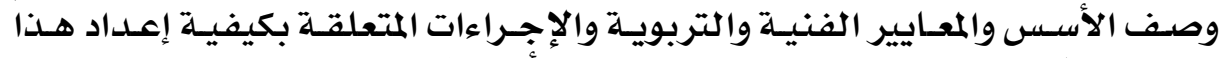

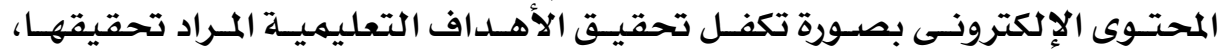

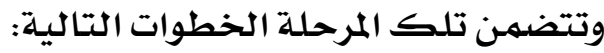

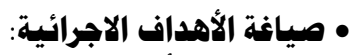

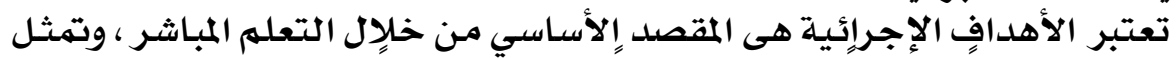

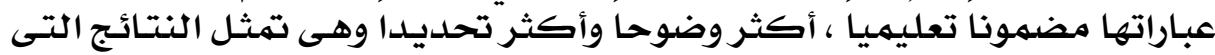

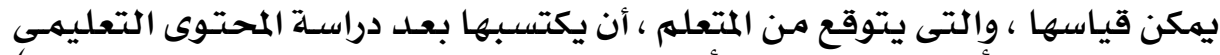

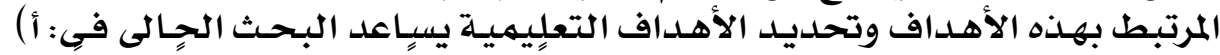

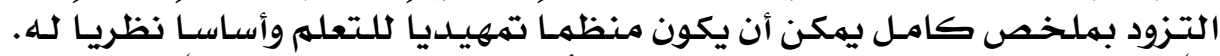

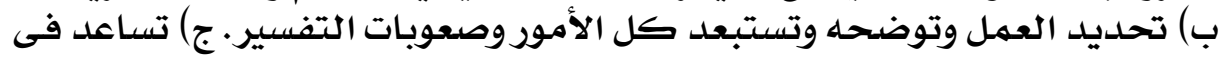

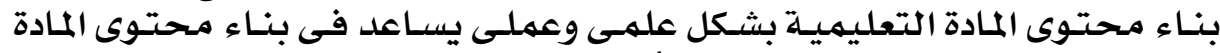

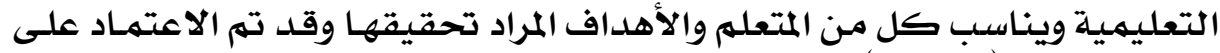

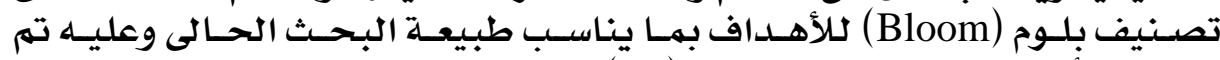

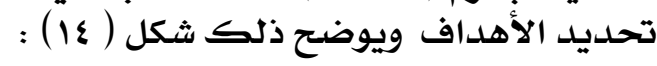

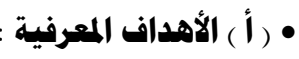

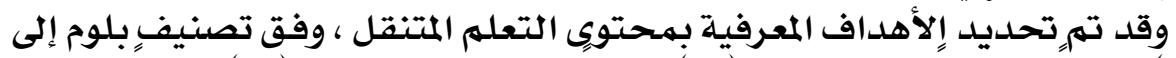

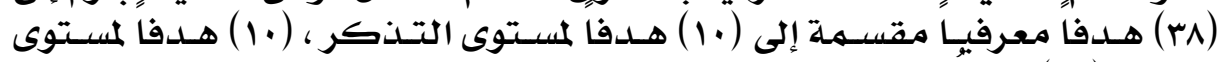

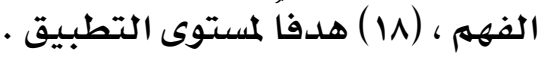

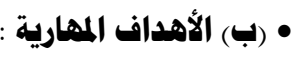

وقد تم تحديد الأهداف المهارية بالمقررو وعددها (rم) هدفاً .

\section{$\varepsilon \odot \wedge$}




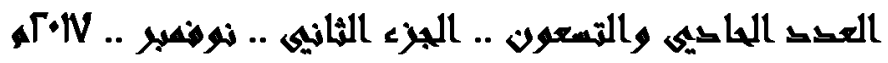

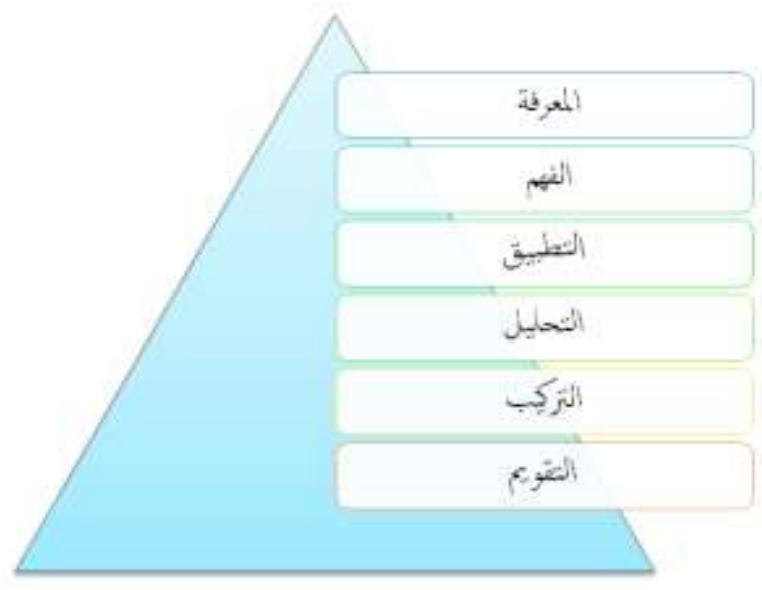

هكل ( 18) يوضح تصنيف بلوم (Bloom ) للأهداف السلوكيت

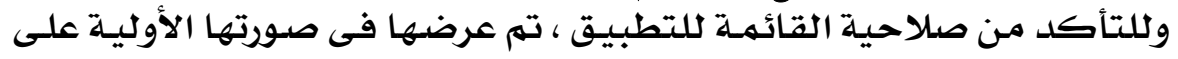

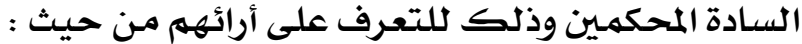

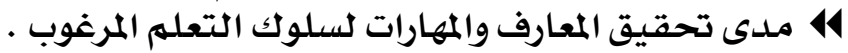

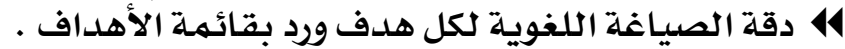

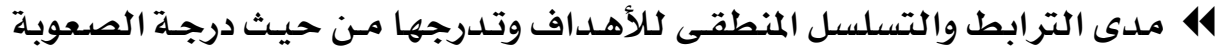
والتعقيد

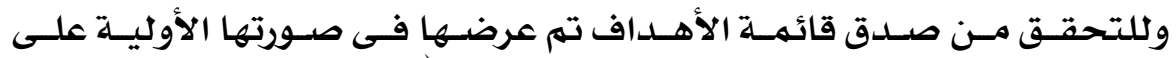

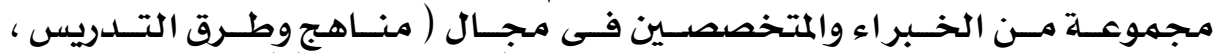

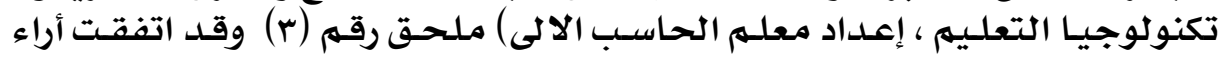

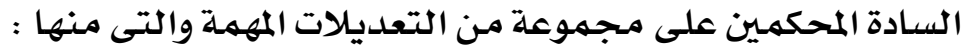

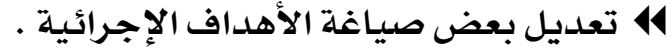

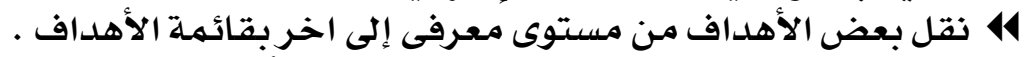

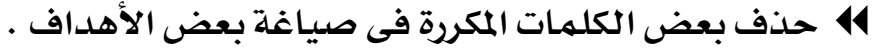

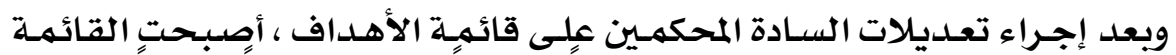

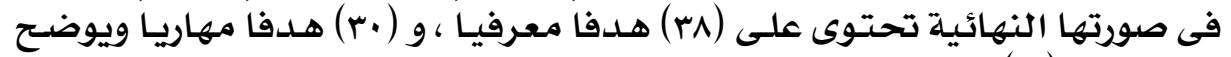

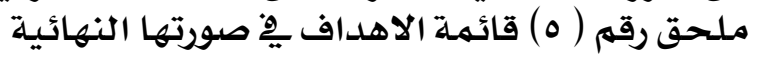

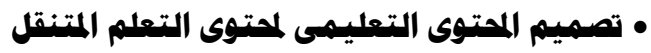

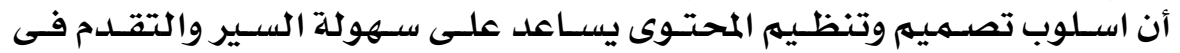

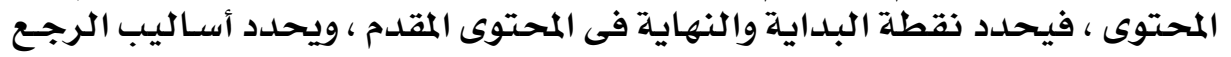

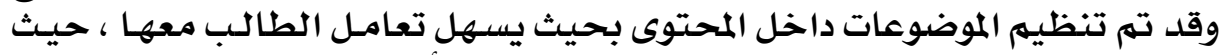

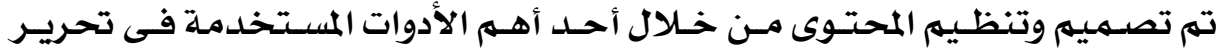

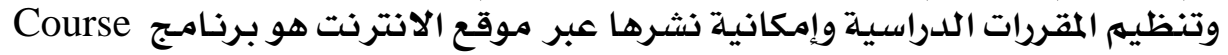

\section{$\varepsilon \odot 9$}




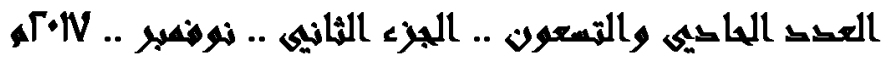

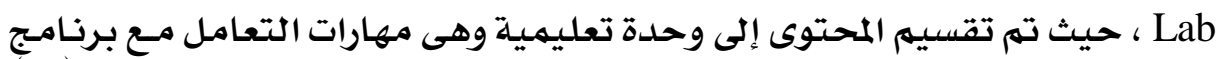

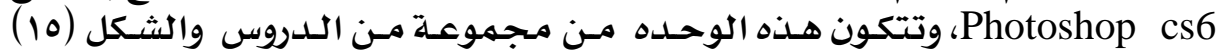
يوضح تقسيم الوحدة إلى خمس دروس فرعية :

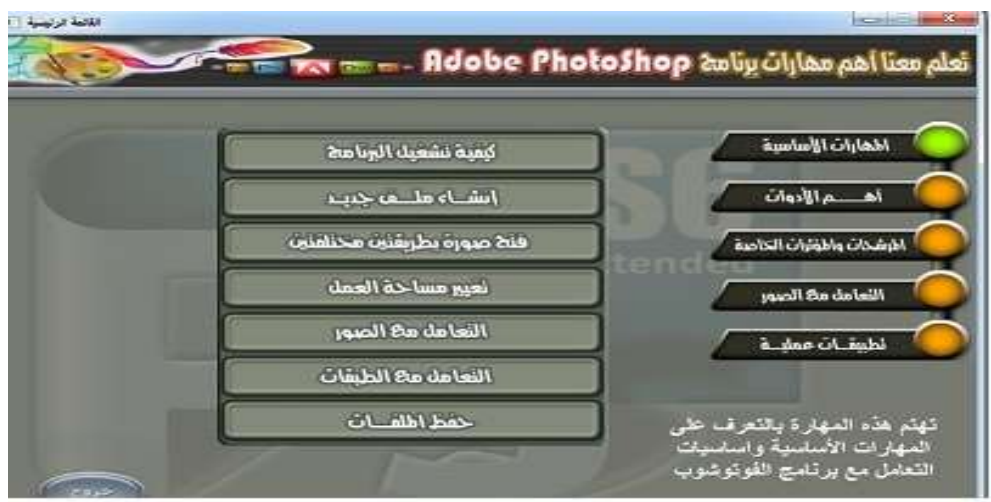

شكل (10) الوحدة التعليميت المقترحت لمعالجتا الصور

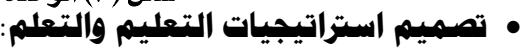

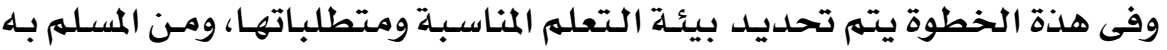

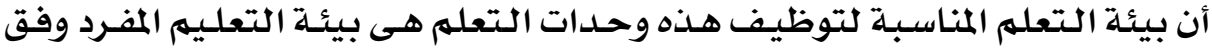

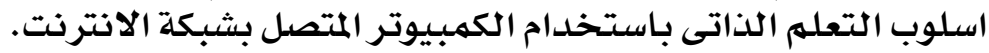

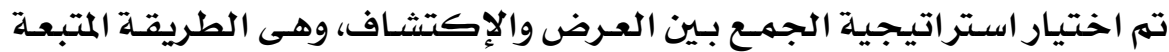

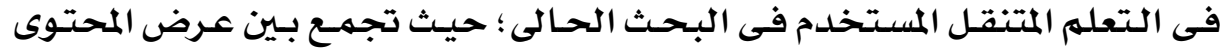

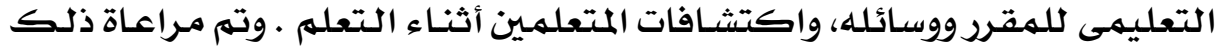

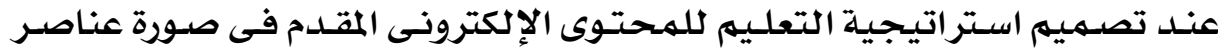

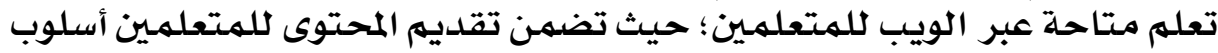

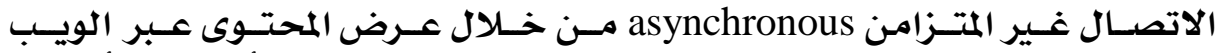

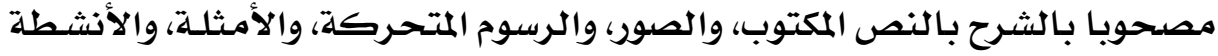

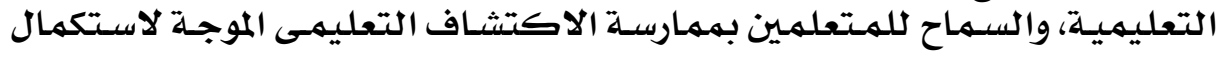

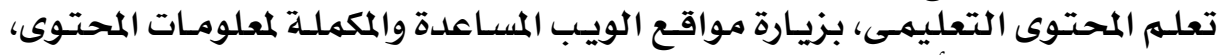

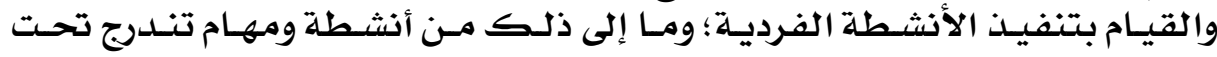

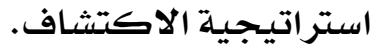

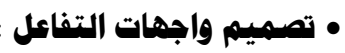

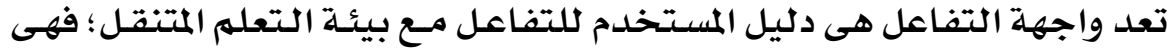

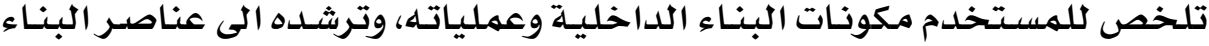

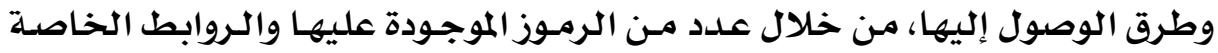

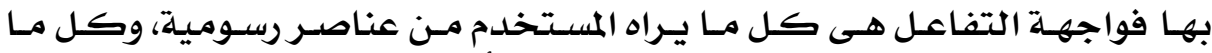

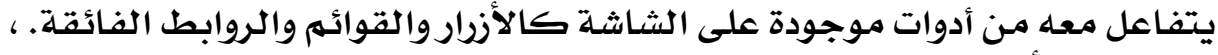

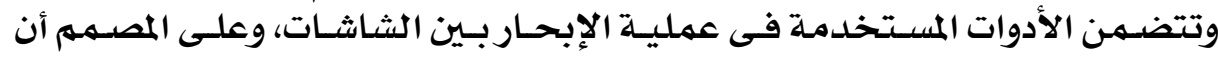

\section{$\varepsilon 7$.}




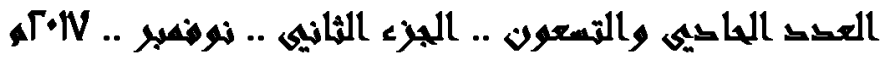

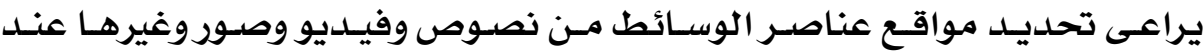

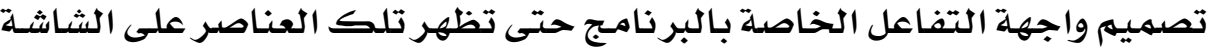

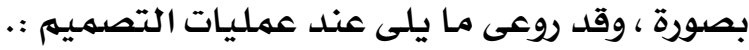
11

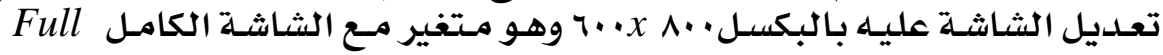
.Screen

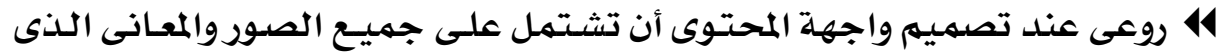

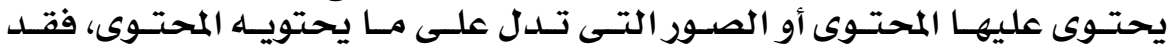

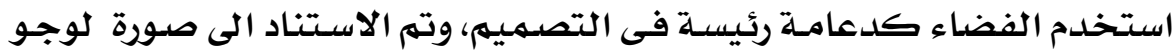

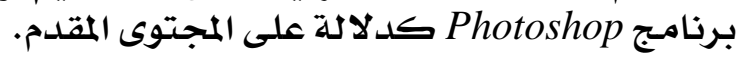

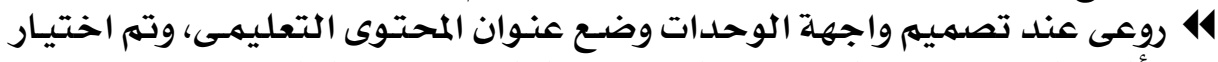

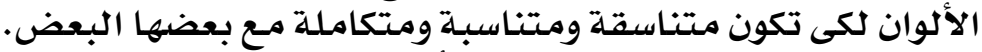

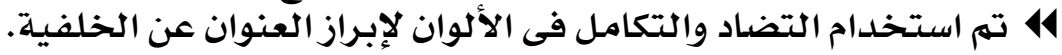

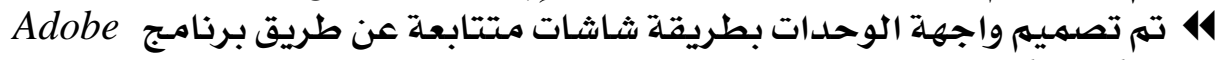
.Photoshop

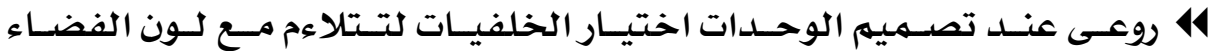

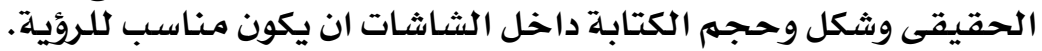

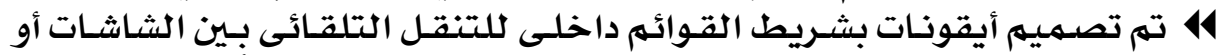

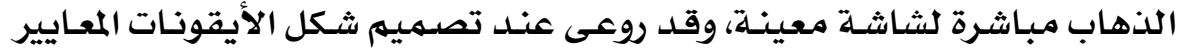

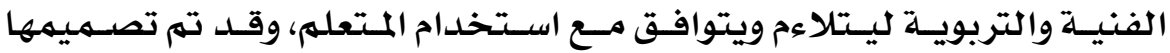

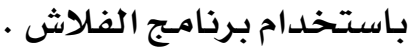

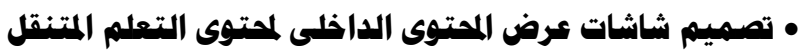

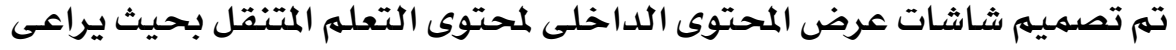

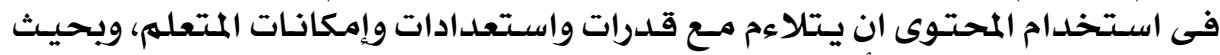

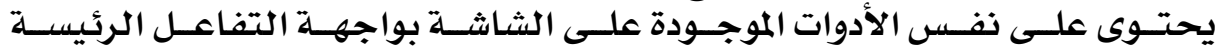

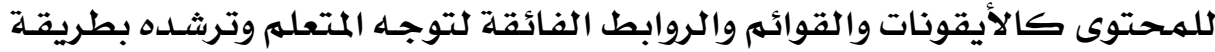

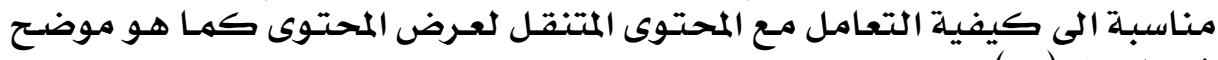

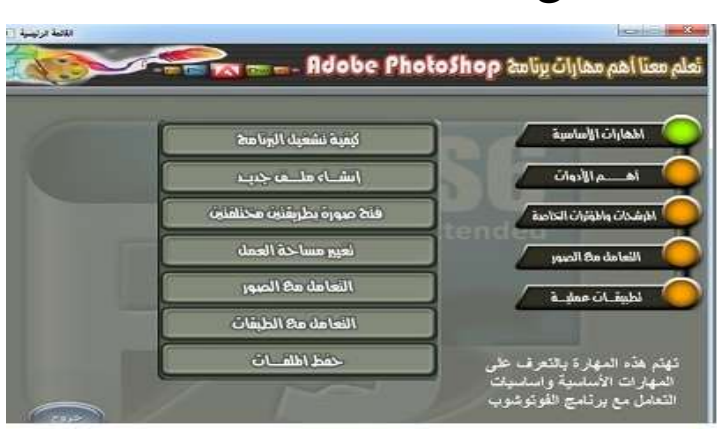
فى الشكل (17) : (17)

شكل (11) يوضح فهرس دروس الوحدة التعليميت 


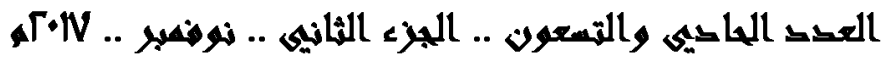

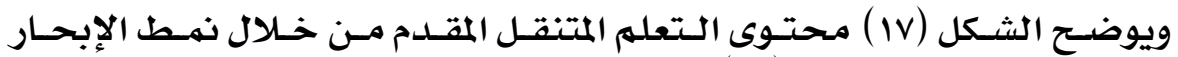

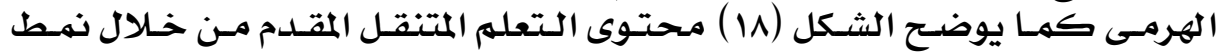

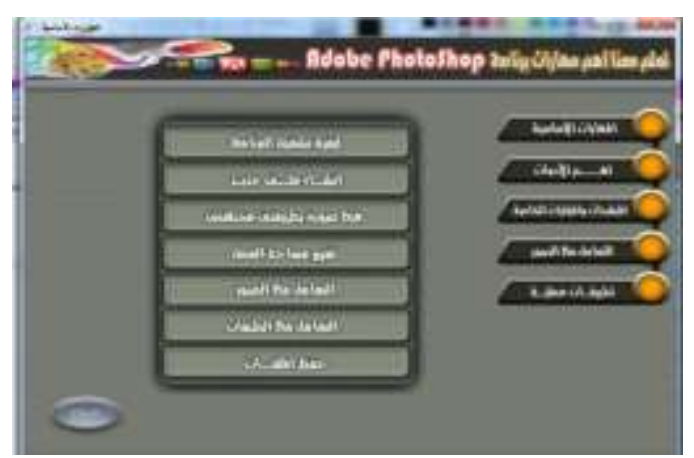

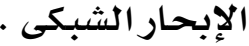

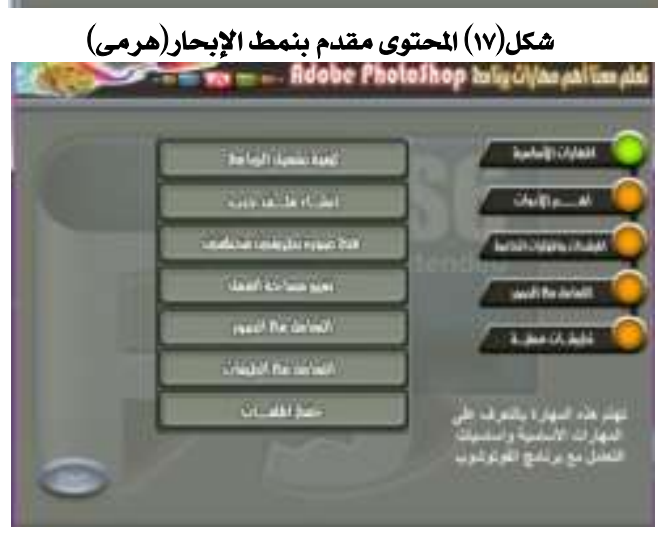

شكل(14) المحتوى مقدم بنمط الإبحار(شبكى)

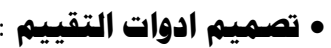

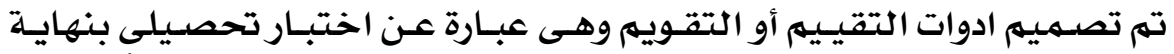

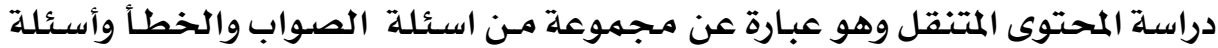

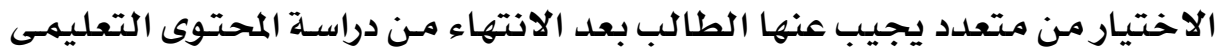

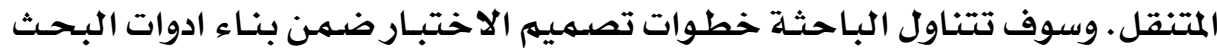
وإجازتها.

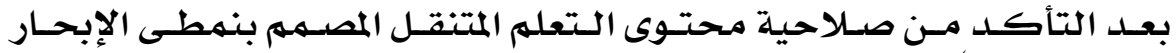

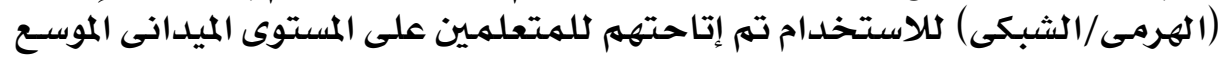
بعد اجراء التعديلات التبكي) الانتخائية.

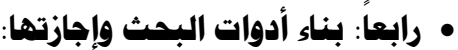
تطلب البحث الحالى البحث وإجداد الأدوات التالية : 


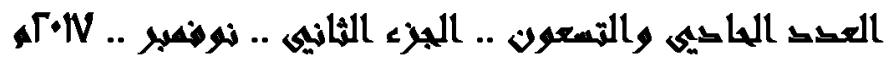

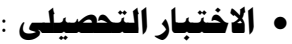

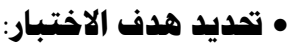

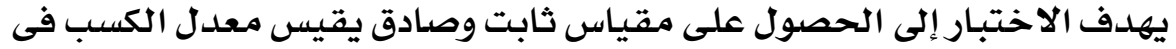

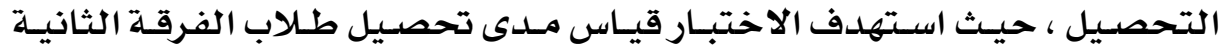

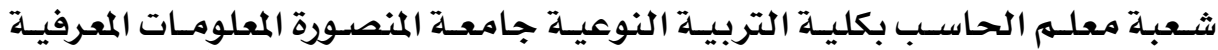

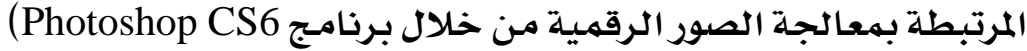

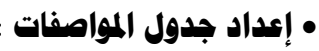

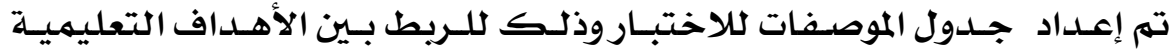

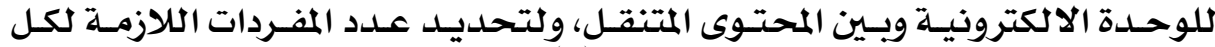

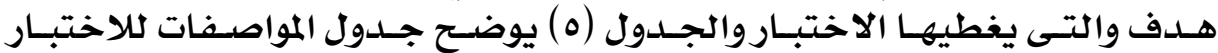

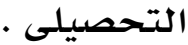

\begin{tabular}{|c|c|c|c|c|c|c|c|c|}
\hline \multirow[b]{2}{*}{ الالنسبيت } & \multirow[b]{2}{*}{ مجمليوت } & \multicolumn{2}{|c|}{ مستوى التطبيق } & \multicolumn{2}{|c|}{ مستوى الثهم } & \multicolumn{2}{|c|}{ مستوى التنكر } & \multirow[b]{2}{*}{ الوحدة التعليميت } \\
\hline & & $\sqrt{7}$ & الأسشلتم & 可 & الأسطليت & 㐓 & أرقام الأسطلت & \\
\hline \% ro & r. & ir & $\begin{array}{l}a-r \\
r r \\
n \\
r a-r \\
r .\end{array}$ & $"$ & $\begin{array}{l}q-r \\
0 \\
r \\
r-10 \\
r \cdot \\
r q-r v\end{array}$ & v & $\begin{array}{l}1 \\
11 \\
17 \\
18 \\
17 \\
14 \\
r 7\end{array}$ & $\begin{array}{l}\frac{3}{3} \\
\frac{3}{3} \\
\frac{3}{3} \\
\frac{7}{3} \\
\frac{3}{2} \\
0 \\
\frac{8}{8} \\
\frac{8}{8} \\
\frac{8}{2}\end{array}$ \\
\hline 炒 & $r$ & & $n$ & & ro & & $\mathfrak{z}$ & لالجموع الكلى \\
\hline
\end{tabular}

• ت تحديد وصياغة هفردات الاختبار:

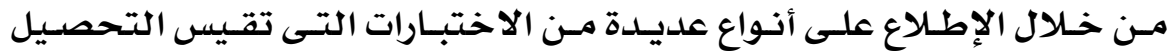

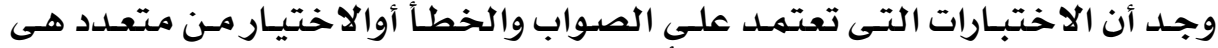

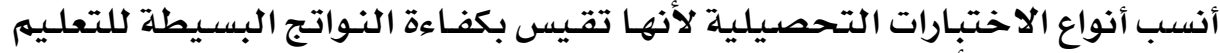

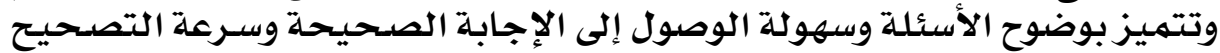

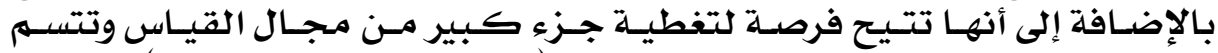

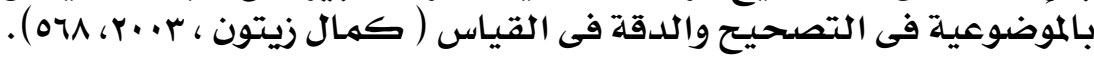

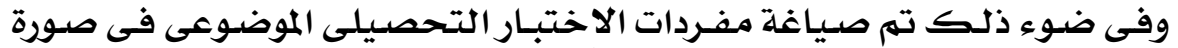

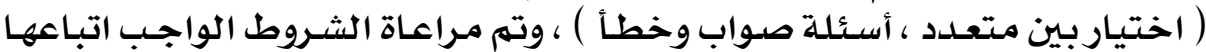

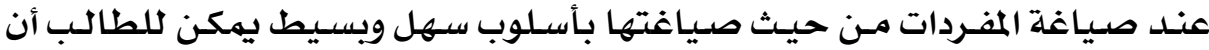

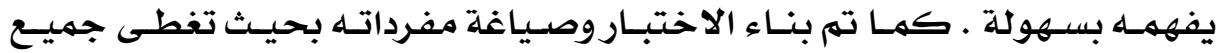

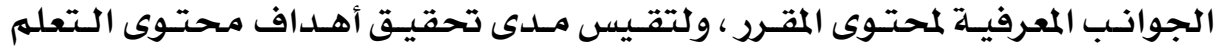

\section{$\varepsilon 7 \%$}




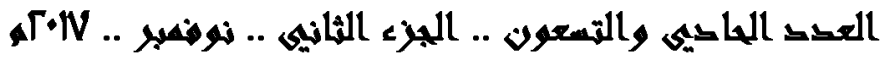

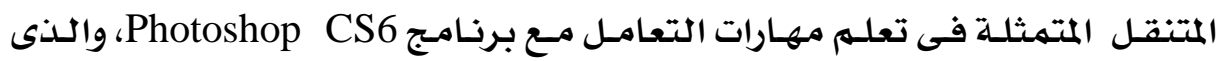

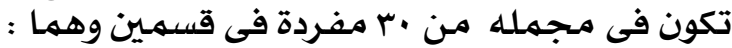

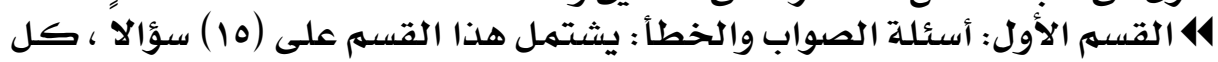

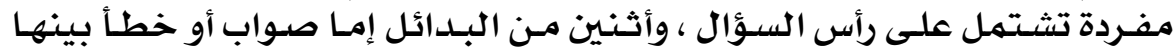

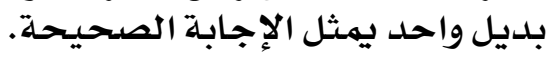

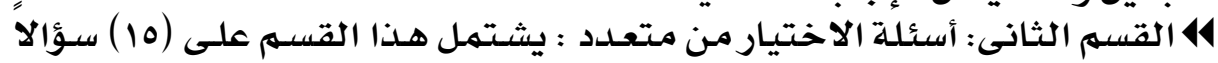

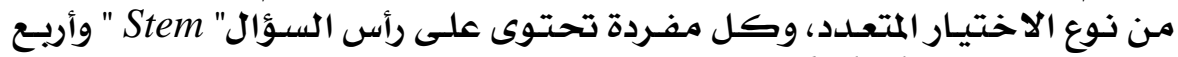

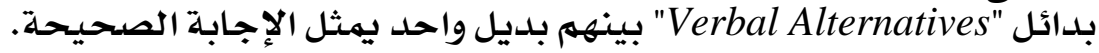

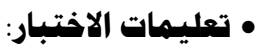

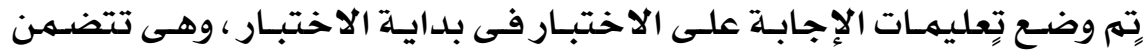

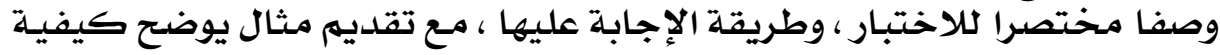

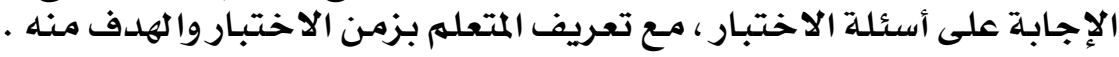

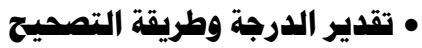

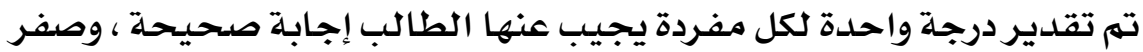

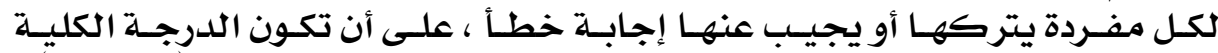

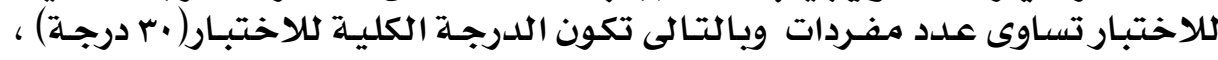

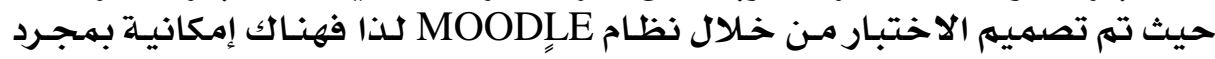

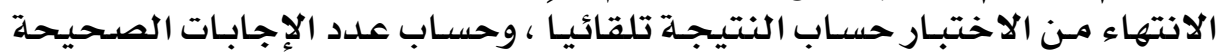

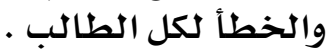

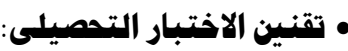
تم تقنين وضبط الاخبط التختبـار من خلال :

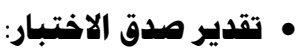

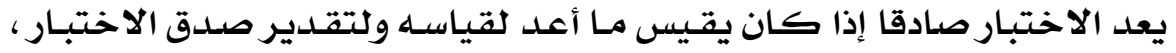

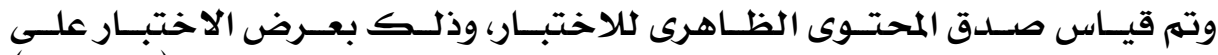

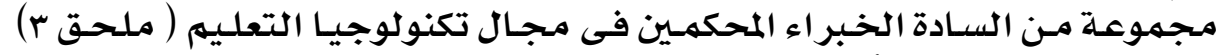

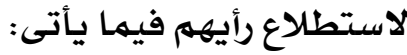

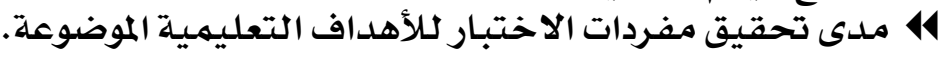

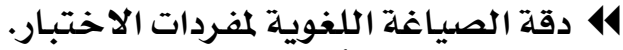

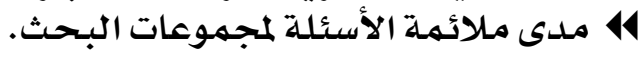

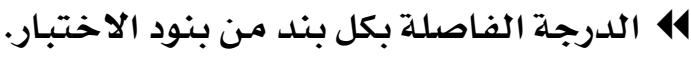

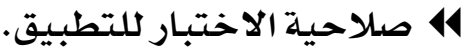

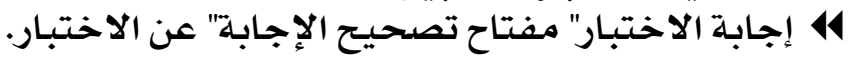
وقد أسفرت آراء السـادة المحكمهين عن بعض التعديلات البسيطة تم تعديلها .

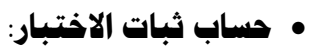

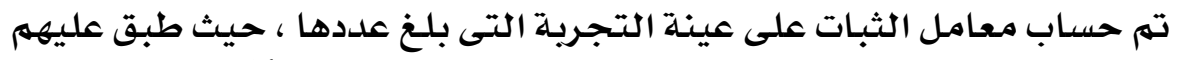

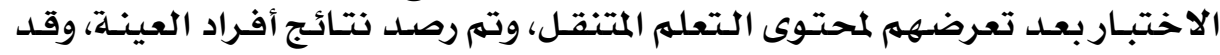




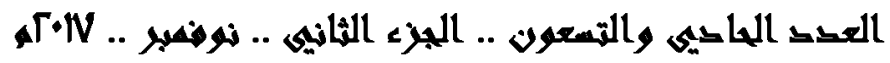

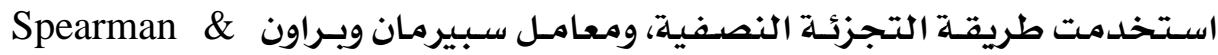

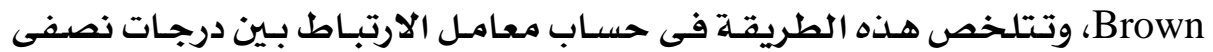

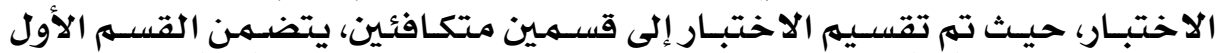

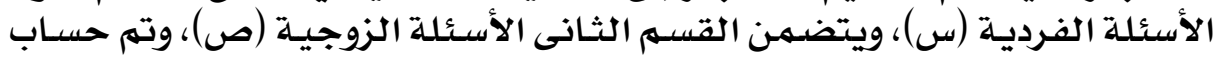

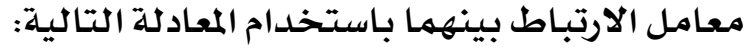

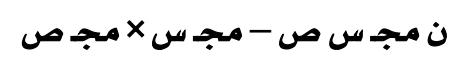

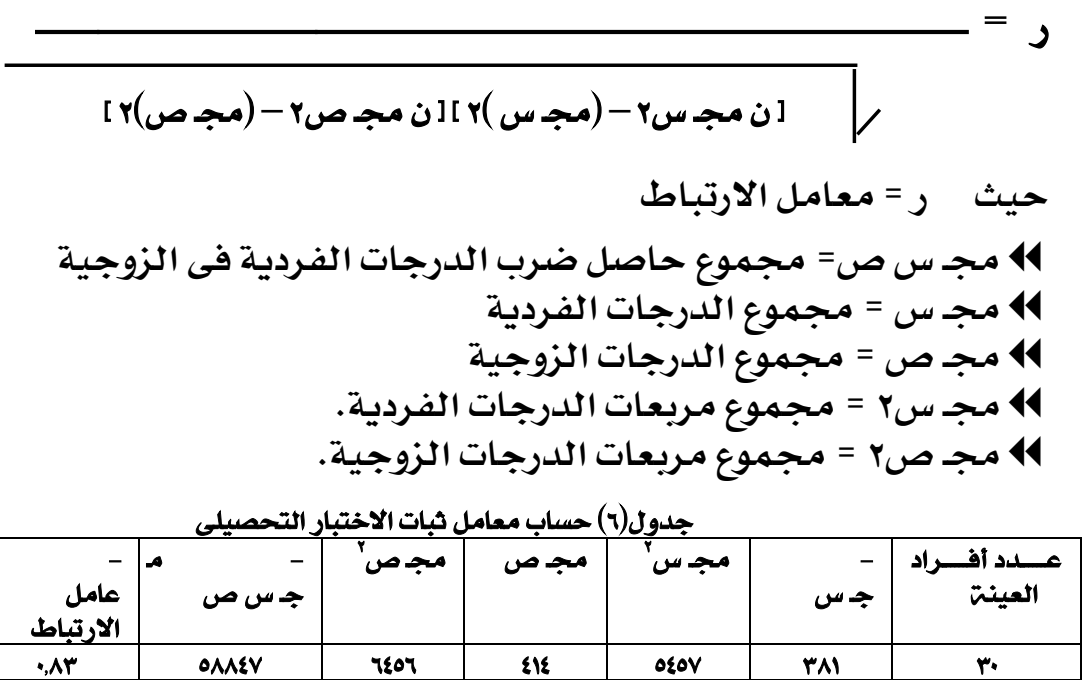

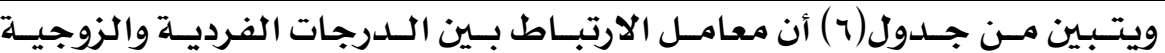

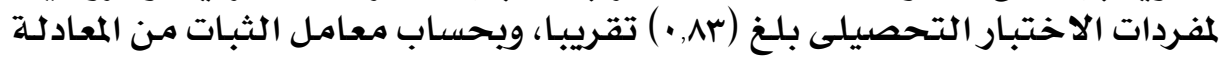

$$
\text { ر أ = }
$$

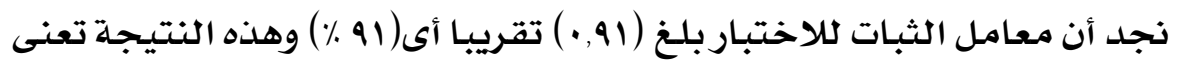

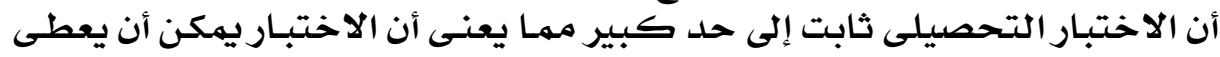

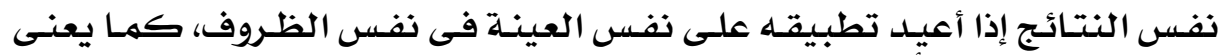

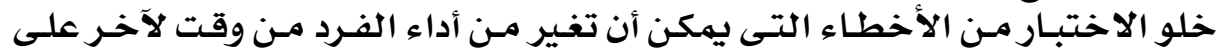
نفس الاختبار.

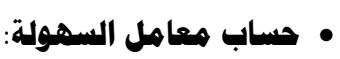

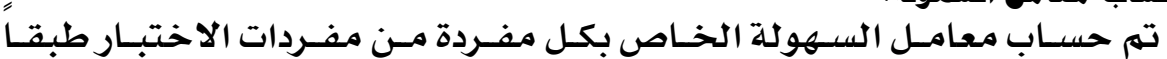

$$
\text { للمعادلة الآتية: }
$$

حيث ( ص ) = عدد الإجابات الصحيحة ، ( خ خ ) عدد الإجابات الخاطئة. 


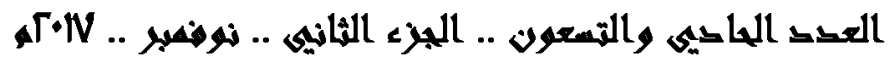

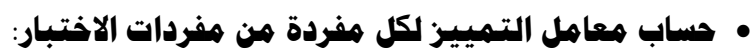

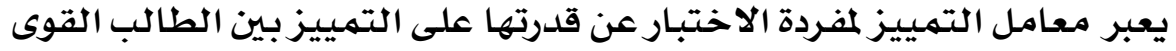

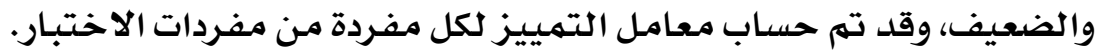

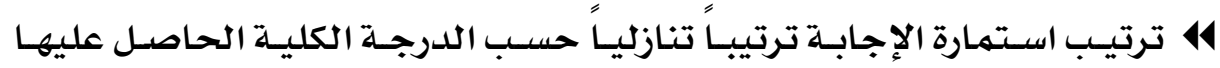

الطالب بالاختبار.

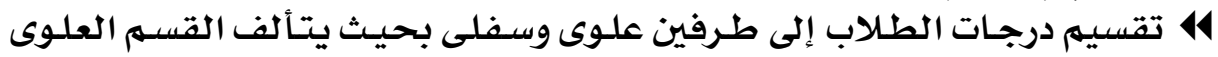

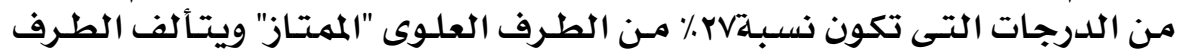

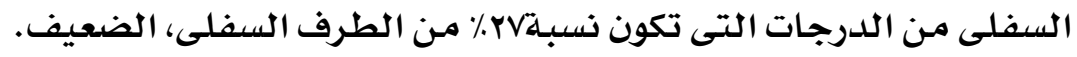

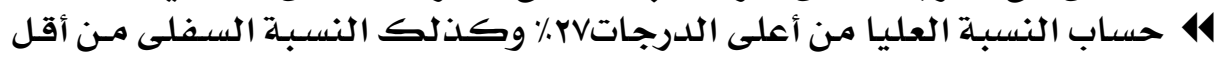

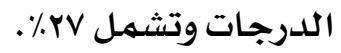

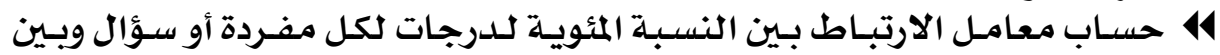

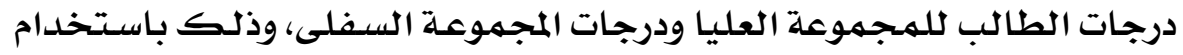

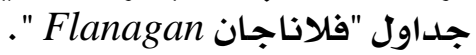

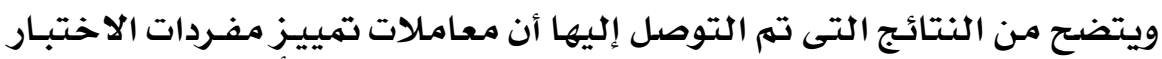

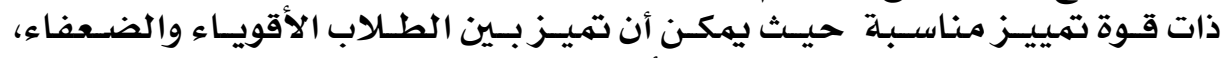

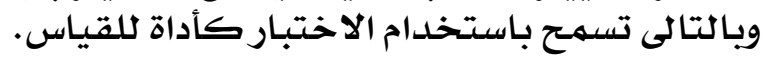

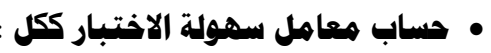

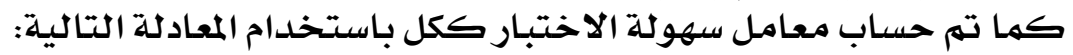

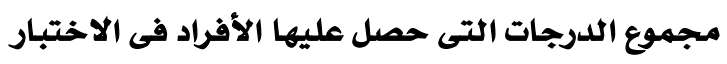

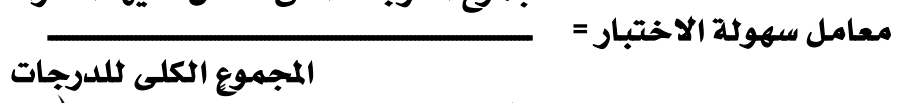

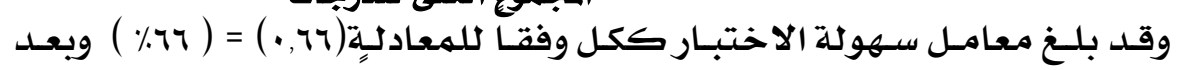

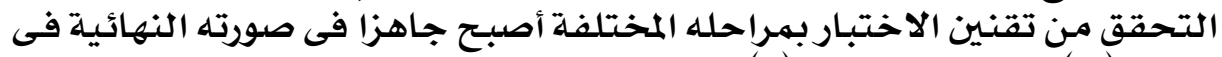

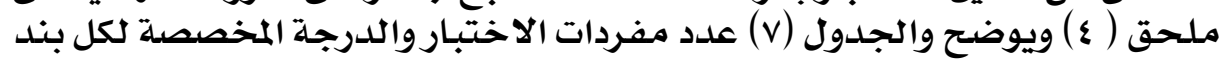
من بنوده.

جدول (v): مدد مفردات الاختبار التحصيلى والدرجت المخصصت لكل بند

\begin{tabular}{|c|c|c|c|}
\hline اللدرجت المخصصدت لكل & اللدرجت المخصصيء & 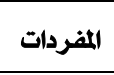 & أجزاء الاختبار \\
\hline درجتو واحلة & 10 & 10 & القسم الأول: أسئلت الصواب والخطا \\
\hline درجت واحلدة & 10 درجتة & 10 & القسم الثانى: الاختيار من متعدد \\
\hline & • ب درجت & •r مفردة & المجمــوع الكلى \\
\hline
\end{tabular}

• ت تعديد الزهن اللازم للإجابة على الاختبار:

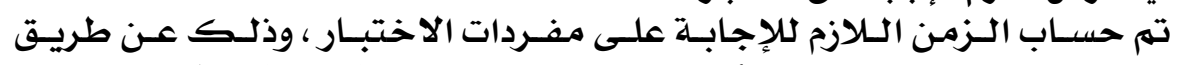

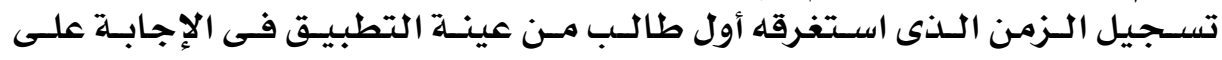

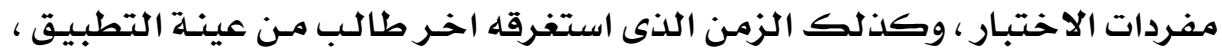

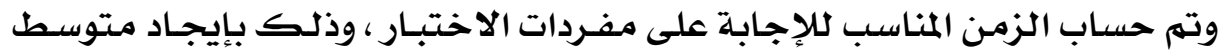




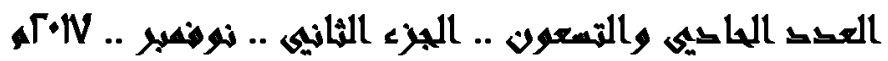

$$
\begin{aligned}
& 414 \text { الزمن الذى استغرقه أول طالب = . .1 دقيقة . }
\end{aligned}
$$

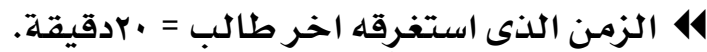

$$
\begin{aligned}
& 414 \text { متوسط الزمنين ( الزمن الكلازم لتطبيق الاختبار) = } 10 \text { دقيقة . }
\end{aligned}
$$

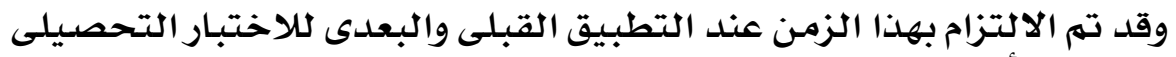

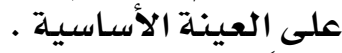

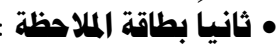

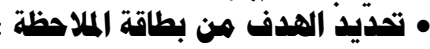

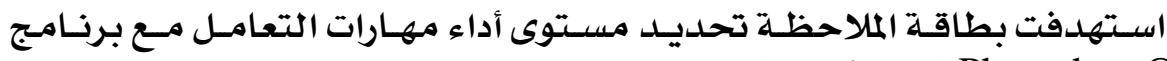

$$
\text { • تدديد الأداءات التى تتضمنها البطاقة : لدينة . }
$$

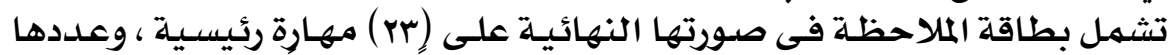

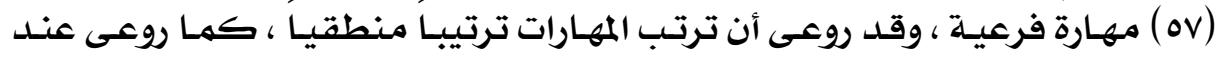

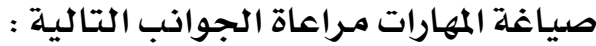
414 وصف الأداء في عبارة قصيرة .

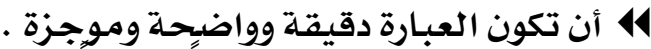

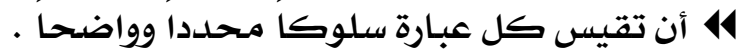

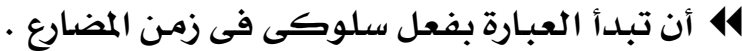

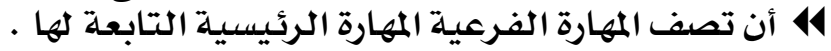

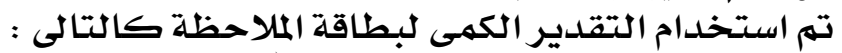

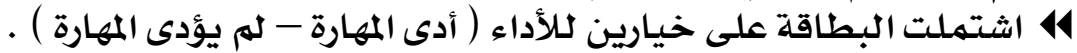

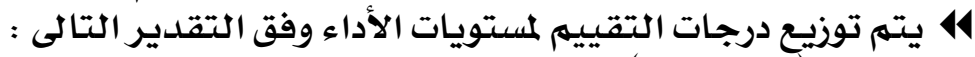

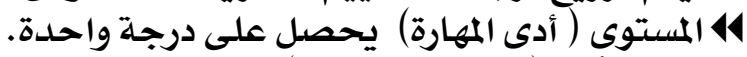

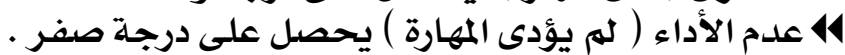
414 في المستوى ( أدى المهارة).

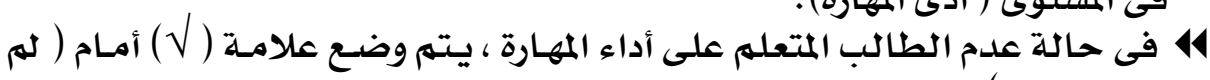

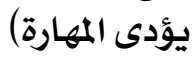

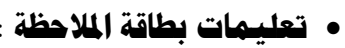

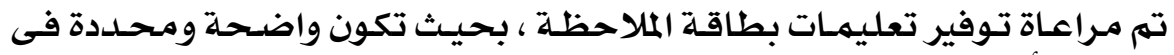

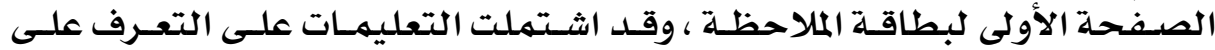

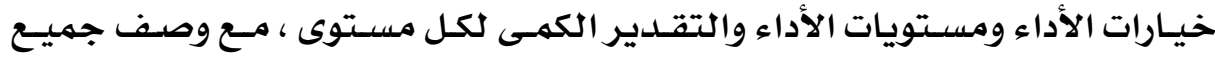

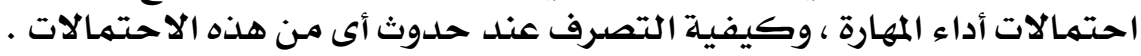

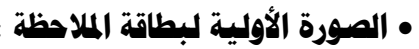

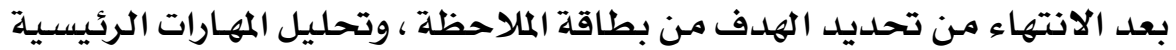

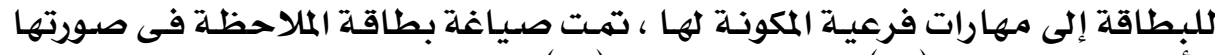

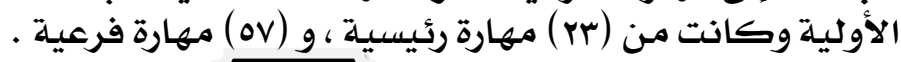




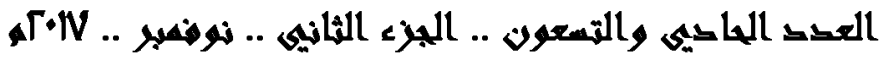

• ض ضبط بطاقة الملاحظة :

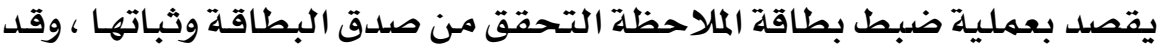

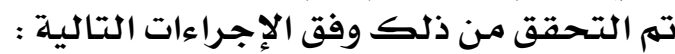

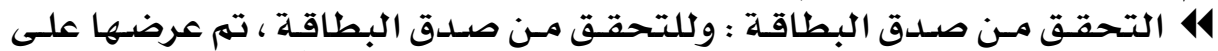

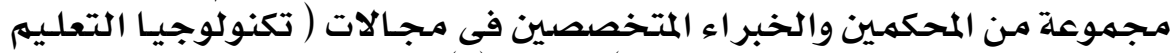

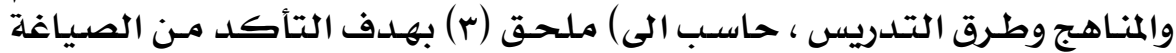

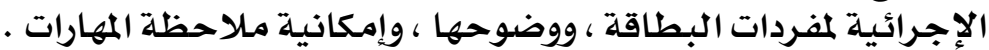

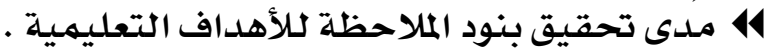

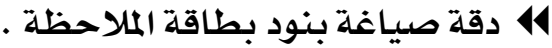

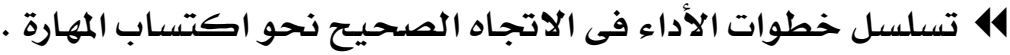

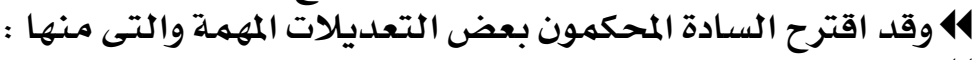

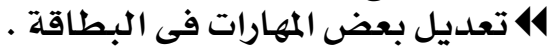

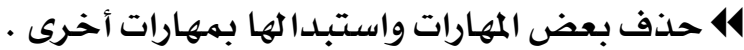
14 حذف بعض الكلهات المكررة بالمهارات الفرعية المسلسلسلة .

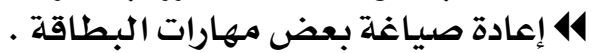

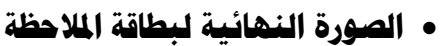

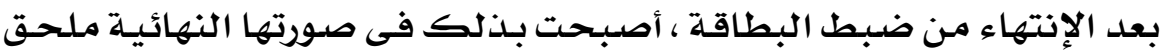

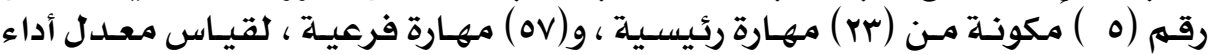

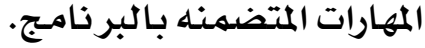

• التطبيق القبلى للاختبار:

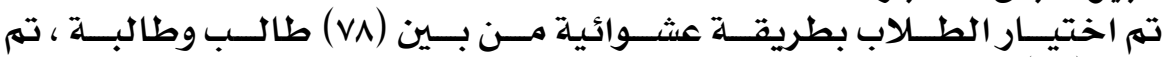

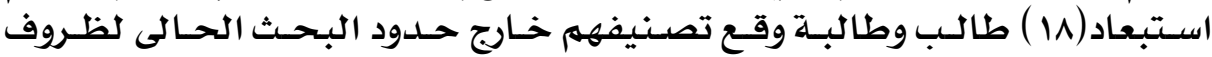

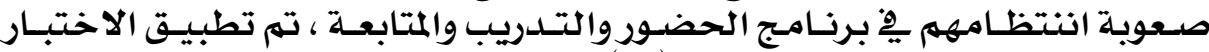

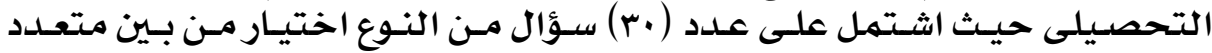

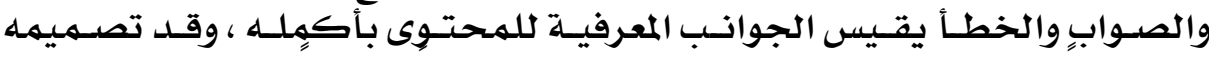

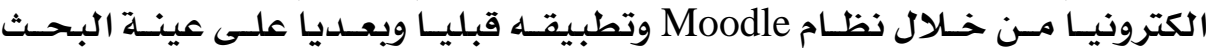

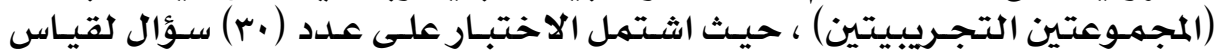

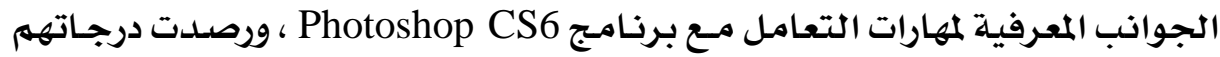

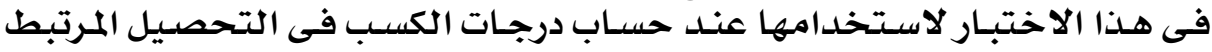

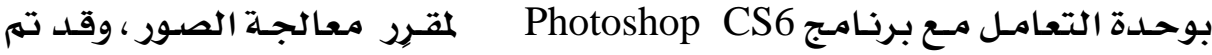

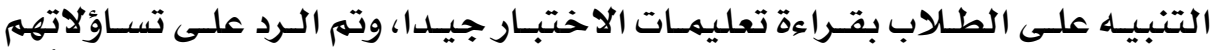

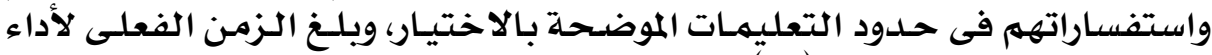

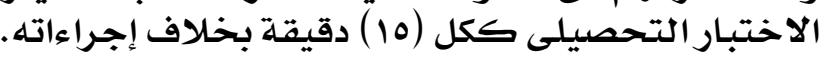

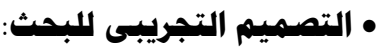

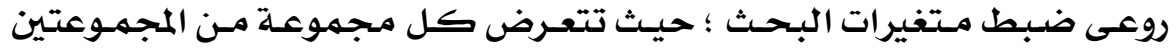

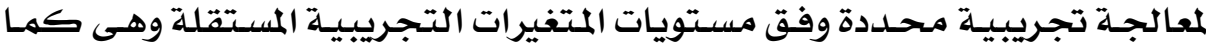




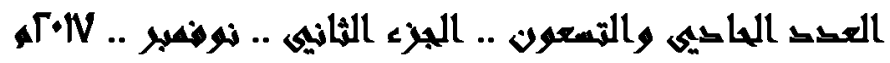

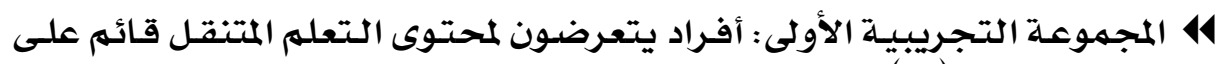

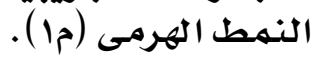

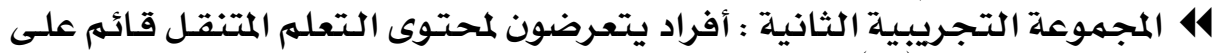

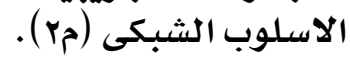

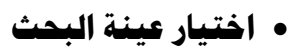

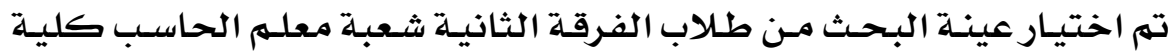

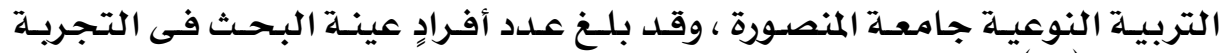

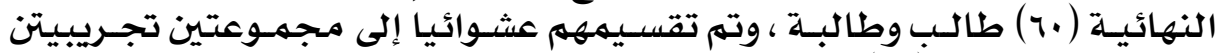

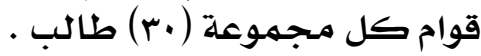

\begin{tabular}{|c|c|c|c|}
\hline وصف المجموعت ونمط دراست اليرنامج & عدد الطلاب & المجموعت & \\
\hline درسوا اليرنامج بنمط الإبحار الهرمى. & $r$. & الأولى الأولى & \\
\hline درسوا البرنامج بنمط الإبحار الشبكى. & $r$. & 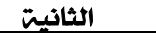 & \\
\hline
\end{tabular}

• التأكد هن تجانس المجموعتين :

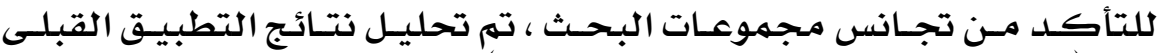

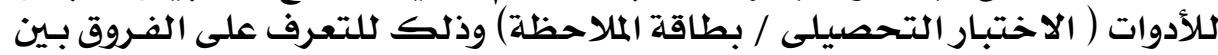

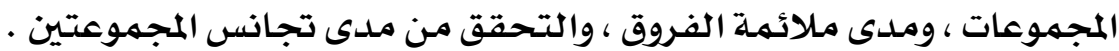

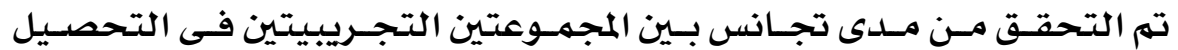

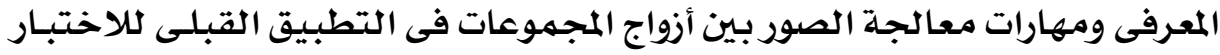

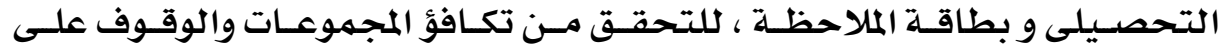

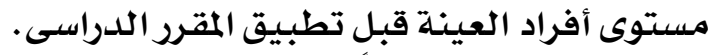

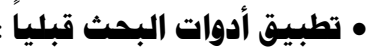

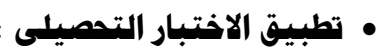

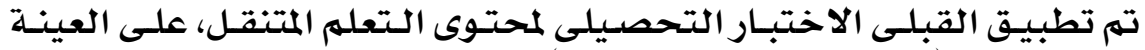

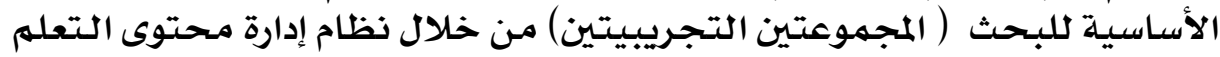
المتنقل MOODLE. • • تطبيق بطاقة الملاحظة

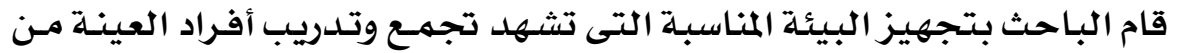

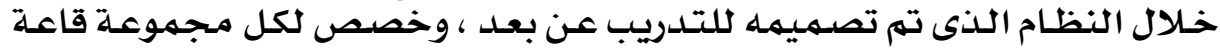
مستقلة تتضمن النفام الندان

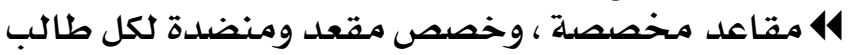

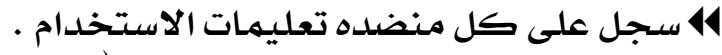

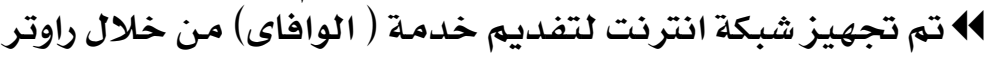

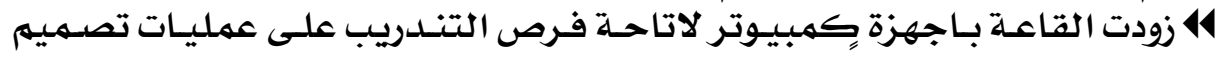

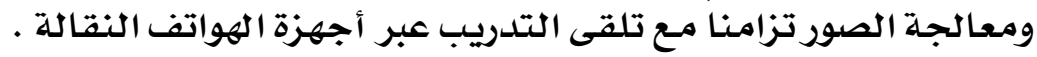

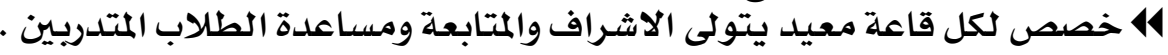




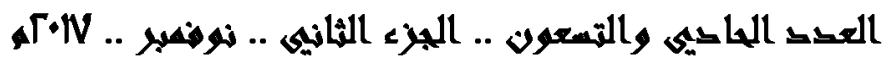

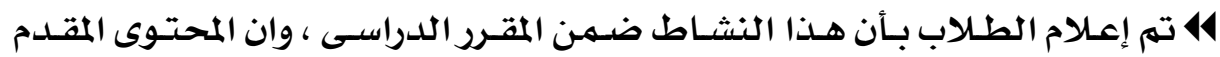

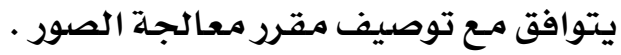

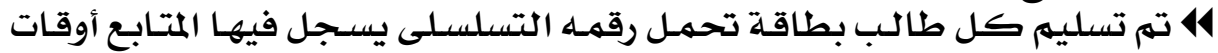

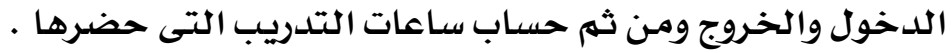

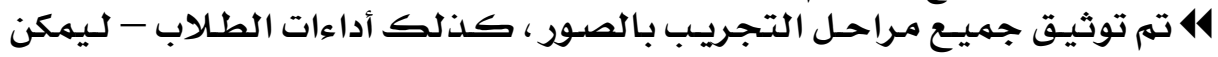

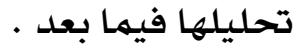

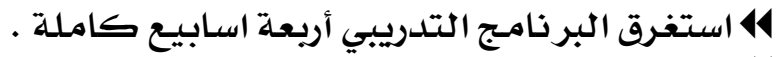

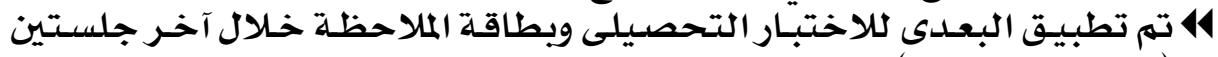

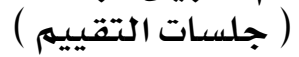

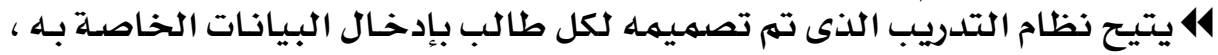

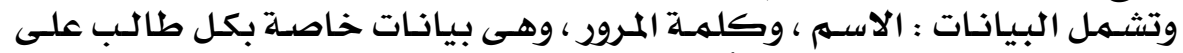

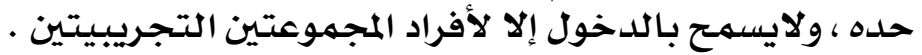

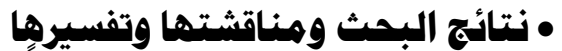

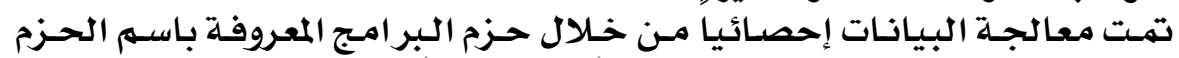

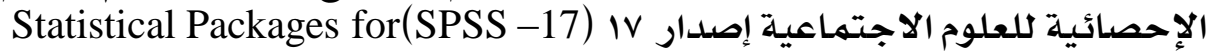
مe Social Sciences • أولاً : إجابة السهوال الفرعي الأول :

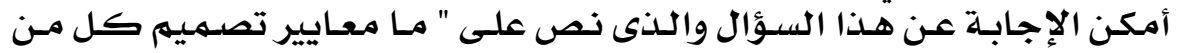

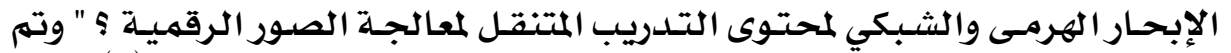

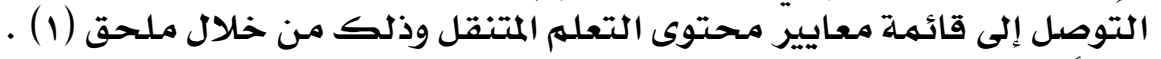

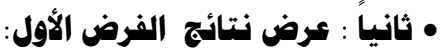

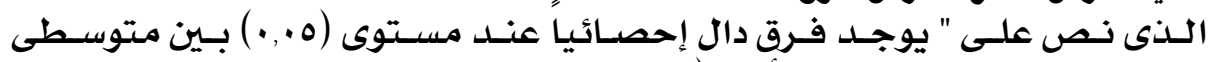

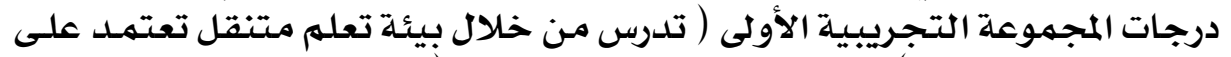

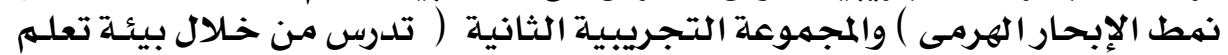

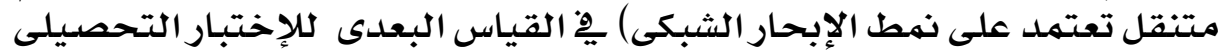

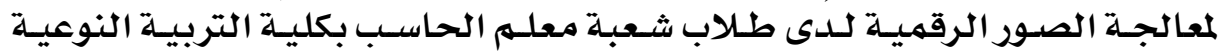

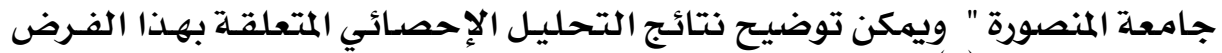

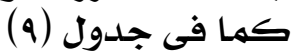

جدول (ه): نتائج التحليل الإحصائي للفروق بين متوسطي درجات الاختبار التحصيلي لمعالجت الصور الرقميتة اللمجمومتين التجريبيتين الأولى والثانيتي الاختيار

\begin{tabular}{|c|c|c|c|c|c|c|c|}
\hline مستوى الدلاكت & قلمسمتوتيت & درجات & الإنعيارى & المتوسط & عدد افراد & المجموعت & المقياس \\
\hline دالتّ عند & \multirow{2}{*}{$\mathbf{A}, \mathbf{A}$} & \multirow{2}{*}{$0 \wedge$} & $\varepsilon, \sqrt{ } 9$ & $19,0$. & $r$ & الهرمى & التحصيل \\
\hline,,$\infty$ & & & Y,Vr & YY,YV & $r$. & الشيكي & التحصيل \\
\hline
\end{tabular}

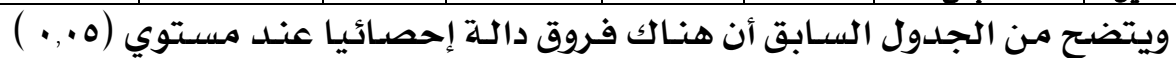

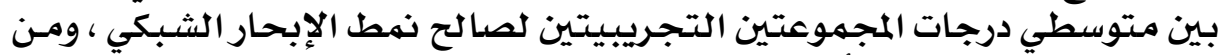

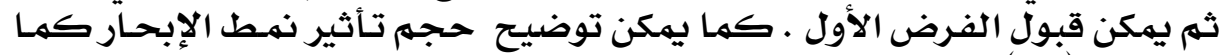
(1. ) 


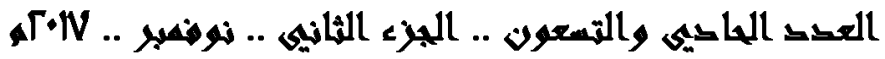

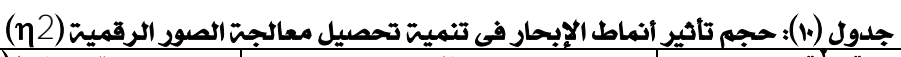

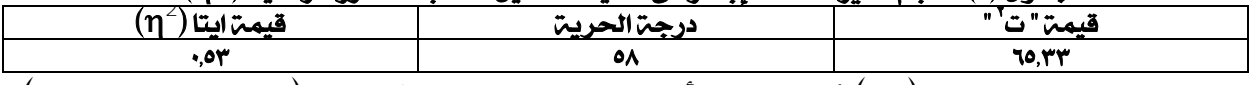

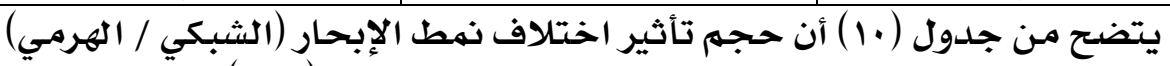

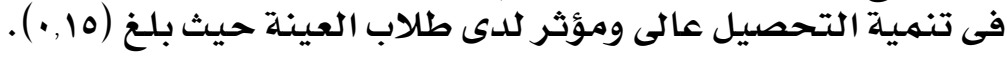

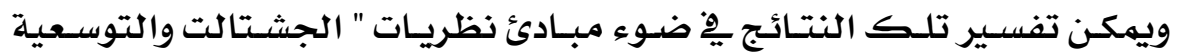

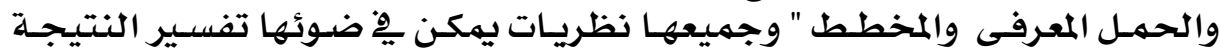

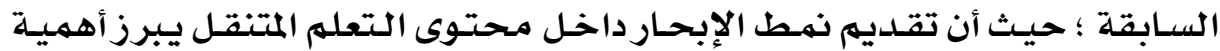

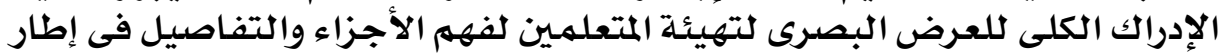

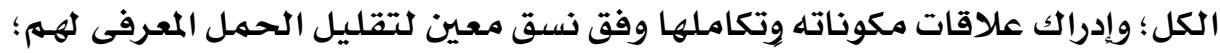

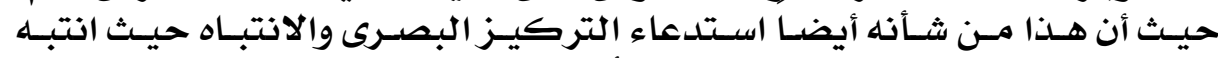

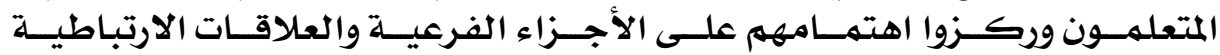

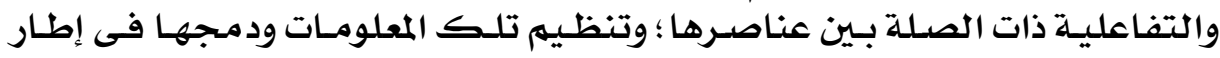

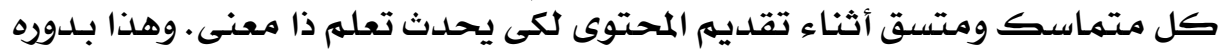

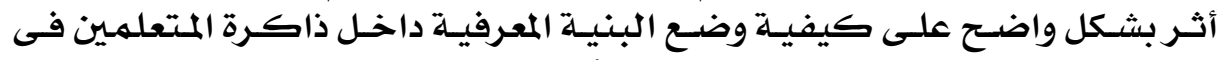

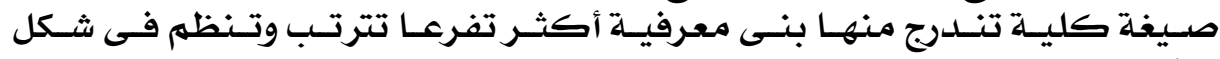

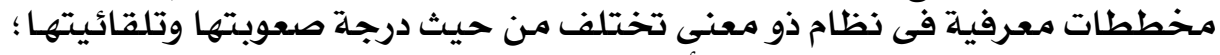

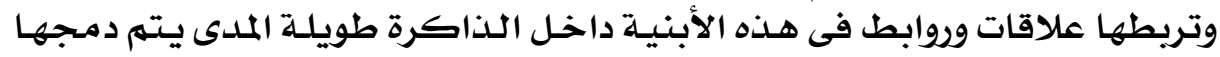

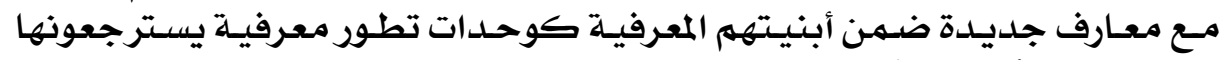

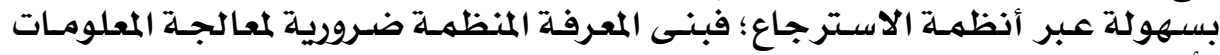

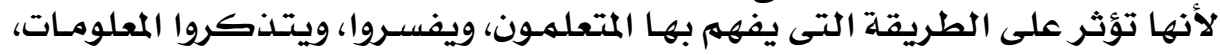

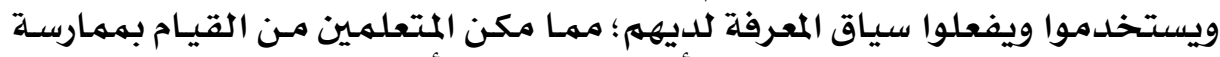

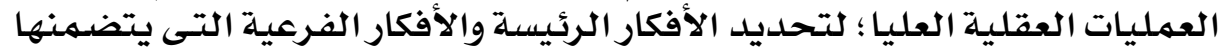

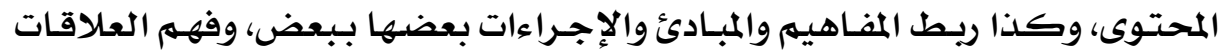

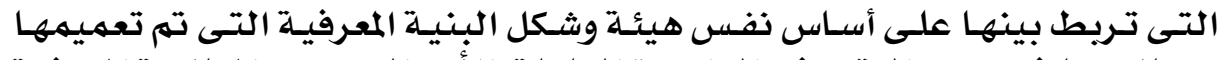

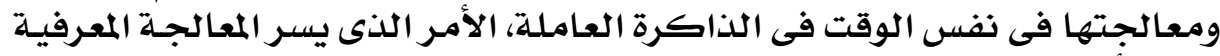

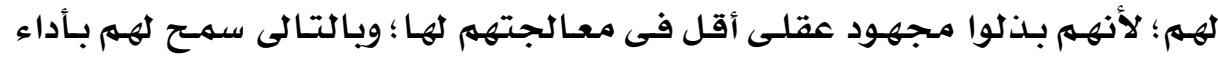

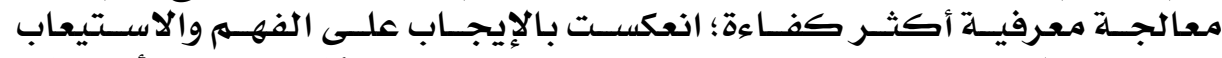

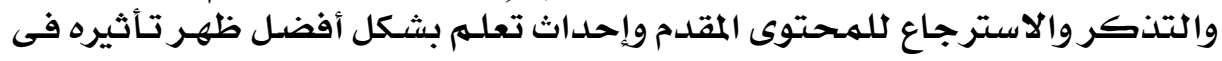
التحصيل المعرفى للهتعلمهين.

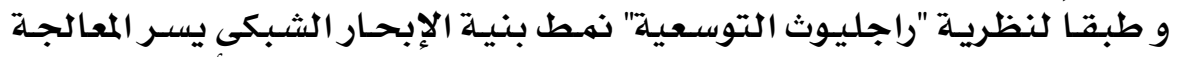

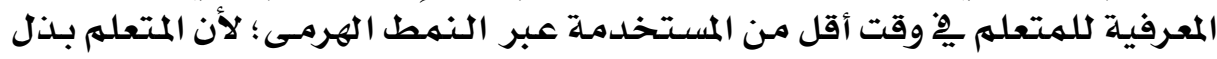

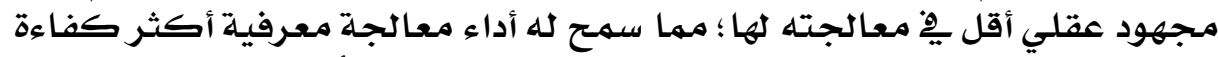

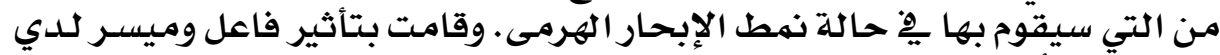

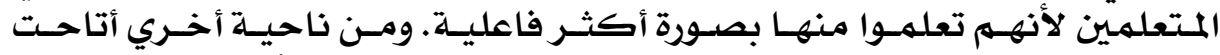

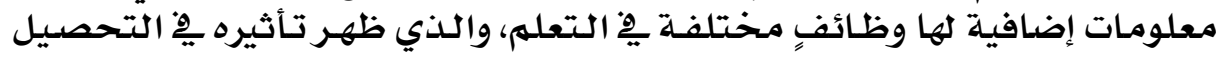

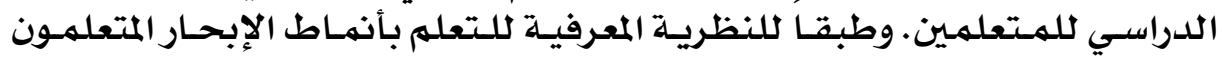




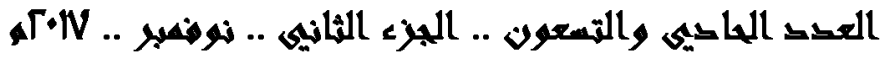

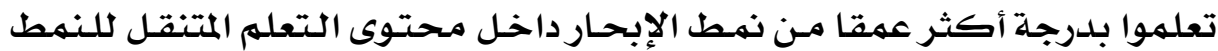

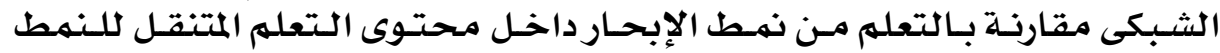

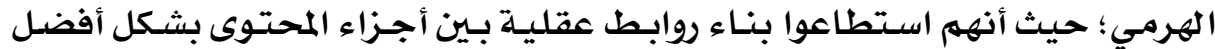

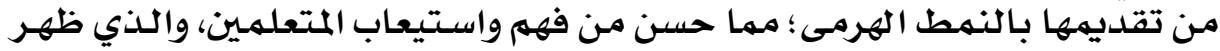

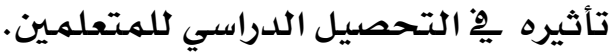

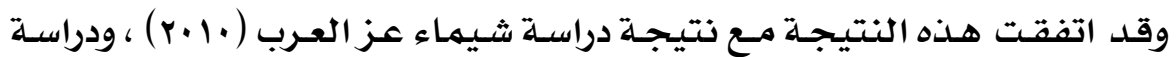

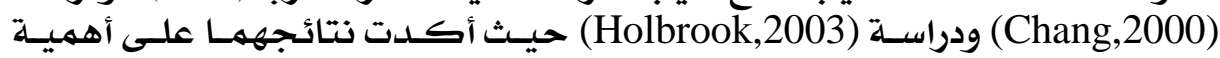

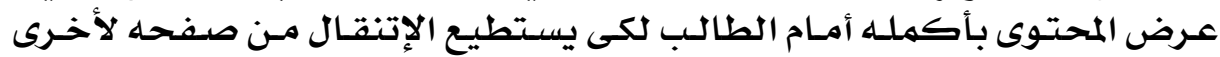

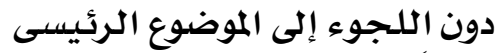

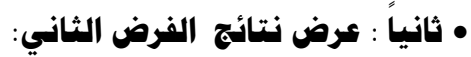

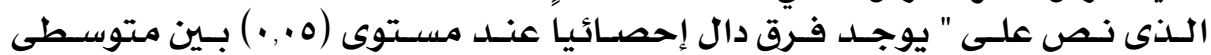

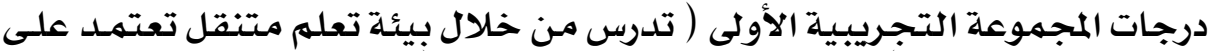

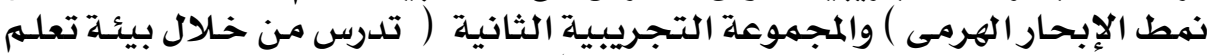

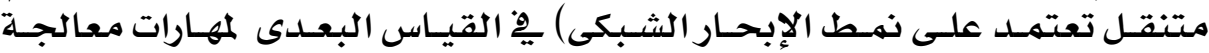

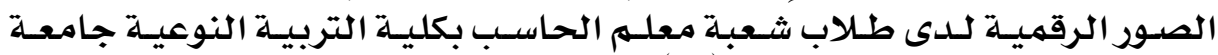

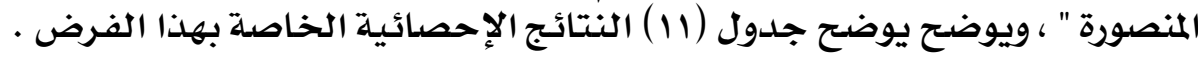

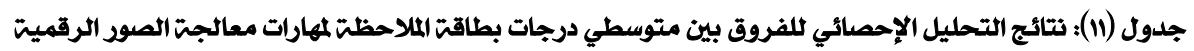
للمجموعتين التجريبيتين الأولى والثانيت

\begin{tabular}{|c|c|c|c|c|c|c|c|}
\hline مستوى الدلاي & قيمتت ت & رجات الحريتة & الإنعيارى & المتوسط & علد افراد & المجمومت & القياس \\
\hline \multirow{2}{*}{ داتم عند } & \multirow{2}{*}{0,07} & \multirow{2}{*}{$0 \wedge$} & 19,12 & IrV,TV & $r$. & الهرمى & بطاقت \\
\hline & & & 10,YY & $\mid \varepsilon V, T V$ & $r$. & الشبكى & المبلاحظتة \\
\hline
\end{tabular}

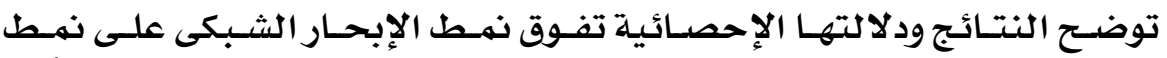

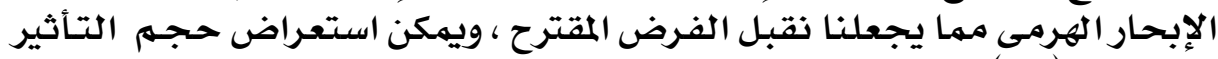

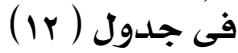

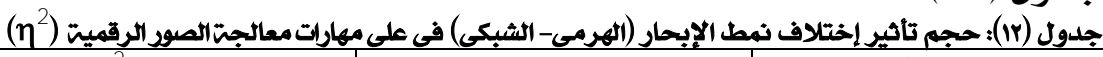

\begin{tabular}{|c|c|c|}
\hline 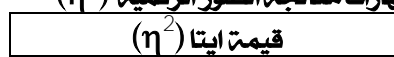 & درجت الحريتة & " قيمتة" ت" " \\
\hline , ro & on & $r . q 1$ \\
\hline
\end{tabular}

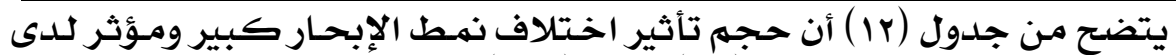

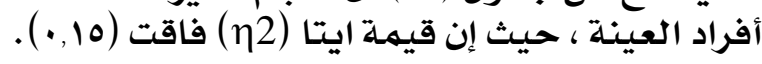

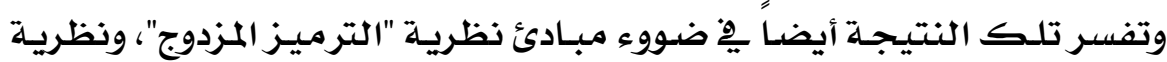

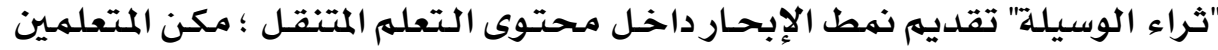

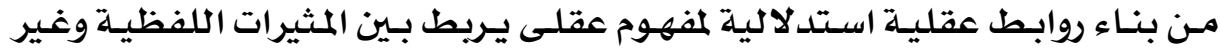

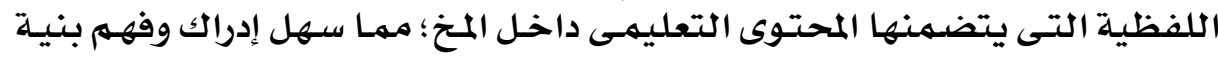

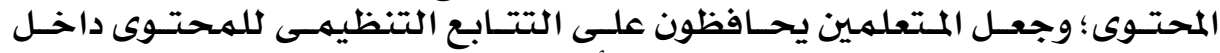

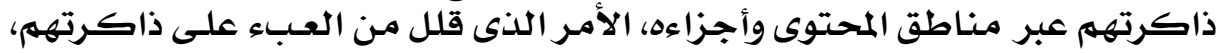




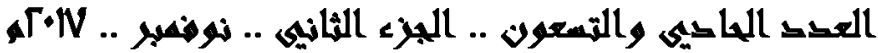

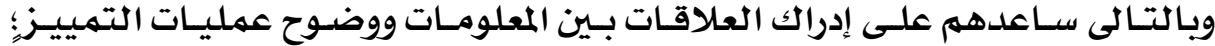

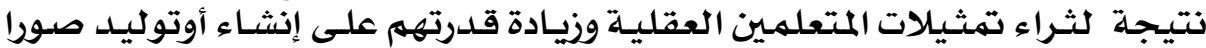

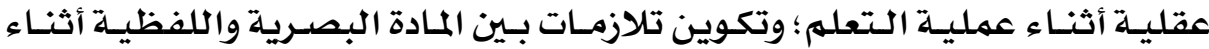

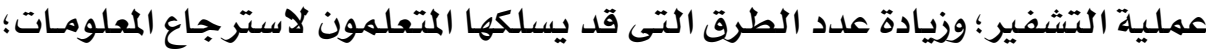

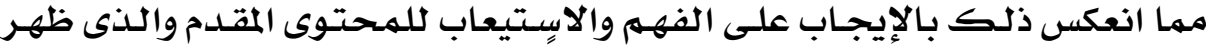

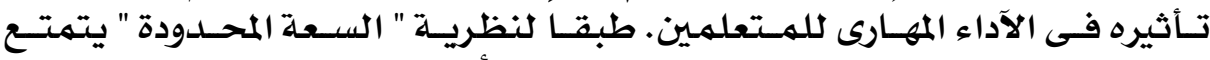

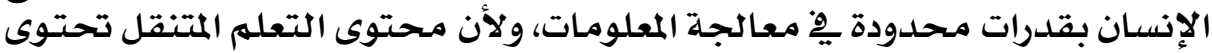

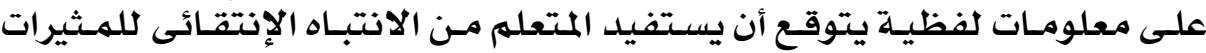

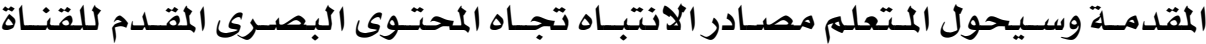

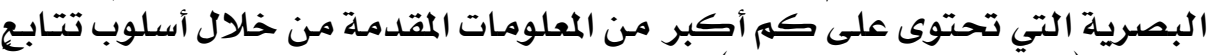

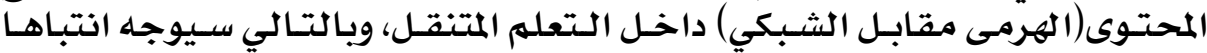

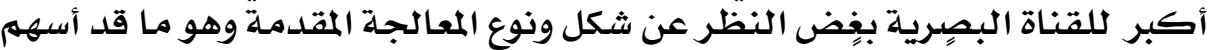

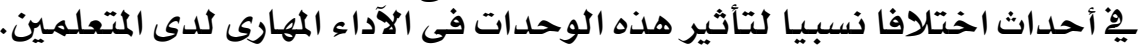

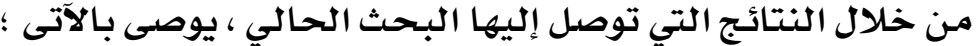

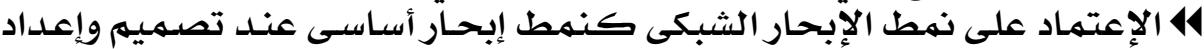

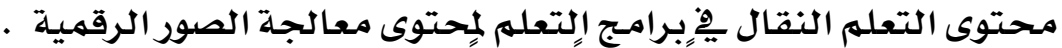

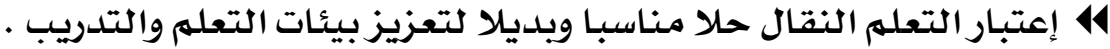

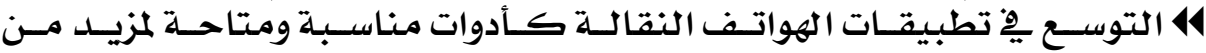

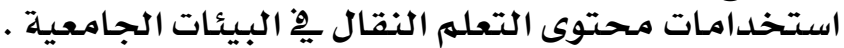

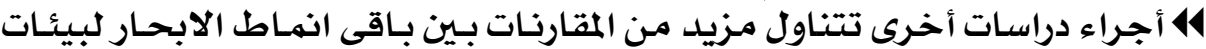

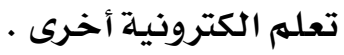
414

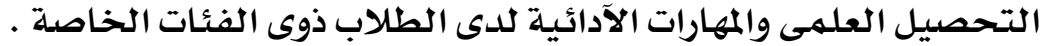

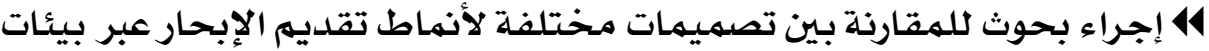

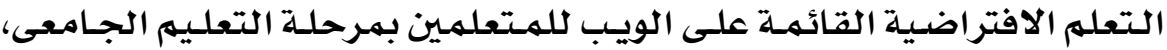

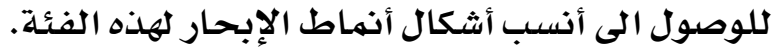

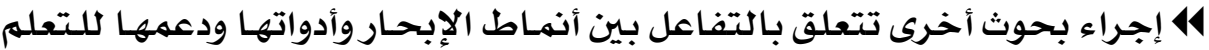

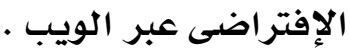

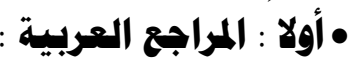
- إبراهيم عبدالوالوكيل الفار (rا.r) تربويات القرن الحادى والعشرين - تكنولوجيا ويب 2.0 ـ طنطا :

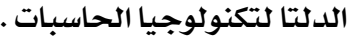

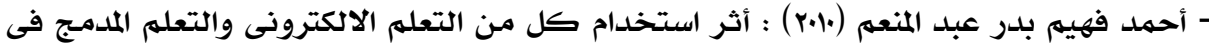

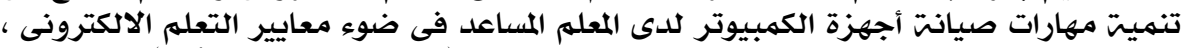

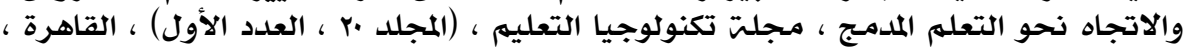

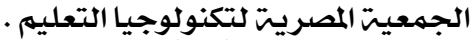

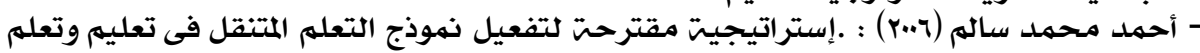

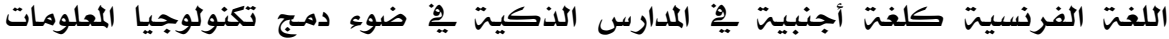




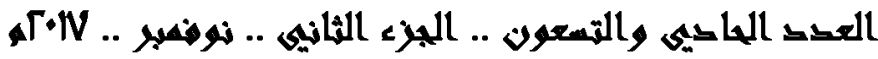

والاتصالات واقتصاد المعرفت ، مركز تطوير التعليم الجامعي بجامعت عين شمس، ع 12 ، القاهرة

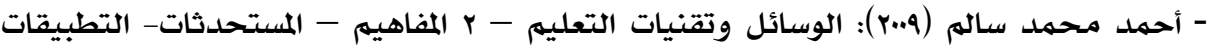

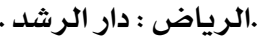

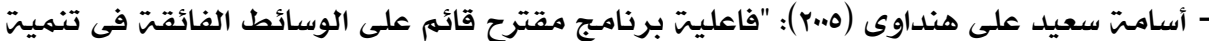

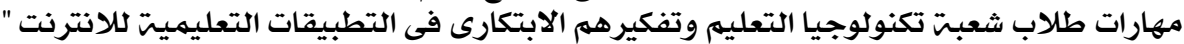

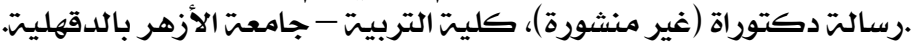

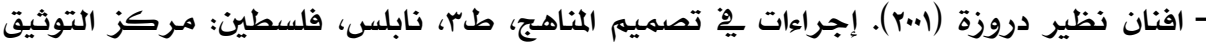
- أفنان نظير دورزة (....r). النظريت فى التدريس وترجمتها عمليا، عمان: دار الشروق للنشر

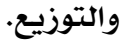

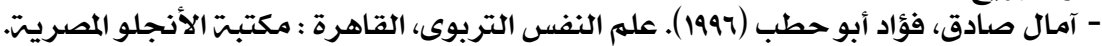

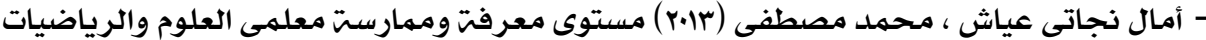

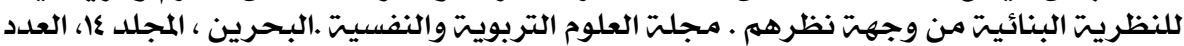
r.

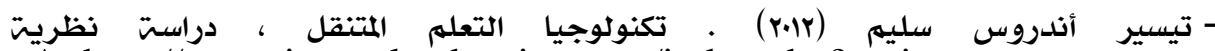
At:http://www.journal.cybrarians.org/index.php?option=com_context \&view=article \&id=617: edu\&catid =254: studies \& Itemid=80

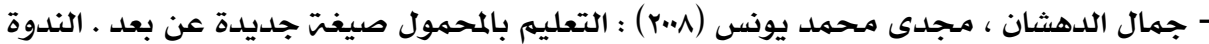

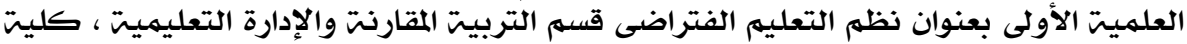

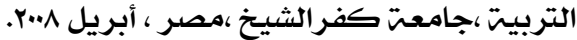

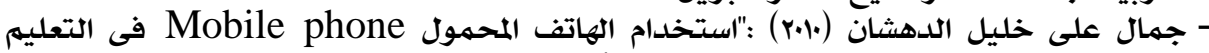

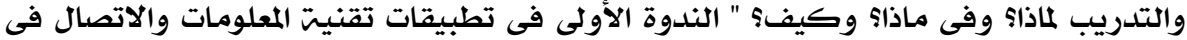

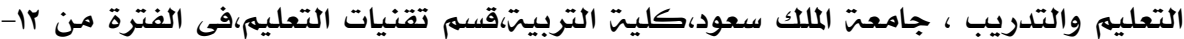

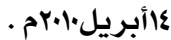

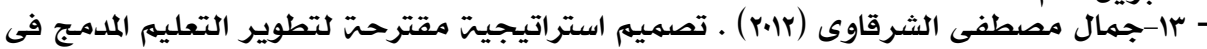

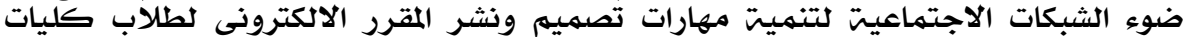

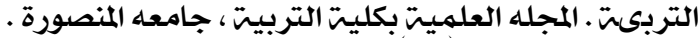

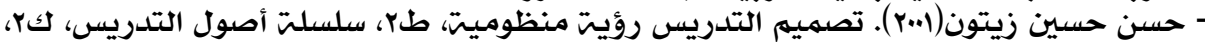

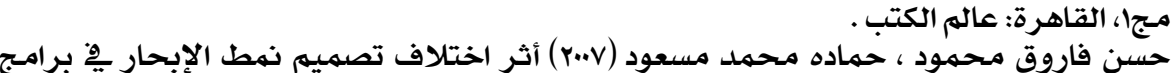

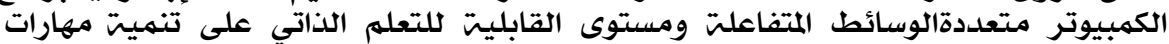

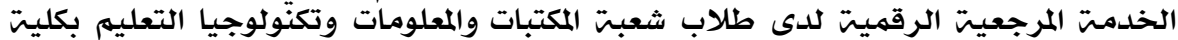

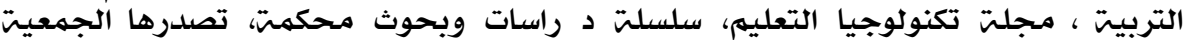

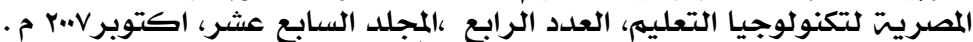

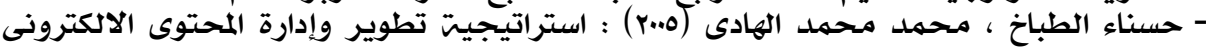

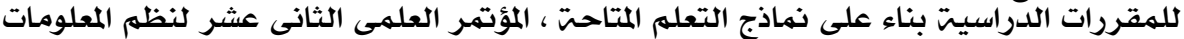

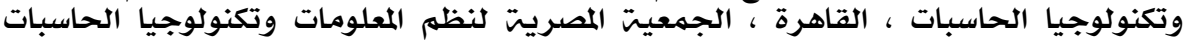

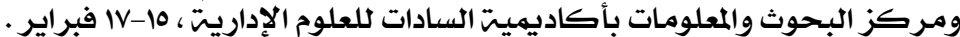

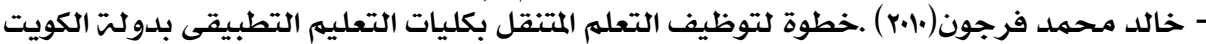

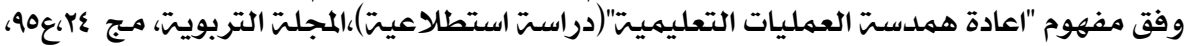
يونيو.

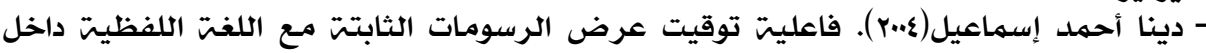

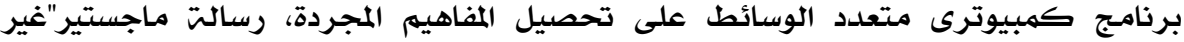
منشورة"، حلوان: كليت التربيتة، جامعت حلواندان. 


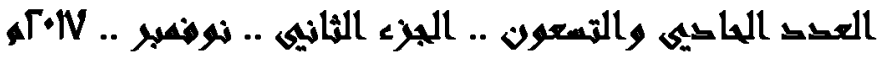

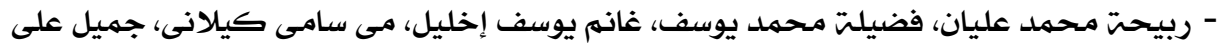

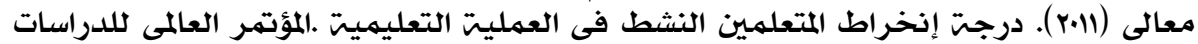

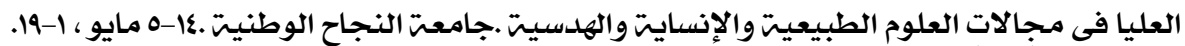

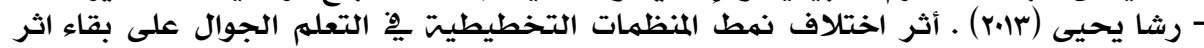

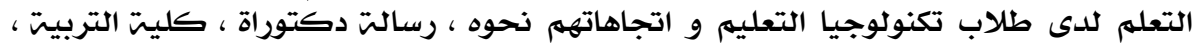

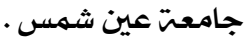

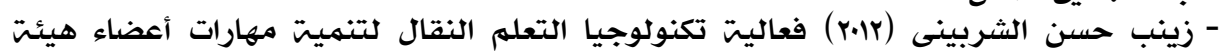

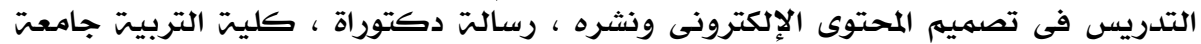

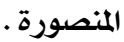

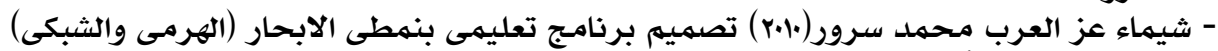

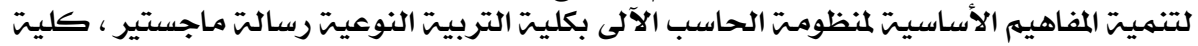

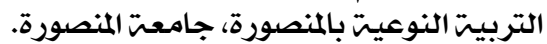

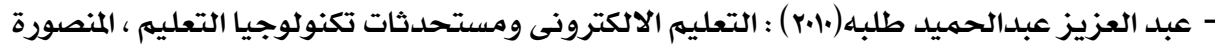

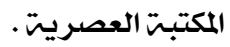

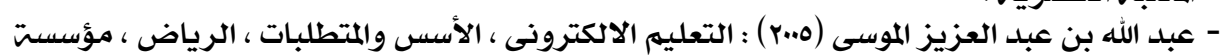

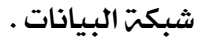

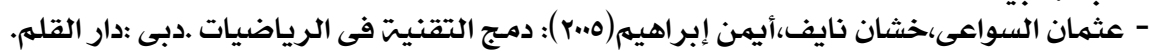

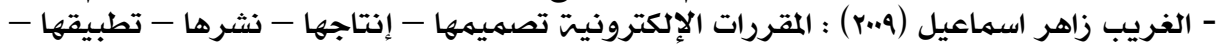

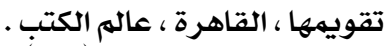

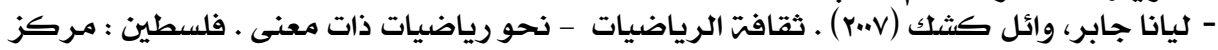

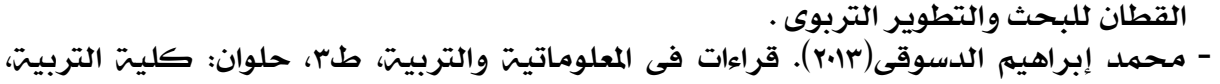
جامعت حلوان.

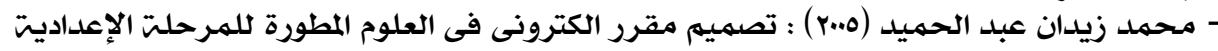

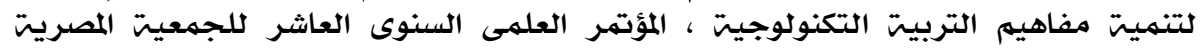

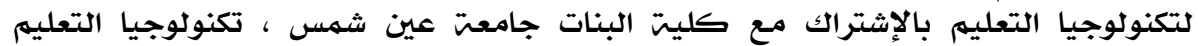

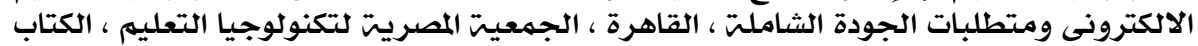

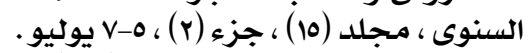

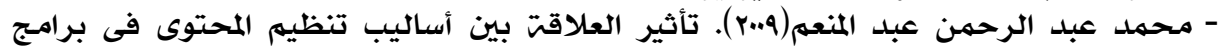

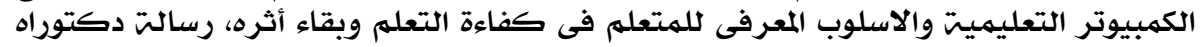

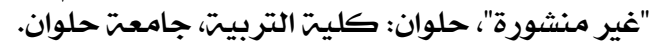

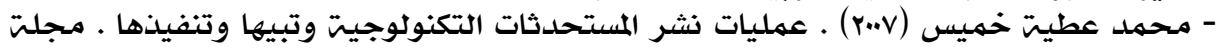

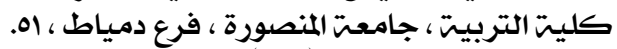

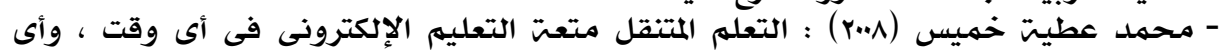

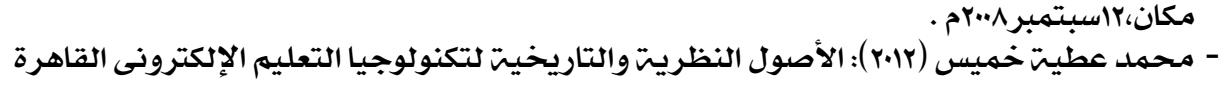

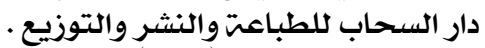

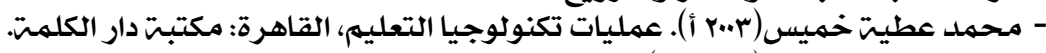

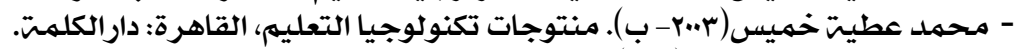

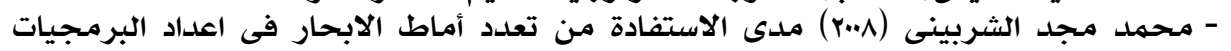

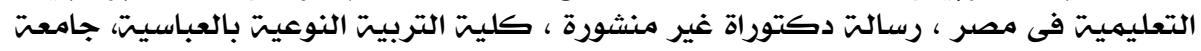
عين شمس. - محمدد محممود الحيلت(بن.بr). تكنولوجيا التعليهم بين النظريت والتطبيق، عمان: دار المسيرة. 


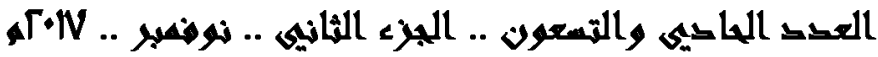

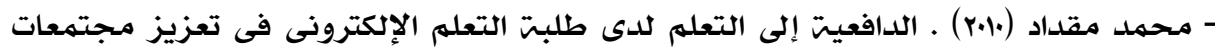

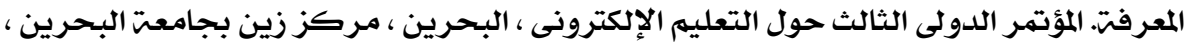

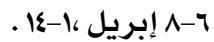

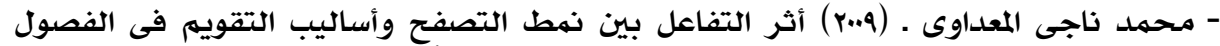

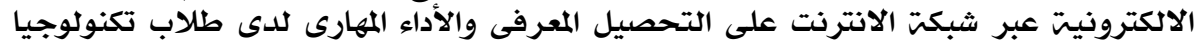

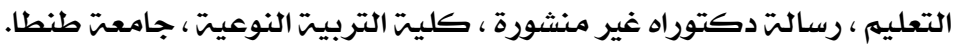

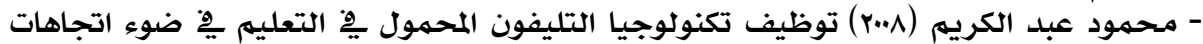

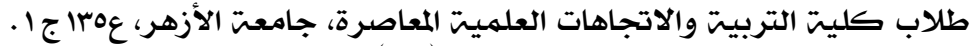

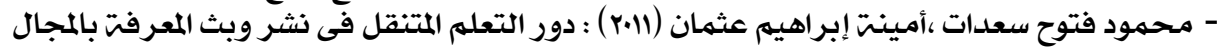

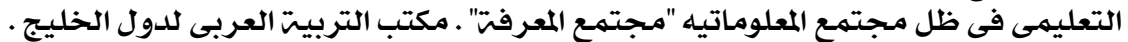

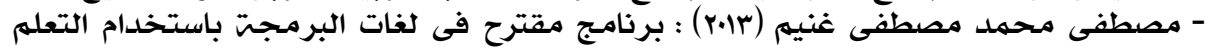

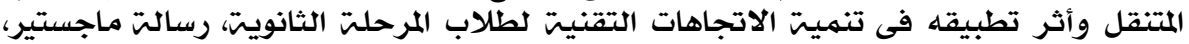

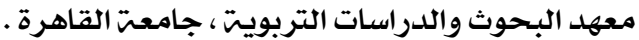

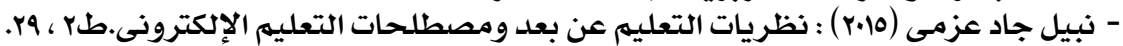

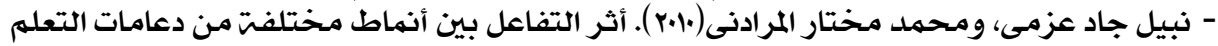

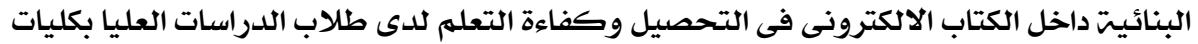

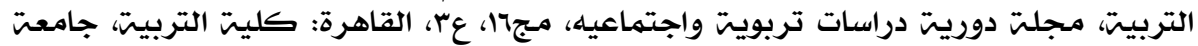

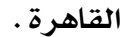

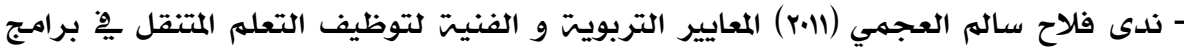

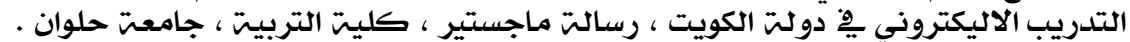

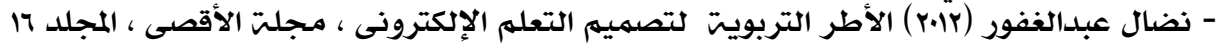

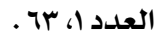

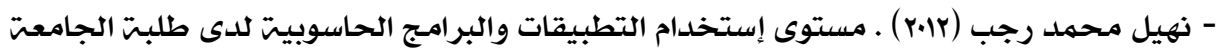

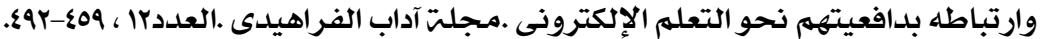

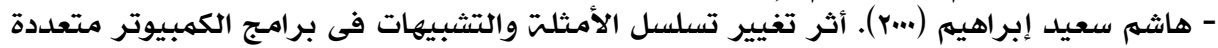

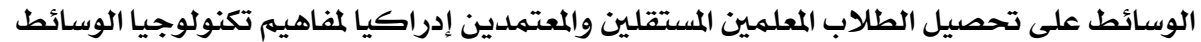

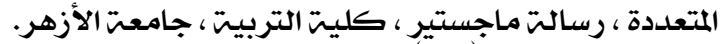

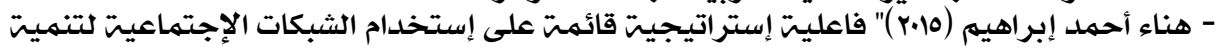

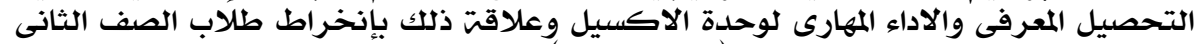

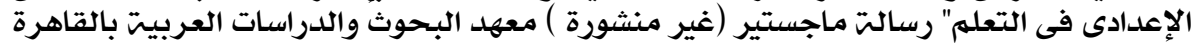
.YO،

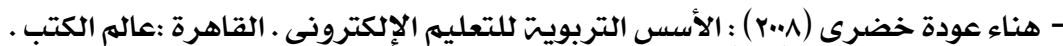

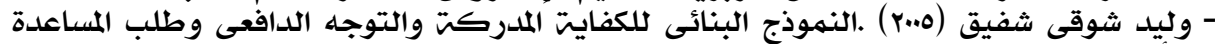

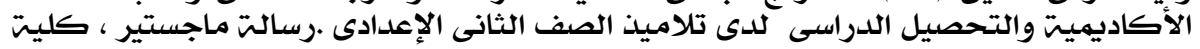

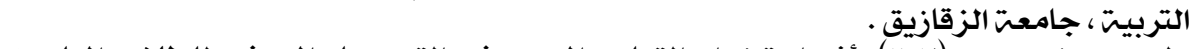

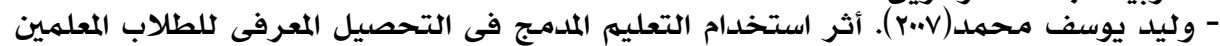

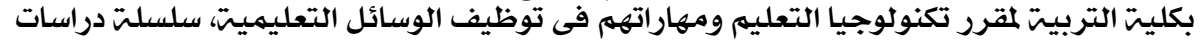

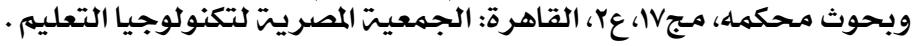

\section{• ثانيا : المراجع الأجنبية مدهنة}

- Alessi, S.M., \& Trollip, S.R.(2008). Multimedia for learning: methods and development. $3^{\text {rd }}$ ed., Boston: Allyn and Bacon.

- Anderson, T. \& Fathi, E . (2004) Theory and Practice of Online Learning Retrieved From http://cde.athabascau.ca/online_book 


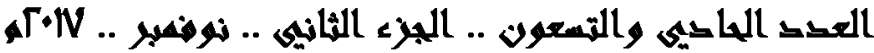

- Arcambault, I, Janosz, M., Morizot, M., and Pagani, L. (2009). Adolescent behavioral, affective, and cognitive engagement in school: relationship to dropout. Journal of school Health, 79(9), 408-415

- Azevedo, R., \& Hadwin, A. F. (2005). Scaffolding Self -regulated Learning and metacognition-Implications for the design of Computer based scaffolds. Instructional Science, 33, 367-377. .

- E-Learning Guild. Retrieved August, 2006, from http://www. elearningguild.com

- Baker,J.A .,Clark ,T.P Maier,K.S ., Viger, S.(2008) The differential influence of instructional context on the academic engagement of student with behavior problems. Teaching and Teacher Education .24, 1867-1883.

- Barab, S.A., Evans, M.A., \& Baek, E.-O.(2004). Activity theory as a lens for characterizing the participatory unit. In D. H. Jonassen (Ed.), Handbook of Research on Educational Communications and Technology, $2^{\text {nd }}$ ed. (pp. 199-214). Mahwah, NJ: Lawrence Erlbaum Associates, Inc.

- Bayram,S.(2005). Software Mapping Assessment Tool Documenting Behavioral Content in Computer Interaction: Examples of Mapped Problems with Kid Pix Program. The Turkish Online Journal of Educational Technology, 4(2), 7-17, Retreived from http://www. tojet. net/articles/v4i2/422.pdf.

- Berlyne, D. E. (1968). Conflict, arousal, and curiosity. New York: McGraw-Hill.Berrett-Koehler Publishers, Inc.

- Brusilovsky, P.(2004). Adaptive navigation support: from adaptive hypermedia to the adaptive web and beyond. PsychNology Journal, 2(1), $7-23$.

- Buendía, F., \& Cano, J.-C.(2006). WebgeneOS: A Generative and Web-Based Learning Architecture to Teach Operating Systems in Undergraduate Courses. IEEE Transactios on Education, 49(4), 464473.

- Cavus , Nadire ( 2010 ) : A Study to Investigate the Opinions of Instructors on Mobile

- Chang, D., Dooley, L.,\& Tuovinen, J. E.(2001). Gestalt Theory in Visual Screen Design - A New Look at an Old Subject. paper was presented at the Seventh World Conference on Computers in Education, Copenhagen, July 29-August 3, Retrieved from http://crpit.com/confpapers/CRPITV8Chang.pdf.

- Chen, K.-C., \& Jang, S.-J.(2010). Motivation in online learning: Testing a model of self-determination theory. Computers in Human Behavior, 26, 741-752.

- Csikszentmihalyi, M. (1997). Flow and Education. NAMTA Journal, 22(2), 2-35. 


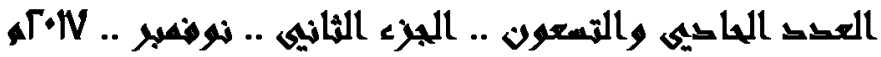

- Dalgarno, B., Hedberg, J., \& Harper, B. (2002). The contribution of 3D environments

- Dumais, S., \& Chen, H.(2006). Hierarchical classification of Web content. Proceedings of the 23rd annual international ACM SIGIR conference on Research and development in information retrieval (pp.256-263). ACM New York, NY, USA. Retrieved from http://comminfo.rutgers.edu/ muresan/614_IR/2004_Fall/Resources/D ocs/sigirDumais2000.pdf.

- Ean-Teng, K., \& Hung, C.S.(2010). XML/XSLT-based Technologies in SCORM-compliant e-Learning for ODL Learning Support. Proceedings of the 24th Asian Association of Open Universities Conference, Hanoi, Vietnam. Retrieved from http://library.wou. edu. my/vertical/vf2010-37.pdf.

- Elgazzar, AbdelLatif E. (2014) Developing eLearning Environments for Field Practitioners and Developmental Researchers: A Third Revision of An ISD Model to Meet eLearning and Distance Learning Innovations. The International Conference on Information Technology in Education (CITE 2014), Engineering Information Institute and the Scientific Research Publishing, Shenzhen, China, January 12-14, 2014.

- Farrell, I.H.(2000). Navigation Tools' Effect on Learners' Achievement and Attitude. (Unpublished doctoral dissertation, March), Blacksburg, Virginia: Virginia Polytechnic Institute and State University. Retrieved from http://scholar.lib.vt.edu/theses/available/ etd- 04132000-16260041/unrestricted/Navigation_Tools.pdf.

- Farrell, I.H., \& Moore, D.M.(2000-2001). The effect of navigation tools on learners' achievement and attitude in a hypermedia environment. Journal of Educational Technology Systems, 29(2), 169181.

- Ford, M. A. (2009). Student engagement . Front. Hum. Nuerosci. 8, 571

- Fry H, Ketteridge S and Marshall S (1999) A Handbook for Teaching and Learning in Higher Education. London: Kogan Page.

- Galarneau, L. (2005). Authentic Learning Experiences through Play: Games,

- Garrett, J. J. (2002). The Elements of User Experience: User-Centered Design .

- Greeno, J. (1996). Cognition and learning. Handbook of educational psychology/ D Berlinder, p. 15-46.

- Guan,Y.-H.(2006).The effects of multimedia presentations on information processing: eye movement analyses of text and picture scenario. Unpublished doctoral dissertation, Bielefeld: University of 


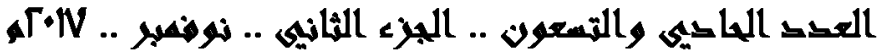

Bielefeld. Retrieved from http://webdoc.sub.gwdg.de/ebook/hk/2003/uni-bielefeld/disshabi/2003/0015.pdf.

- Harris, D. (1999). Creating a Complete Learning Environment. In: D. French, C. Hale, C. Johnson \& G. Farr (Eds.) Internet based learning: An Introduction and Framework for Higher Education and Business. (pp. 139-164) U.S.A. \& Canada: Kogan Page.

- Hartman.Janet D.;Vila. Joaquin A (2001). Mariner - A3- Dimensional Navigation Language. Journal of Education and Hypermedia, Vol. (10), I. (4).

- Hartnett, M, George, A., \& Dron, J, (2011). Examining motivation in online distance learning environments: Complex, multifaceted and situation - dependent .The International Review of Research in open and Distance Learning, 12(6), 20-38.

- Herrington, j. (2012, April).critical characteristics of authentic tasks in mobile learning. Paper presented at the meeting of applications of information and communication technology in education and training from 26-29/4/2010, King Saud University, riyad on line.

- Hubbard, Bryan (2006): Understanding content management, 2001 available at: http://www.asis.org/ bulletin/Ind ex.html., (1-12-2008).

- Hsu, Y.-C., Lin, H., Ching, Y.-H., \& Dwyer, F.M.(2009). The effects of web-based instruction navigation modes on undergraduates' learning outcomes. Educational Technology \& Society, 12 (1), 271284.http://www.hq.nasa.gov/pao/portal/usability/process/ucdMethods. htm\#23

- Hu S, Kuh GD and Li S (2008) The effects of engagement in inquiryoriented activities on student learning and personal development. Innovative Higher Education 33: 71-81.

- Keller, J.M.(2008). First principles of motivation to learn and e3learning. Distance Education, 29(2), 175-185.

- Kim, K.J., \& Frick, T. W. (2011) .Changes in student Motivation during online learning Journal of Educational computing Research, 44(1), 1-23.

- Klem, A.M., \& Connell, J.P. (2004).Relationships matter: linking teacher support to student engagement and achievement Journal of school health .74(7), 262-273.

- Levene, M., \& Wheeldon, R.(2004). Navigating the World-Wide-Web. In: M. Levene and A. Poulovassilis (Eds.) Web Dynamics, Adapting to Change in Content, Size, Topology and Use (pp. 117-151). Retrieved fromhttp://www.dcs.bbk.ac.uk/ mark/download/navigatingtheweb. pdf.

- Lujan HL and Dicarlo SE (2006) Too much teaching, not enough learning: What is the solution? Advances in Physiology Education 30:17-22. 


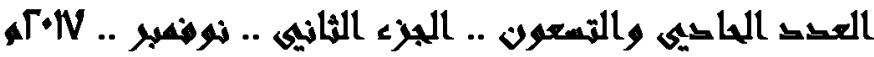

- Mantovani, F. \& Castelnuovo, G. (2003). Sense of Presence in Virtual Training:

- Mantovani, F. (2003). VR Learning: Potential and Challenges for the Use of 3D

- Martin, D., \& Peim, N.(2009). Critical perspectives on activity theory. Educational Review, 61(2),131-138.

- Rogers, Kipp D. (2011) . Mobile learning devices . Bloomington : A joint publication, Solution Tree and NAESP.

- Rotto, L. I. (1994). Curiosity, Motivation, and "Flow" in ComputerBased Instruction.

- Rowan, L., \& Bigum, C.(2003). Actor network theory and the study of online learning: new perspectives on quality. In G. Davies \& E. Stacey (Eds.), Specific Education @ a distance. Proceedings of the IFIP TC3/WG3.6 Working Conference on Specific Education @ a Distance, February 3-6, Geelong, Australia, (pp. 179-188), Boston: Kluwer Academic.

- Skinner , E ., Furrer .C.,Marchand ,G., \& Kinderman , T.(2008) . Engagement and disaffection in the classroom: Part of a large motivational dynamic? Journal of Educational psychology, 100(4), 765-781.

- Skinner. \& Belmont, M.J (1993).Motivation in the classroom reciprocal effects of teacher behavior and student engagement across the school year. Journal of Education psychology, 85(4), 571-581.

- Smith KA, Sheppard SD, Johnson DW and Johnson RT (2005) Pedagogies of engagement: Classroom-based practices. Journal of Engineering Education 94: 87-101.

- Sofia, S. (2013) Designing Mobile Learning Activities in the Malaysian He Context : A Social Constructivist Approach . (Published Doctoral Dissertation) . University of Salford, UK.

- Sorensen, Christopher (2010): Learning With Mobile Technologies: The Use of Out-Of

- Stahl, G. (2005). Foreword. In D. Hung \& M. S. Khine (Eds.), Engaged learning with

- Young MS, Robinson S and Alberts P (2009) Students pay attention! Active Learning in Higher Education 10: 41-55.

- Zazelenchuk, T. W. \& Boling, E. (2003). Considering User Satisfaction in Designing 